\title{
An Integrated Chemical and Stable-Isotope Model of the Origin of Midocean Ridge Hot Spring Systems
}

\author{
Teresa Suter Bowers ${ }^{1}$ and Hugh P. Taylor, Jr.
}

\author{
Division of Geological and Planetary Sciences, California Institute of Technology, Pasadena
}

\begin{abstract}
Chemical and isotopic changes accompanying seawater-basalt interaction in axial midocean ridge hydrothermal systems are modeled with the aid of chemical equilibria and mass transfer computer programs, incorporating provision for addition and subtraction of a wide-range of reactant and product minerals, as well as cation and oxygen and hydrogen isotopic exchange equilibria. The models involve stepwise introduction of fresh basalt into progressively modified seawater at discrete temperature intervals from $100^{\circ}$ to $350^{\circ} \mathrm{C}$, with an overall water-rock ratio of about 0.5 being constrained by an assumed $\delta^{18} \mathrm{O}_{\mathrm{H}_{2} \mathrm{O}}$ at $350^{\circ} \mathrm{C}$ of +2.0 per mil $(\mathrm{H}$. Craig, personal communication, 1984). This is a realistic model because: (1) the grade of hydrothermal metamorphism increases sharply downward in the oceanic crust; (2) the water-rock ratio is high $(>50)$ at low temperatures and low $(<0.5)$ at high temperatures; and (3) it allows for back-reaction of earlier-formed minerals during the course of reaction progress. The results closely match the major-element chemistry (Von Damm et al., 1985) and isotopic compositions (Craig et al., 1980) of the hydrothermal solutions presently emanating from vents at $21^{\circ} \mathrm{N}$ on the East Pacific Rise. The calculated solution chemistry, for example, correctly predicts complete loss of $\mathbf{M g}$ and $\mathrm{SO}_{4}$ and substantial increases in $\mathrm{Si}$ and $\mathrm{Fe}$; however, discrepancies exist in the predicted $p \mathrm{H}$ (5.5 versus 3.5 measured) and state of saturation of the solution with respect to greenschist-facies minerals. The calculated $\delta \mathrm{D}_{\mathrm{H}_{2} \mathrm{O}}$ is +2.6 per mil, in excellent agreement with analytical determinations. The calculated chemical, mineralogic, and isotopic changes in the rocks are also in good accord with observations on altered basalts dredged from midocean ridges (Humphris and Thompson, 1978; Stakes and O'Neíl, 1982), as well as with data from ophiolites (Gregory and Taylor, 1981). Predicted alteration products include anhydrite and clay minerals at low temperatures and a typical albite-epidote-chlorite-tremolite (greenschist) assemblage at $350^{\circ} \mathrm{C}$. The models demand that the major portion of the water-rock interaction occur at temperatures of $300^{\circ}-350^{\circ} \mathrm{C}$. Interaction at temperatures below approximately $250^{\circ} \mathrm{C}$ results in negative $\delta^{18} \mathrm{O}_{\mathrm{H}_{2} \mathrm{O}}$ shifts, contrary to the observed positive $\delta^{1 \theta} \mathrm{O}$ values of the fluids exiting at midocean ridge vents. Hydrogen isotope fractionation curves by Suzuoki and Epstein (1976), Lambert and Epstein (1980), and Liu and Epstein (1984), among others, are compatible with the model, and require $\delta D_{\mathrm{H}_{2} \mathrm{O}}$ to increase at all temperatures as a result of seawater-basalt interaction.
\end{abstract}

\section{INTRODUCTION}

The discovery and subsequent sampling and analysis of submarine hot springs (e.g., at $13^{\circ} \mathrm{N}$ and $21^{\circ} \mathrm{N}$ on the East Pacific Rise (EPR)) provide an excellent opportunity for the development of theoretical models to describe the midocean ridge (MOR) alteration process. This is because the chemical and stable-isotope compositions of both the starting solution (seawater) and the final hydrothermal endmember are well constrained. In addition, the observed alteration products in the basalts provide data on chemical and isotopic gains and losses to the rock.

Throughout the oceans, and in particular at the MOR spreading centers, the only important rock types are the characteristic, relatively uniform MOR-type basalts and gabbros made up of plagioclase + pyroxene \pm olivine \pm glass. Also, the initial water entering the hydrothermal systems is ocean water, which has had a fairly uniform $\delta^{18} \mathrm{O}, \delta \mathrm{D}$, and chemical composition over the course of geologic time. Thus, the simplicity and uniformity of the starting materials in submarine hydrothermal systems allow us to make very realistic calculations that have broader applicability than is the case for most active or fossil systems on continents.

\footnotetext{
${ }^{1}$ Now at Department of Earth, Atmospheric and Planetary Sciences, Massachusetts Institute of Technology, Cambridge.

Copyright 1985 by the American Geophysical Union.

Paper number 4B5398.

0148-0227/85/004B-5398\$05.00
}

Two major factors affect the outcome of water-rock interactions for a given initial composition of water and rock: temperature of interaction and water-rock ratio. These parameters can vary independently, and it is often difficult to assess the importance of each from the petrologic record alone. The primary goal of this project is to utilize a reaction-path computer model that integrates both the chemical and stable isotope equilibria in an attempt to narrow down the possible paths seawater can follow in simultaneously producing the observed secondary alteration of basalt and the chemical and isotopic modification of the submarine hydrothermal fluids. A 'path' is defined as some combination of systematic and sequential change in temperature, pressure, and water-rock ratio during evolution of the fluids and rocks within the zone of hydrothermal activity. The following are observational constraints which should be met by the model.

The mineralogical characteristics of seafloor basalts and their associated alteration products are described by Ito and Anderson [1983], Humphris and Thompson [1978], and Rona [1978, 1976], among others. For example, the data of Humphris and Thompson [1978] provide a number of important constraints on the predictions of our computer models. They described two series of greenschist-facies (albite-chloriteactinolite-epidote) rocks with minor amounts of quartz and pyrite, one a chlorite-rich, and another an epidote-rich assemblage. Consistent with the results of laboratory experiments (see below), the chlorite-rich rocks exhibit a gain of $\mathrm{Mg}$ and $\mathrm{H}_{2} \mathrm{O}$ and a loss of $\mathrm{Ca}$ and $\mathrm{Si}$, while the epidote-rich rocks exhibit slightly lower $\mathrm{Mg}$ contents and slightly higher Ca contents compared to unaltered basalt. Humphris and Thompson propose that the differences in rock type are a function of 
temperature, water-rock ratio, composition of the circulating fluid, and rate of fluid flow relative to reaction rates.

Ito and Clayton [1983] measured $\delta^{18} \mathrm{O}$ and $\delta \mathrm{D}$ values of altered gabbros dredged from the Mid-Cayman Rise in the Caribbean. These samples from the deeper parts of the ocean crust were altered at high temperatures $\left(>350^{\circ} \mathrm{C}\right)$ and low water-rock ratios $(<2)$. Stakes and $O^{\prime} N e i l$ [1982] found that several rocks from the EPR and MAR were altered at $35^{\circ}$ to $350^{\circ} \mathrm{C}$ and water-rock ratios ranging from $>50$ at low temperatures to $\sim 1$ at high temperatures. The low-temperature, saponite-rich rocks are enriched in ${ }^{18} \mathrm{O}$ compared to midocean ridge basalt (MORB), and the high-temperature chlorite- and epidote-rich greenstones are depleted in ${ }^{18} \mathrm{O}$. The whole-rock $\delta^{18} \mathrm{O}$ values range from +3.7 (ultramafic) to +10.1 per mil (saponite-rich pillow breccias); $\delta \mathrm{D}$ values range from -79 (saponite) to -13 per mil (epidote). Böhlke et al. [1984] report $\delta^{18} \mathrm{O}$ as high as +24 for smectites and $\mathrm{K}$ feldspar and +30 for calcite in MOR basalts from DSDP cores. Estimated alteration temperatures range from $8^{\circ}$ to $50^{\circ} \mathrm{C}$.

An additional source of data is provided by mineralogical and isotopic studies of ancient oceanic crust, such as the Samail ophiolite in Oman [Gregory and Taylor, 1981; Stakes et al., 1984]. Whether they formed at midocean ridges or in back-arc spreading basins, such ophiolites clearly exhibit the effects of a fossil marine hydrothermal system that involved heated ocean water; such systems are probably similar to present-day MOR systems. Gregory and Taylor [1981] report a pattern of mineralogical alteration in the Oman ophiolite ranging from amphibole plus some chlorite and epidote in the high-level gabbros to common greenschist assemblages including actinolite, chlorite, saussurite, leucoxene and epidote in the diabase, to zeolites and secondary carbonate in the pillow basalts. This is accompanied by whole-rock $\delta^{18} \mathrm{O}$ values ranging from a high of about +13 per mil in the pillow basalts to a minimum of about +3.8 per mil at depths 1.5 to $2 \mathrm{~km}$ below the diabase-gabbro contact.

Chemical and isotopic analyses of MOR hot-spring waters [Edmond et al., 1979; Edmond, 1980; Welhan and Craig, 1979; Craig et al., 1980; Craig, 1981; Michard et al., 1984; Von Damm et al., 1985] provide a picture of the $350^{\circ} \mathrm{C}$ hydrothermal endmember: magnesium and sulfate have been quantitatively removed; silica has reached a concentration controlled by quartz or amorphous silica saturation two orders of magnitude higher than in seawater; iron concentrations are approximately six orders of magnitude higher than seawater; and $\mathrm{pH}$ has dropped off from a value of about 8 for seawater to about 3.5. In addition, the $\delta^{18} \mathrm{O}$ and $\delta \mathrm{D}$ of seawater (which both start at zero per mil relative to standard mean ocean water (SMOW)) have increased in the hydrothermal endmember to approximately +2.0 and +2.5 per mil, respectively [H. Craig, personal communication, 1984; Craig et al., 1980]. Because $\delta^{18} \mathrm{O}$ is the one variable that is most simply and straightforwardly related to water-rock ratio, its value in the hydrothermal endmember is used to set the endpoint in the calculated reaction paths discussed below.

Utilizing these starting conditions and constraints, we develop an integrated stable-isotope, chemical equilibria and mass transfer computer model based on the EQ3/6 computer software package [Wolery, 1978, 1979, 1983]. We then use this to calculate chemical and isotopic modifications of seawater together with mineralogical and isotopic alterations of fresh basalt, for comparison with the known petrology and chemistry of seafloor hydrothermal systems.

\section{Previous Work}

\section{Laboratory Experiments}

Seawater-basalt interactions have been widely studied experimentally. Bischoff and Dickson [1975] reacted seawater and basalt in a 10 to 1 mass ratio at $200^{\circ} \mathrm{C}$ and 500 bars. The resulting solutions and alteration mineral assemblages compared favorably to those observed in the Icelandic geothermal fields. Further experiments were designed to determine whether the interaction of seawater and basalt could: (1) produce the types of metabasalts collected from midocean ridges and ophiolite complexes; (2) be responsible for fixing the concentrations of some chemical species in seawater; and (3) produce seafloor metalliferous deposits.

Several additional experiments were conducted at various temperatures with diverse rock types (basalt, basalt glass, diabase, peridotite) and over a range of water-rock ratios [Bischoff and Rosenbauer, 1983; Seyfried and Mottl, 1982, 1977; Janecky, 1982; Seyfried and Bischoff, 1981, 1979, 1977; Seyfried and Dibble, 1980; Mottl and Seyfried, 1980, 1977; Mottl et al., 1979; Bischoff and Seyfried, 1978, 1977; Mottl and Holland, 1978; Mottl, 1976; Hajash, 1975]. A summary of the results of these experiments is given by Mottl [1983]. At water-rock ratios $\leq 50$, nearly all the dissolved $\mathrm{Mg}$ is removed from seawater and taken up by secondary alteration minerals in the basalt, with a concomitant drop in $\mathrm{pH}$. At higher water-rock ratios the removal is less complete, but still dramatic. The decrease in $p H$ speeds up the alteration process, particularly the leaching of heavy metals. Seyfried and Mottl [1982] note that the additional $\mathrm{H}^{+}$ions are consumed during alteration of the primary silicates, resulting in competing effects on the $p H$. Thus, once the $\mathrm{Mg}^{++}$concentration drops to a low value, the $p \mathrm{H}$ increases rapidly back to a value near neutrality as a result of continued silicate hydrolysis.

In addition to $\mathrm{Mg}$ removal, various experiments indicate removal of some $\mathrm{Na}^{+}$at low water-rock ratios and addition of $\mathrm{Ca}^{++}$to the solution (leaching of $\mathrm{Ca}^{++}$from primary silicates balances the removal of $\mathrm{Mg}^{++}$to alteration phases [Mottl and Holland, 1978; Seyfried and Bischoff, 1981]). In these aqueous solutions, dissolved silica contents are commonly near the level of quartz saturation.

Although the laboratory experiments have worked out fairly well in producing aqueous solutions similar to those observed in the Icelandic geothermal fields, the Galapagos Rift and the East Pacific Rise, poor agreement is observed between the rock alteration assemblages produced in the laboratory and the known mineralogy of altered oceanic rocks [Mottl, 1983]. Greenschist-facies basalts are most often either chlorite- or epidote-rich [Humphris and Thompson, 1978], while laboratory alteration products are most often smectiterich. Nucleation difficulties and kinetics may in part explain these discrepancies. Note that a recent experiment by Seyfried and Mottl [1982] resulted in the formation of a mixed-layer smectite-chlorite during a reaction of basalt glass with seawater.

\section{Thermodynamic Calculations}

In addition to laboratory experiments, the consequences of water-rock interaction can be calculated with the aid of chemical equilibria and mass transfer computer programs using thermodynamic data for minerals and solutions. However, although fairly realistic calculations have been carried out for cation species in minerals and aqueous fluids [Wolery, 1978; Janecky, 1982; Reed, 1983], up to the present no one 
has performed similarly detailed calculations for ${ }^{18} \mathrm{O} /{ }^{16} \mathrm{O}$ or $\mathrm{D} / \mathrm{H}$.

Wolery [1978] revised and extended the mass transfer computer program of Helgeson [1968] and Helgeson et al. [1970] to calculate chemical equilibria among aqueous and mineral phases in basalt-seawater systems. He conducted a computer experiment in which seawater was heated from $0^{\circ}$ to $350^{\circ} \mathrm{C}$ at 500 bars, the results of which compared favorably with the experimental results of Bischoff and Seyfried [1978]. In addition, the experiment accurately reproduced changes in composition of the solution, including an acidic $p \mathrm{H}$ at $T>200^{\circ} \mathrm{C}$. Differences between the computer calculations and the results of the laboratory experiments were attributed to lack of equilibrium in the experiments, sluggish reaction rates in experiments at $T<150^{\circ} \mathrm{C}$ [Seyfried, 1976], and inaccuracies in the thermodynamic data for important species in the theoretical calculations.

Wolery [1978] also calculated solution composition changes and rock alteration accompanying reaction of seafloor basalt with seawater in isothermal, closed systems at 500 bars and various temperatures from $0^{\circ}$ to $340^{\circ} \mathrm{C}$. Among the alteration minerals predicted were smectites, chlorites, kaolinite, muscovite, albite, quartz, anhydrite, dolomite, calcite, and several iron and copper sulfides.

More recently, Janecky [1982] used EQ3/6 to calculate mineralogical and chemical changes attending seawaterperiodite interaction at $300^{\circ} \mathrm{C}$ and 500 bars, employing experimentally determined relative dissolution rates for the common peridotite minerals. Substantial agreement was found between the experiments and the calculations for both the solution composition trends and for the precipitates. Reed [1983] has modeled deposition of massive sulfides in fluids derived from high-temperature seawater-basalt interaction followed by cooling of the fluid and subsequent mixing with seawater.

\section{Oxygen Isotope Modeling}

Previous computer models of oxygen isotope mass transfer among minerals and aqueous solutions include those advanced by Cathles [1983], Parmentier [1981], and Norton and Taylor [1979], none of which took into account the detailed variations in product and reactant mineral phases. Cathles modeled ${ }^{18} \mathrm{O}$, anhydrite, and silica redistribution in a hydrothermal system and compared the results to the Kuroko massive sulfide deposits. Kinetic constraints and formation permeabilities were considered, and the calculated whole-rock $\delta^{18} \mathrm{O}$ anomalies showed a pattern similar to those associated with the Fukazawa massive sulfide deposit in Japan. Norton and Taylor [1979] analyzed fossil geothermal systems associated with the Skaergaard intrusion, using a numerical approximation of heat and mass transport [Norton and Knight, 1977] and porosity and permeability [Norton and Knapp, 1977], which permitted simulation of the thermal history and pattern of energy loss during crystallization of this layered gabbro. In this system, little or no mineralogical change occurred in the gabbro, and Norton and Taylor [1979] were thus able to make a close match between their calculated $\delta^{18} \mathrm{O}$ values and the measured $\delta^{18} \mathrm{O}$ of Taylor and Forester [1979] for the principal rock types in and around the intrusion. Although that study was quite successful, particularly in predicting permeabilities of large masses of rock in the earth's crust, neither it nor the study by Parmentier [1981] attempted to account for any secondary alteration minerals, or take into account the consequences that formation of large amounts of such alteration products would have on the chemical and oxygen isotope mass balances.

\author{
Description of Computer Programs \\ and Data BaSes
}

\section{Computer Modeling}

The EQ3/6 package used in the present study was developed by Wolery $[1978,1979,1983]$. EQ3 computes a distribution-of-species in the aqueous solution and generates concentrations and activities of ions and complexes; it then calculates which, if any, of the mineral phases are saturated with respect to the solution. EQ6 then calculates chemical equilibrium and mass transfer in aqueous solution-mineral systems. These programs are similar to, and derivative from, those of Helgeson [1968] and Helgeson et al. [1970]. Mathematical equations describing mass action, mass balance, charge balance, and nonideality are solved at each step in the reaction progress (for each increment of reactant phases added to the solution) with a Newton-Raphson technique.

EQ6 includes provision for: (1) variations in temperature, (2) variable rates of titration of reactants, (3) suppressed formation of undesired precipitates (this allows, for example, formation of kinetically favored, although thermodynamically metastable phases), and (4) reaction in either a closed-system or open-system mode.

The closed-system model is directly applicable to hydrothermal bomb experiments. Reactant solid phases are titrated at specified relative rates into solution, and the chemical composition of the solution is progressively modified by dissolution of the reactant phases, as well as by precipitation and dissolution of product phases, which remain in the system and continue to take part in the equilibria. The reaction progresses until equilibrium is completely attained.

In contrast to the situation described above, dissolution of product phases is not allowed in the "simple" open-system model. Secondary phases are instantaneously removed from the system as they precipitate to simulate a packet of fluid flowing through unaltered, pristine rock composed only of the reactant phases. In this case, the alteration products do not interact with the system after they have formed, and they are assumed to be left behind in the hydrothermal conduit. In this paper, we have not made any model calculations of this type, because we feel that a "complex" open-system model is more realistic. The "complex" open-system is one in which products are periodically removed from the system (for example, at specified temperature intervals), but also one in which the product minerals remain available between these intervals, where they can dissolve or otherwise take part in the equilibria of the system.

\section{Thermodynamic Data Base}

The thermodynamic properties of a large number of minerals are either well known [Helgeson et al., 1978; Robie et al., 1978], or can be estimated [Wolery, 1978]. Except for a few clays, chlorites, and epidotes whose compositions are listed in Figure 10, the chemical formulas for all minerals considered in this study are standard end-member compositions; they are all given in the work of Helgeson et al. [1978] and Wolery [1978]. Wolery's data indicate that clays remain stable at temperatures as high as $350^{\circ} \mathrm{C}$, although mineralogical studies of oceanic rocks indicate the occurrence of chlorites rather than clays at high temperatures. Thus in the present work, forma- 


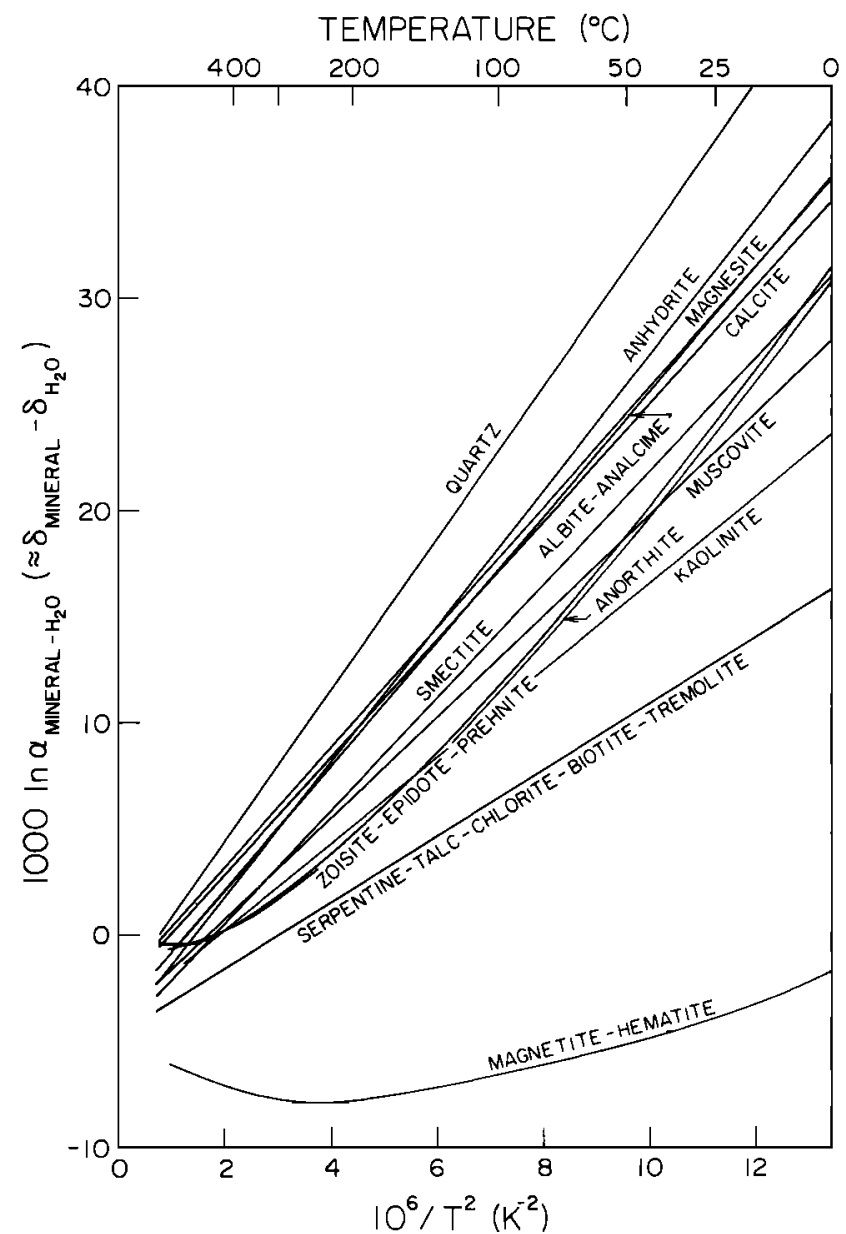

Fig. 1. Experimentally and empirically determined equilibrium oxygen isotope fractionation curves employed in our calculations, plotted as a function of temperature. Quartz- $\mathrm{H}_{2} \mathrm{O}$, Clayton et al [1972]; anhydrite- $\mathrm{H}_{2} \mathrm{O}$, Chiba et al. [1981]; magnesite- $\mathrm{H}_{2} \mathrm{O}$, Perry and Tan [1972]; calcite- $\mathrm{H}_{2} \mathrm{O}, \mathrm{O}^{\prime}$ Neil et al. [1969]; albite- $\mathrm{H}_{2} \mathrm{O}, \mathrm{O}^{\prime} \mathrm{Neil}$ and Taylor [1967]; smectite- $\mathrm{H}_{2} \mathrm{O}, \quad Y$ Yeh and Savin [1977]; muscovite- $\mathrm{H}_{2} \mathrm{O}, \mathrm{O}^{\prime}$ Neil and Taylor [1969]; zoisite- $\mathrm{H}_{2} \mathrm{O}$, Matthews et al. [1983c]; anorthite- $\mathrm{H}_{2} \mathrm{O}$, Matthews et al. [1983b]; kaolinite- $\mathrm{H}_{2} \mathrm{O}$ Kulla and Anderson [1978]; serpentine- $\mathrm{H}_{2} \mathrm{O}$, Wenner and Taylor [1971]; magnetite- $\mathrm{H}_{2} \mathrm{O}$, Becker [1971].

tion of smectites has been suppressed at temperatures of $200^{\circ} \mathrm{C}$ and above.

In addition to the above-mentioned thermodynamic data for minerals, recent studies have provided solid-solution models for some of the important minerals, e.g., epidote [Bird and Helgeson, 1980] and chlorite [Stoessell, 1984]. However, the EQ3/6 computer program does not contain adequate provision for solid solutions at the present time. Inclusion of nonideal solid solution models in the calculations would improve the predictive ability of the models.

Thermodynamic data for water and aqueous species are taken from Helgeson and Kirkham [1974a, b], Helgeson et al. [1981], and Helgeson [1969]. Additional data for aqueous complexes have been compiled by Wolery and he supplies supporting data files for EQ3/6 which cover a temperature range of $0^{\circ}$ to $300^{\circ} \mathrm{C}$ (extended to $350^{\circ} \mathrm{C}$ where data are available or extrapolated if necessary) at a pressure corresponding to the water-steam saturation curve. All calculations in the present work were carried out at 500 bars. Thermodynamic data for the complexes were generated at 500 bars by applying the isodielectric correction suggested by Helgeson [1969]. The thermodynamic data base we are using for this work has already been tested extensively in theoretical calculations, and it typically yields remarkably good agreement with observations. For example, theoretical modeling of porphyry copper ores in Butte, Montana by Brimhall and Ghiorso [1983] and Brimhall [1980,1979], and of serpentinization of peridotites by Janecky [1982], and water-sediment interaction in Guaymas basin by Bowers et al. [1985] has provided an excellent match with observed mineral assemblages.

\section{Isotopic Fractionation Factors}

The integration of ${ }^{18} \mathrm{O} /{ }^{16} \mathrm{O}$ and $\mathrm{D} / \mathrm{H}$ isotope mass distributions into EQ6 requires an additional data base composed of the equilibrium fractionation factors for ${ }^{18} \mathrm{O} /{ }^{16} \mathrm{O}$ and $\mathrm{D} / \mathrm{H}$ exchange among minerals and water as a function of temperature. Mineral-mineral and mineral- $\mathrm{H}_{2} \mathrm{O}$ fractionation curves for oxygen isotopes are well known for a large number of geologically important systems. Experimentally determined and calculated ${ }^{18} \mathrm{O} /{ }^{16} \mathrm{O}$ fractionation factors (through 1976) for ${ }^{18} \mathrm{O}$ exchange between $\mathrm{H}_{2} \mathrm{O}$ and calcite, dolomite, anhydrite, quartz, K-feldspar, plagioclase, muscovite, paragonite, biotite, magnetite, pyroxene, garnet, amphibole, and olivine are summarized by Friedman and $O^{\prime} N e i l$ [1977]. More recent papers include Kulla and Anderson [1978] (kaolinite), Chiba et al. [1981] (anhydrite), and Matthews et al. [1983a, b, c] (quartz, albite, anorthite, jadeite, diopside, wollastonite, calcite, and zoisite). Empirically determined ${ }^{18} \mathrm{O} /{ }^{16} \mathrm{O}$ fractionation factors are available over limited temperature ranges for kaolinite, serpentine, chlorite, gibbsite, illite, and smectite [Savin and Epstein, 1970a, b; Wenner and Taylor, 1971; Lawrence and Taylor, 1971; Eslinger and Savin, 1973; Yeh and Savin, 1977, 1976; O'Neil and Kharaka, 1976; O'Neil and Taylor, 1969]. Oxygen isotope fractionation curves employed in this study (Figure 1) can be represented by

$$
\begin{aligned}
10^{3} \ln \alpha_{\min -\mathrm{H}_{2} \mathrm{O}} & =a+b\left(\frac{10^{3}}{T}\right)+c\left(\frac{10^{6}}{T^{2}}\right) \\
& \approx \delta_{\min }-\delta_{\mathrm{H}_{2} \mathrm{O}}=\Delta_{\min -\mathrm{H}_{2} \mathrm{O}}
\end{aligned}
$$

where $b=0$ for the curves which plot as straight lines. Because a variety of simple relationships exist between ${ }^{18} \mathrm{O} /{ }^{16} \mathrm{O}$ fractionation and mineral structures [e.g., Taylor and Epstein, 1962; O'Neil et al., 1969], minerals for which no experimental ${ }^{18} \mathrm{O} /{ }^{16} \mathrm{O}$ data are available can be assigned the fractionation curves of chemically or structurally similar compounds. Although the calculations presented below involve extrapolation of several curves beyond the temperature range for which they were determined, differences of only 1 to 3 per mil arise for even the most poorly defined $\Delta^{18} \mathrm{O}_{\min -\mathrm{H}_{2} \mathrm{O}}$ values; such uncertainties make little difference in the outcome of the calculations.

$\mathrm{D} / \mathrm{H}$ fractionation factors of mineral- $\mathrm{H}_{2} \mathrm{O}$ systems are less well-defined than those for oxygen isotopes. Several curves are shown in Figure 2 for micas and amphiboles [Suzuoki and Epstein, 1976], kaolinite, illite, montmorillonite, gibbsite [Lambert and Epstein, 1980; O'Neil and Kharaka, 1976; Lawrence and Taylor, 1972, 1971; Savin and Epstein, 1970a], epidote and zoisite [Graham et al., 1980], and serpentine [Sakai and Tsutsumi, 1978; Wenner and Taylor, 1973]. Some of these curves and individual data points are incompatible (e.g., kaolinite- $\mathrm{H}_{2} \mathrm{O}$ and chrysotile- $\mathrm{H}_{2} \mathrm{O}$ ). These problems are a reflection of the difficulty of the experiments, the large effects that changes in chemical composition of a mineral have on its $\mathrm{D} / \mathrm{H}$ fractionation and the ambiguity associated with hy- 


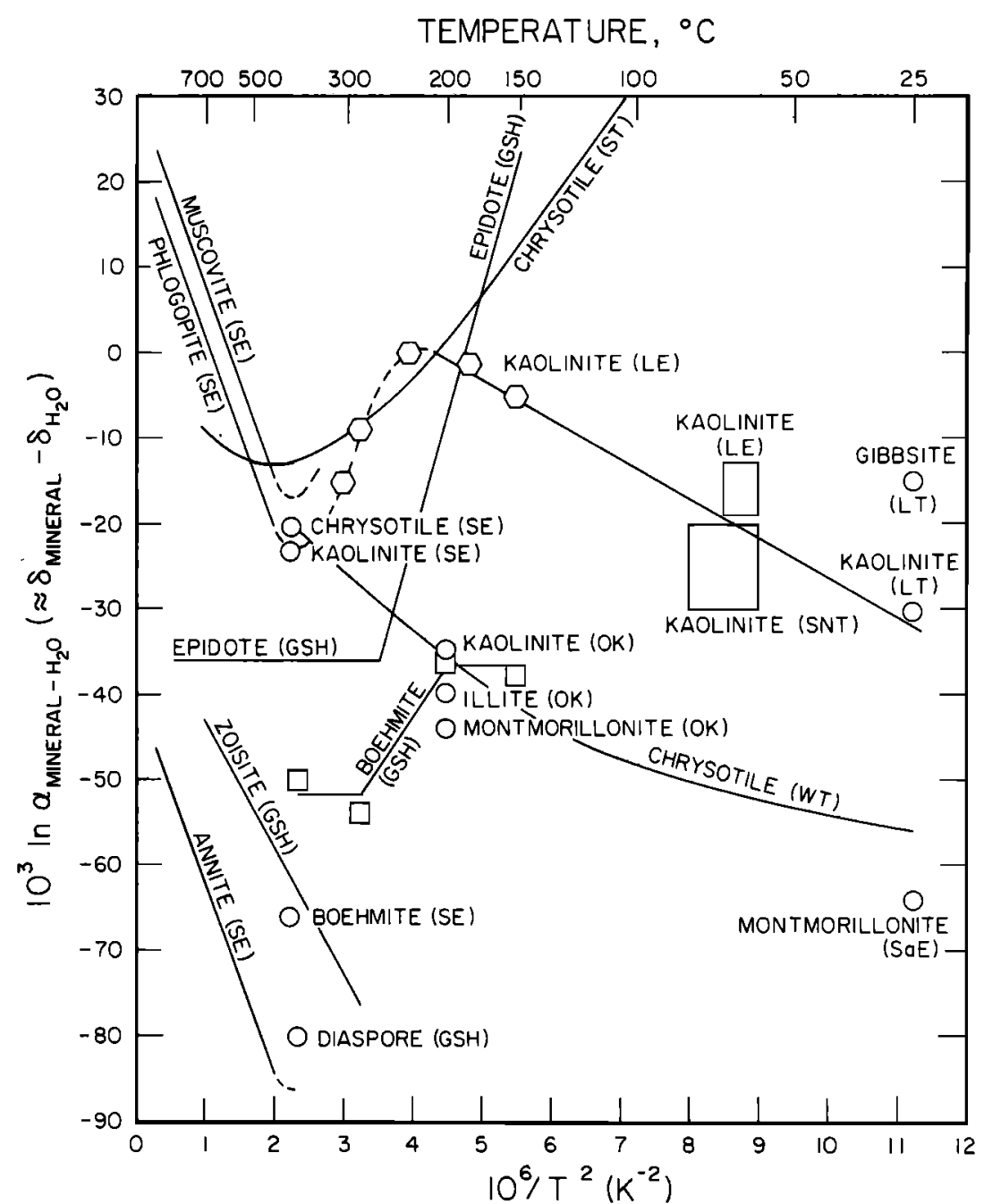

Fig. 2. Summary of experimental and empirical determinations of equilibrium hydrogen isotope fractionation curves as a function of temperature. Size of the box symbols represents approximate error. SNT, Sheppard et al. [1969]; SaE, Savin and Epstein [1970a]; LT, Lawrence and Taylor [1971]; WT, Wenner and Taylor [1973]; OK, O'Neil and Kharaka [1976]; SE, Suzuoki and Epstein [1976]; ST, Sakai and Tsutsumi [1978]; GSH, Graham et al. [1980]; LE, Lambert and Epstein [1980].

drogen occurrence in more than one structural $\mathrm{OH}$ site in some minerals, e.g., chlorites.

Because of the above problems, we somewhat arbitrarily developed a consistent set of fractionation factors for $D / H$ fractionation between minerals and $\mathrm{H}_{2} \mathrm{O}$, requiring exclusion of some of the available data. The curves used in this study are shown in Figure 3, and their positions on the diagram are based primarily on the observations of Suzuoki and Epstein [1976], Lambert and Epstein [1980], and Liu and Epstein [1984]. Between $450^{\circ}$ and $800^{\circ} \mathrm{C}$ these fractionation factors are approximately linear on a plot of $1 / T^{2}$, and the $\mathrm{D} / \mathrm{H}$ fractionations relative to $\mathrm{H}_{2} \mathrm{O}$ for two minerals of constant but differing composition plot as parallel lines (i.e., the fractionation between the two minerals is independent of temperature). These relationships can be expressed as

$$
10^{3} \ln \alpha_{\min -\mathrm{H}_{2} \mathrm{O}}=a+b\left(\frac{10^{6}}{T^{2}}\right)
$$

which is the same expression used for most ${ }^{18} \mathrm{O} /{ }^{16} \mathrm{O}$ fractionation curves. At temperatures between $450^{\circ}$ and $400^{\circ} \mathrm{C}$ the curves deviate from the linear dependence on $1 / T^{2}$ and a possible reversal in slope is indicated. Lambert and Epstein [1980] discuss approximate fractionation factors for kaolinite- $\mathrm{H}_{2} \mathrm{O}$ between $25^{\circ}$ and $400^{\circ} \mathrm{C}$ obtained empirically from kaolinites in hydrothermally altered rocks of the Valles Caldera. These have been substantiated experimentally by Liu and Epstein [1984]. Below $230^{\circ} \mathrm{C}$ the curve is linear with respect to $1 / T^{2}$ (equation (2)). The curve then goes through a maximum at a temperature around $230^{\circ} \mathrm{C}$ and has a positive slope between $230^{\circ}$ and $400^{\circ} \mathrm{C}$. This ties in with the positive slope exhibited at temperatures below $400^{\circ} \mathrm{C}$ for the micas and amphiboles. Deuterium fractionations between minerals and water can apparently be best represented by curves that change slope twice, with a negative slope at both high and low temperatures and a positive slope at intermediate temperatures. The hightemperature reversal in slope occurs close to $374^{\circ} \mathrm{C}$, the critical temperature of water.

We have chosen to represent the fractionation factors of all the $\mathrm{OH}$-bearing minerals except epidote as three straight-line segments with a maximum at $245^{\circ} \mathrm{C}$ and a minimum at $374^{\circ} \mathrm{C}$ (Figure 3). This representation results in larger inaccuracies in the fractionation curves in the temperature neighborhood of the extrema, but it has little effect on the outcome of the calculations presented herein, because the important feature of 


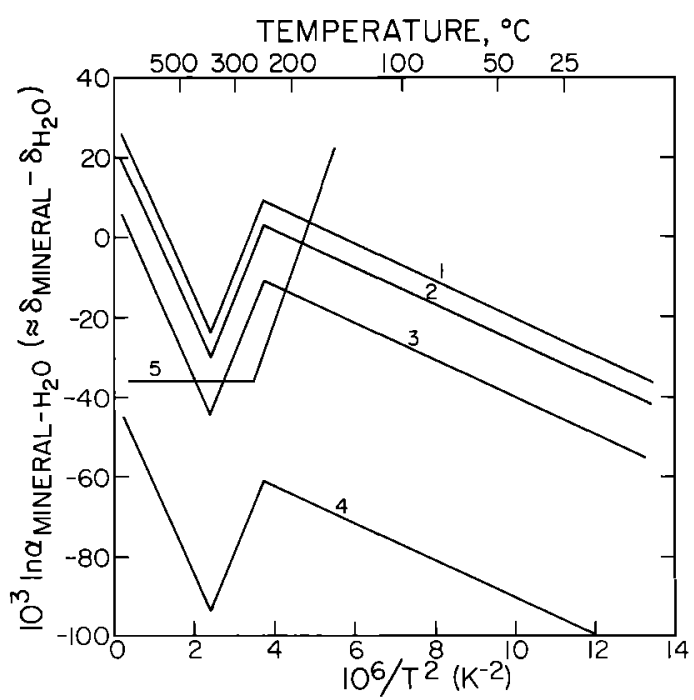

Fig. 3. Approximated equilibrium hydrogen isotope fractionation curves employed in our calculations, based on the data shown in Figure 2. The curve labeled 1 corresponds to the fractionation between $\mathrm{H}_{2} \mathrm{O}$ and muscovite, paragonite, beidellites, margarite and prehnite; 2, kaolinite, phlogopite, saponites, tremolite and talc; 3, chrysotile, clinochlore, amesite and antigorite; 4 , annite, minnesotaite, nontronites and daphnite; and 5 , epidote.

the curves is that the aqueous fluid concentrates deuterium relative to $\mathrm{OH}$-bearing minerals throughout the temperature range of interest, and the typical fractionations are on the order of 20 to 60 per mil. The epidote curve determined by Graham et al. [1980] and used for this study shows no temperature dependence above $260^{\circ} \mathrm{C}$ and a large slope between $260^{\circ}$ and $150^{\circ} \mathrm{C}$. Note that the hydroxyl position in the epidote structure is considerably different than that of most of the common silicate minerals.

Figure 3 exhibits four parallel curves displaying two extrema. The top curve corresponds to muscovite (pure Alendmember of the mica series), the second curve to both phlogopite (pure $\mathrm{Mg}$-endmember) and kaolinite, the third to serpentine and magnesium chlorites, and the lowest curve to annite (pure Fe-endmember) and iron-chlorites. In the temperature range of interest, the kaolinite curve may be the best constrained of the four, based on the work of Liu and Epstein [1984] and Lambert and Epstein [1980], and the lowtemperature portions of the mica curves are assumed to be parallel to the kaolinite curve. The phlogopite and kaolinite curves roughly coincide so they are shown as one curve. The serpentine curve corresponds approximately at low temperatures to empirical fractionation factors determined by Wenner and Taylor [1973]; however, at higher temperatures the Wenner-Taylor curve has been changed to follow the extrema pattern established by the mica and kaolinite curves. Smectites contain OH-groups in structurally similar sites to those in mica. Therefore, beidellites have been assigned to the muscovite curve, saponites to the phlogopite curve, and nontronites to the annite curve.

Chlorites present a problem in that there are no empirically or experimentally determined fractionation factors, and they show a wide range of $\mathrm{Al}$ contents and contain $\mathrm{OH}$-groups in two different structural sites; this causes difficulty in predicting the fractionation curves. Because of the two distinct $\mathrm{OH}$ sites and the resulting differences in bond strength, chlorites that are compositionally similar to micas will probably exhibit slightly lower $\delta \mathrm{D}$ values than the micas [Suzuoki and Epstein,
1976]. We have therefore assigned $\mathrm{Mg}$-chlorites to the serpentine curve and $\mathrm{Fe}$-chlorites to the annite curve.

\section{MATHEMATICS OF INCORPORATION OF OXYGEN AND HYDROGEN ISOTOPES IN EQ6}

In contrast to the simplistic way in which isotopic modeling of hydrothermal systems has been done in the past, in this study we wish to take into account as many aspects of the formation of secondary mineral phases as possible. EQ3/6 allows us to determine exactly how the production or dissolution of each mineral will affect the overall transfer. For example, if there is an approximately $1: 1$ replacement of a primary mineral by a secondary phase for which the $\Delta^{18} \mathrm{O}$ fractionation happens to be zero, there obviously will be no net change in the $\delta^{18} \mathrm{O}$ of the fluid. As water-rock ratios are often calculated on the basis of oxygen isotope exchange without regard to the effects of secondary mineral formation, incomplete or erroneous information may result.

Water-rock ratios have often been calculated from oxygen isotope analyses of whole-rocks and fluid, using a simplified material-balance procedure [Taylor, 1974, 1977], where for a closed system

$$
W / R=\frac{\delta_{\text {rock }}{ }^{f}-\delta_{\text {rock }}^{i}}{\delta_{\mathrm{H}_{2} \mathrm{O}}{ }^{i}-\left(\delta_{\text {rock }}{ }^{f}-\Delta\right)}
$$

where $\Delta=\delta_{\text {rock }}{ }^{f}-\delta_{\mathrm{H}_{2} \mathrm{O}}{ }^{f}$. This model requires adequate knowledge of both the initial $(i)$ and final $(f)$ isotopic states of the system. Taylor [1977] suggests that it is a reasonable approximation to set $\delta^{18} \mathrm{O}_{\text {rock }}$ equal to $\delta^{18} \mathrm{O}$ of plagioclase. This procedure was followed by the East Pacific Rise Study Group [1981] in an estimation of water-rock ratios for the $350^{\circ} \mathrm{C}$ hydrothermal fluids venting at $21^{\circ} \mathrm{N}$ on the EPR. They calculate water/plagioclase of about 1.7 which gives $W / R \sim 1$. However, at the relatively low temperatures of the EPR solutions $\left(<350^{\circ} \mathrm{C}\right)$, secondary alteration minerals are ubiquitous; therefore, approximating the altered basalt as plagioclase gives a poor representation of $\delta^{18} \mathrm{O}_{\text {rock }}$.

Possible mechanisms of isotopic exchange between minerals and $\mathrm{H}_{2} \mathrm{O}$ include solution-precipitation (recrystallization) processes and diffusion. Solution-precipitation has been observed attending isotopic exchange by several workers; recent scanning electron microscope and rate studies by Matthews et al. $[1983 a, b, c]$ demonstrate that solution-precipitation is the major mechanism of isotopic exchange in quartz-, wollastonite-, diopside- and zoisite-water reactions in the laboratory. Experimental work by O'Neil and Taylor [1967], Yund and Anderson [1974], and Matthews et al. [1983a], as well as calculations by Cole et al. [1983], indicate that the dominant mechanism of isotopic exchange is by dissolution/precipitation reactions when the fluids and minerals are out of equilibrium, but that a much slower, diffusional mechanism takes over once chemical equilibrium has been achieved.

For the purpose of modeling isotopic exchange with EQ6 we chose to ignore diffusional mechanisms and concentrate only on solution-precipitation. EQ6 utilizes stepwise dissolution of reactants that remain out of chemical equilibrium with the rest of the system (fluid + product mineral). If reactants are also out of isotopic equilibrium with the system, their dissolution results in unequal additions of each isotope to the mass balances of the equilibrium system. Subsequently formed product minerals precipitate in isotopic equilibrium with the fluid.

Conservation of mass of the isotopes of an element is a 
logical additional step to the conservation of charge and mass of each element that currently serve as constraints for the mass transfer calculations performed by EQ6. If the initial fluid is undersaturated with respect to all possible products, after the first increment of reactants has been added to the system, the $\delta^{18} \mathrm{O}$ of the system at $\xi$ (reaction progress variable) can be expressed as

$$
\delta^{18} \mathrm{O}_{s}(\xi)=\frac{n_{\mathrm{O}}{ }^{\mathrm{H}_{2} \mathrm{O}}}{n_{\mathrm{O}}{ }^{s}} \delta^{18} \mathrm{O}_{\mathrm{H}_{2} \mathrm{O}}\left(\xi^{\circ}\right)+\frac{1}{n_{\mathrm{O}}{ }^{s}} \sum_{r} n_{\mathrm{O}}{ }^{r} \delta^{18} \mathrm{O}_{r}
$$

where

$$
n_{\mathrm{O}}{ }^{s}=n_{\mathrm{O}}^{\mathbf{H}_{2} \mathrm{O}}+\sum_{r} n_{\mathrm{O}}{ }^{r}
$$

where ${n_{\mathrm{o}}}^{\mathrm{H}_{2} \mathrm{O}}$ represents the moles of oxygen in the fluid phase, $n_{\mathrm{o}}{ }^{\prime}$ is the moles of oxygen in reactant phase $r$, and $n_{\mathrm{o}}{ }^{s}$ denotes moles of oxygen in the entire system. $\xi^{0}$ represents one $\xi$-step before the present value of $\xi$, in this case, the initial state of the system prior to any dissolution of reactants. Note that (4) and (5) together with the following equations can readily be written for hydrogen (or other) isotopes as well, but for the sake of simplicity the procedure is shown only once, for oxygen.

As long as no products form, $\delta^{18} \mathrm{O}$ of the fluid registers only the response to dissolution of the reactants, and $\delta^{18} \mathrm{O}_{s}(\xi)=$ $\delta^{18} \mathrm{O}_{\mathrm{H}_{2} \mathrm{O}}(\xi)$. As soon as products form, $\delta^{18} \mathrm{O}_{\mathrm{s}}$ must be redistributed between the fluid and these product phases according to

$$
\delta^{18} \mathrm{O}_{s}(\xi)=\frac{n_{\mathrm{O}}{ }^{\mathrm{H}_{2} \mathrm{O}}}{n_{\mathrm{O}}{ }^{s}} \delta^{18} \mathrm{O}_{\mathrm{H}_{2} \mathrm{O}}(\xi)+\frac{1}{n_{\mathrm{O}}{ }^{s}} \sum_{p} n_{\mathrm{O}}{ }^{p} \delta^{18} \mathrm{O}_{p}(\xi)
$$

where $n_{\mathrm{O}}{ }^{\mathrm{s}}$ has the same value as in (4) but $n_{\mathrm{O}}{ }^{\mathrm{H}_{2} \mathrm{O}}$ has been modified by the precipitation of products, and $\delta^{18} \mathrm{O}_{\mathrm{H}_{2} \mathrm{O}}$ and $\delta^{18} \mathrm{O}_{p}$ at $\xi$ must now be calculated from equilibrium fractionation curves for the product minerals and $\mathrm{H}_{2} \mathrm{O}$. Equation (6) can be rewritten as

$$
\begin{aligned}
& \delta^{18} \mathrm{O}_{s}(\xi)=\frac{n_{\mathrm{O}}{ }^{\mathrm{H}_{2} \mathrm{O}}}{n_{\mathrm{O}}{ }^{s}} \delta^{18} \mathrm{O}_{\mathrm{H}_{2} \mathrm{O}}(\xi)+\frac{1}{n_{\mathrm{O}}{ }^{s}} \sum_{p} n_{\mathrm{O}}^{p} \\
& \cdot\left[\left(1000+\delta^{18} \mathrm{O}_{\mathrm{H}_{2} \mathrm{O}}(\xi)\right) \alpha_{p-\mathrm{H}_{2} \mathrm{O}}-1000\right]
\end{aligned}
$$

where

$$
\alpha_{p-\mathrm{H}_{2} \mathrm{O}}=\frac{1000+\delta^{18} \mathrm{O}_{p}(\xi)}{1000+\delta^{18} \mathrm{O}_{\mathrm{H}_{2} \mathrm{O}}(\xi)}
$$

Equation (7) can be solved for $\delta^{18} \mathrm{O}_{\mathrm{H}_{2} \mathrm{O}}(\xi)$, and $\delta^{18} \mathrm{O}_{p}(\xi)$ is subsequently calculated from $(8)$.

The next incremental step in reaction progress involves addition of isotopes through dissolution of reactants to an equilibrium system already containing products. If the entirety of these products is retained in isotopic equilibrium, redistribution of the isotopes is calculated in the following manner:

$$
\begin{aligned}
\delta^{18} \mathrm{O}_{s}(\xi)=\frac{n_{\mathrm{O}}{ }^{\mathrm{H}_{2} \mathrm{O}}}{n_{\mathrm{O}}{ }^{s}} \delta^{18} \mathrm{O}_{\mathrm{H}_{2} \mathrm{O}}\left(\xi^{\circ}\right) \\
\quad+\frac{1}{n_{\mathrm{O}}{ }^{s}} \sum n_{\mathrm{O}}{ }^{r} \delta^{18} \mathrm{O}_{r}+\frac{1}{n_{\mathrm{O}}{ }^{s}} \sum_{p} n_{\mathrm{O}}{ }^{p} \delta^{18} \mathrm{O}_{p}\left(\xi^{\circ}\right)
\end{aligned}
$$

where

$$
n_{\mathrm{O}}{ }^{s}=n_{\mathrm{O}}{ }^{\mathrm{H}_{2} \mathrm{O}}+\sum_{r} n_{\mathrm{O}}{ }^{r}+\sum_{p} n_{\mathrm{O}}{ }^{p}
$$

$n_{\mathrm{O}}{ }^{r}$ refers to moles of oxygen in reactants added in this incremental step only, $n_{\mathrm{O}}{ }^{p}$ refers to moles of oxygen in product phases precipitated prior to this step (at $\xi^{\circ}$ ), and $\delta^{18} \mathrm{O}_{\mathrm{H}_{2} \mathrm{O}}$ and $\delta^{18} \mathrm{O}_{p}$ retain their values calculated from (7) and (8). A new value of $\delta^{18} \mathrm{O}_{s}(\xi)$ is computed from (9) and used in (7) to redistribute the isotopes among product phases (including the current increment to the products) and fluid. Note that in the case described above the entire product phase is reequilibrated with the fluid at each step in the reaction progress, resulting in its uniform isotopic composition. In contrast, products will be isotopically zoned if only the additional increment to the product phase at a given step of reaction progress is considered to be in isotopic equilibrium with the fluid. The small chemical affinities of isotopic reactions suggest this likelihood [Walther and Rye, 1982]. However, for simplicity we have assumed uniform isotopic composition of products because very little zoning of isotopes would develop in an isothermal reaction.

The underlying assumptions of this model are that isotopic equilibrium is achieved as last as chemical equilibrium, and that there is no net flux of ${ }^{18} \mathrm{O}$ either into or out of the system, other than that achieved through dissolution of reactants or removal of product phases from the system. This also signifies that isotopic exchange with undissolved reactants (in this case, mineralogically unaltered basalt) is not considered, i.e., no diffusion. In other words, if there is no recrystallization, there is no isotopic exchange; at the relatively low temperatures considered here, this seems to be a realistic assumption.

A further assumption is that the composition of the fluid has no effect on the degree to which it fractionates isotopes. Taube [1954] and Truesdell [1974] have in fact shown that this is not strictly true. The value of $\Delta$ solution-water for 1 to 4 molal solutions of $\mathrm{KCl}, \mathrm{CaCl}_{2}$ and $\mathrm{MgCl}_{2}$, for example, may vary from approximately -2 to +2 per mil. However, this variance shows no clear relationship to temperature and is therefore difficult to incorporate mathematically into the model; in any case $\mathrm{NaCl}$ is the most worrisome impurity in natural hydrothermal fluids, and addition of this salt has a negligible effect [Taube, 1954; Kendall et al., 1983], contradicting the observations of Truesdell [1974].

\section{Model Calculations of Seawater-Basalt INTERACTION}

\section{Starting Compositions}

The chemical composition of seawater is well known (Table 1; see Von Damm et al. [1985]). Seawater has a high $p \mathrm{H}$ $(\sim 7.8)$, is supersaturated with respect to dissolved oxygen, and at $2^{\circ} \mathrm{C}$ (temperature of deep ocean water) is also supersaturated with respect to dolomite and quartz. These minerals are not precipitating from seawater at $2^{\circ} \mathrm{C}$, presumably because of kinetic inhibitions. Oxygen and hydrogen isotopic $\delta$-values of deep ocean water are very uniform at zero per mil, relative to SMOW.

We have chosen to use the same basalt starting composition employed by Wolery [1978]. The composition shown in Table 2 corresponds to sample V25-RD1-T3, a fresh basalt from the Mid-Atlantic Ridge reported by Miyashiro et al. [1969], modified to contain $1100 \mathrm{ppm}$ sulfur. This value is midway in the range from 680 to $1800 \mathrm{ppm}$ described by Moore and Fabbi [1971] and Mathez [1976] for fresh basalt glasses, and is selected based on a linear relationship between Fe and $S$ concentrations proposed by Mathez [1976]. Typical fresh MOR basalts have very uniform $\delta^{18} \mathrm{O}=+5.7 \pm 0.2$. 
TABLE 1. Chemical and Isotopic Composition of Seawater, of the Calculated Hydrothermal Fluids at Various Temperatures, and of the $350^{\circ} \mathrm{C}$ East Pacific Rise $\left(21^{\circ} \mathrm{N}\right)$ Hot Spring Fluids

\begin{tabular}{lllllllll}
\hline $\begin{array}{c}\text { Elements } \\
\text { or } \\
\text { Species }\end{array}$ & \multicolumn{7}{c}{ Concentration, mmol/kg } \\
\cline { 2 - 9 } & Seawater $\left(2^{\circ} \mathrm{C}\right)$ & $100^{\circ} \mathrm{C}$ & $150^{\circ} \mathrm{C}$ & \multicolumn{1}{c}{$200^{\circ} \mathrm{C}$} & \multicolumn{1}{c}{$250^{\circ} \mathrm{C}$} & $300^{\circ} \mathrm{C}$ & \multicolumn{1}{c}{$350^{\circ} \mathrm{C}$} & EPR Fluid \\
\hline $\mathrm{Na}$ & 463. & 476. & 484. & 503. & 527. & 542. & 607. & $430-510$ \\
$\mathrm{Cl}$ & 540. & 541. & 541. & 545. & 550. & 553. & 574. & $490-580$ \\
$\mathrm{~K}$ & 9.8 & 0.743 & 2.20 & 4.96 & 9.22 & 15.1 & 29.1 & $23-26$ \\
$\mathrm{Al}$ & $2.0 \times 10^{-5}$ & $2.1 \times 10^{-3}$ & 0.134 & 0.716 & 2.63 & 5.00 & 0.179 & $0.004-0.005$ \\
$\mathrm{Si}$ & 0.18 & 0.471 & 2.11 & 3.85 & 6.14 & 7.27 & 11.6 & $15-20$ \\
$\mathrm{Mg}$ & 52.6 & 2.43 & $5.2 \times 10^{-2}$ & $4.8 \times 10^{-2}$ & $2.1 \times 10^{-2}$ & $1.1 \times 10^{-2}$ & $9.8 \times 10^{-2}$ & 0 \\
$\mathrm{Fe}$ & $1.5 \times 10^{-6}$ & $4.4 \times 10^{-3}$ & $4.3 \times 10^{-4}$ & $2.6 \times 10^{-3}$ & $2.2 \times 10^{-3}$ & 0.191 & 63.2 & $0.7-2.5$ \\
$\mathrm{Ca}$ & 10.2 & 48.3 & 33.4 & 18.9 & 8.11 & 1.04 & 0.774 & $11-20$ \\
$\mathrm{SO}{ }_{4}$ & 28. & 18.5 & 5.69 & $1.5 \times 10^{-9}$ & 0 & 0 & 0 & 0 \\
$\mathrm{H} \mathrm{S}_{2}$ & 0 & $1.7 \times 10^{-4}$ & $6.9 \times 10^{+3}$ & 0.419 & 2.31 & 5.72 & 14.2 & $6-9$ \\
$p \mathrm{H}$ & 7.8 & 6.38 & 6.31 & 5.99 & 5.80 & 5.98 & 5.67 & $3.3-3.8$ \\
$\log f_{\mathrm{O}_{2}}$ & -1.24 & -51.5 & -45.0 & -44.4 & -40.2 & -36.3 & -32.1 & -30.9 \\
$\delta^{18} \mathrm{O}$ & 0.0 & -0.126 & -0.202 & -0.107 & 0.145 & 0.508 & 2.02 & 2 \\
$\delta \mathrm{D}$ & 0.0 & 0.021 & 0.022 & 0.200 & 0.406 & 0.721 & 2.67 & 2.5 \\
\hline
\end{tabular}

\section{Pathlines in Open Versus Closed Systems}

In nature, the interaction of basalt with heated seawater takes place as neither a perfectly open system nor a perfectly closed system in the sense defined above in the discussion of the EQ6 model. A packet of seawater being heated and reacting with fresh basalt at some temperature can perhaps be envisioned in this way: as temperature increases with depth and proximity to the ridge axis, this packet of seawater will presumably move along a pathline downward and inward toward the heat source (MOR), and along the way it should encounter some relatively unaltered basaltic material. On the other hand, it will also encounter basalts altered to varying degrees by earlier packets of seawater that have passed through the system. The assumption is made here that EPRtype hydrothermal fluids result from interaction of seawater with basalt along a steep temperature gradient where fresh basalt is being continually supplied to the system (i.e., by magmatism at the ridge axis). In contrast, off-axis hydrothermal circulation probably entails low-temperature alteration of basalts previously altered at higher temperatures. This latter scenario is not considered in the present study.

Whatever the values of parameters such as temperature or water-rock ratio, two things seem certain. (1) The alteration process should not be modeled simply as a closed system undergoing a stepwise temperature increase where all newly formed alteration products are available for back-reaction at higher temperatures. (2) It should also not be modeled as a "simple," or perfectly open system where all secondary minerals formed are instantaneously removed from the system, with no back-reaction whatsoever being allowed. Utilizing the above constraints, together with the capabilities and limitations of the EQ6 model, the following path of seawaterbasalt interaction is used as the basis for the calculations.

Interaction of unaltered seawater and fresh basalt is assumed to begin at $100^{\circ} \mathrm{C}$, and an arbitrary amount of basalt is dissolved isothermally into one kilogram of seawater using the EQ6 closed system model. Note that this solutionredeposition procedure requires that the basalt reacts homogeneously with seawater. At present, no provision is made for the probability that some components of the basalt will alter more rapidly than others, or that some components will undergo isotopic exchange more easily. Product minerals form as a result of the $100^{\circ} \mathrm{C}$ interaction, and they may back-react at any given stage in the reaction progress that they become unstable, all under isothermal $\left(100^{\circ} \mathrm{C}\right)$ conditions. Once the specified amount of fresh basalt and newly-formed alteration minerals have completely reacted, all solid phases are removed from the system and the packet of exchanged seawater (which is now somewhat modified both chemically and isotopically, and which may be less than one kilogram as a result of hydration reactions) is heated up to $150^{\circ} \mathrm{C}$. No reaction with basalt is considered during the heating stage. However, note that simply heating the solution from $100^{\circ}$ to $150^{\circ} \mathrm{C}$ may result in supersaturations of some minerals; in our model these are precipitated at the beginning of reaction with basalt at $150^{\circ} \mathrm{C}$, implying that the concentrations of certain species in solution at the initiation of the $150^{\circ} \mathrm{C}$ step may be slightly different from their values at the end of the $100^{\circ} \mathrm{C}$ step. At $150^{\circ} \mathrm{C}$, after the chemical species in the fluid are redistributed according to the new equilibrium conditions, the packet of (modified) seawater is again allowed to react isothermally with fresh basalt in a closed system.

In the above scenario, seawater reacts isothermally with fresh basalt at each increment in temperature. We continue this procedure in steps of $50^{\circ} \mathrm{C}$ to the final temperature of $350^{\circ} \mathrm{C}$. Back-reaction of the exchanged fluid with alteration products occurs during each isothermal stage of the reaction; however, at the conclusion of reaction at each temperature step, all secondary minerals are removed from the equilibrium system. This corresponds to a progressively decreasing waterrock ratio with increasing temperature (more precisely, it is an

TABLE 2. Calculated Chemical Compositions (wt \%) of the Predicted Hydrothermally Altered Basalts at the End-Points of the Various Temperature Steps Described in the Text

\begin{tabular}{lrrrrrrr}
\hline Oxide & $100^{\circ} \mathrm{C}$ & $150^{\circ} \mathrm{C}$ & $200^{\circ} \mathrm{C}$ & $250^{\circ} \mathrm{C}$ & $300^{\circ} \mathrm{C}$ & $350^{\circ} \mathrm{C}$ & V25-RD1-T3 \\
\hline $\mathrm{SiO}_{2}$ & 47.57 & 47.25 & 49.21 & 49.25 & 49.54 & 49.80 & 49.87 \\
$\mathrm{Al}_{2} \mathrm{O}_{3}$ & 15.00 & 14.95 & 15.50 & 15.49 & 15.56 & 15.71 & 15.70 \\
$\mathrm{FeO}$ & 0.62 & 0.63 & 6.54 & 7.75 & 7.38 & 7.93 & 8.24 \\
$\mathrm{Fe}_{2} \mathrm{O}_{3}$ & 9.59 & 9.57 & 3.31 & 2.04 & 2.49 & 1.51 & 1.40 \\
$\mathrm{MgO}$ & 15.09 & 8.25 & 8.27 & 8.28 & 8.32 & 8.36 & 8.37 \\
$\mathrm{CaO}$ & 2.71 & 12.56 & 10.90 & 10.81 & 10.78 & 10.65 & 10.66 \\
$\mathrm{Na}_{2} \mathrm{O}$ & 1.42 & 2.14 & 2.68 & 2.63 & 2.76 & 2.81 & 2.93 \\
$\mathrm{~K}_{2} \mathrm{O}$ & 1.69 & 0.0 & 0.15 & 0.12 & 0.08 & 0.15 & 0.21 \\
$\mathrm{H}_{2} \mathrm{O}$ & 4.16 & 2.40 & 3.26 & 3.55 & 3.02 & 2.99 & 1.00 \\
$\mathrm{~S}$ & 1.18 & 1.27 & 0.18 & 0.08 & 0.07 & 0.09 & 0.11 \\
\hline
\end{tabular}

Sample V25-RD1-Te [Miyashiro et al., 1969] represents the unaltered basalt. 
increasing rock-water ratio, in the way the titration in the computer calculation is actually carried out, as more and more fresh rock is added to the initial $\mathrm{kg}$ of seawater). Predictions of the model are dependent on the amount of rock interacting with fluid at each temperature, and this parameter can be varied in different models. Also, different paths of temperature and water-rock ratio can be tested for agreement with the analytically determined chemical and isotopic compositions of the EPR hydrothermal system.

The computational procedures outlined above represent a realistic compromise between the constraints of the EQ6 models and actual MOR hydrothermal systems. Our calculations produce a vertically stratified oceanic crust in which the grade of hydrothermal metamorphism increases downward, as it should. The model also has the advantage that at the starting point of each successive temperature step, the only reactant material that has changed its chemical and isotopic composition is the fluid. This means that the reader can more readily visualize what is going on at each temperature interval than if we had substituted some arbitrary, path-dependent, altered basaltic material at the start of each step. For example, by the time one had traveled through several temperature steps in any of several more complex types of temperaturecomposition paths that one might imagine, it would be difficult not to lose sight of which parameters are most important in producing specific cause-and-effect relationships. There are so many variables and so many possible paths that even if a good isotopic and chemical match were to be made between calculation and observation, it would be difficult to single out the critical features of the models.

\section{Temperatures of Reaction}

We have made a somewhat arbitrary selection of $100^{\circ} \mathrm{C}$ as a starting temperature for our calculations, even though data such as those of Böhlke et al. [1984] and Stakes and O'Neil [1982] document formation of alteration phases at temperatures below $100^{\circ} \mathrm{C}$. We can do this because the effect of low-temperature interaction on a given packet of seawater is small as a result of kinetic factors and the high water-rock ratios involved at the lower temperatures. Only minor errors are introduced by neglecting interaction at temperatures below $100^{\circ} \mathrm{C}$ in our calculations.

An upper limit of approximately $350^{\circ} \mathrm{C}$ is imposed on our model because of present constraints on the thermodynamic data base, but this limit seems appropriate for several other reasons as well. The exiting solutions at $21^{\circ} \mathrm{N}$ on the EPR are the highest-temperature fluids $\left(350^{\circ} \mathrm{C} \pm 5^{\circ}\right)$ yet measured at midocean ridges. Recently, higher temperatures have been reported by Delaney et al. [1984] and Kim et al. [1984], but these measurements have yet to be substantiated. Von Damm et al. [1985] calculate temperatures at depth for the EPR vent fluids assuming adiabatic cooling and using silica concentration in the fluids as a geobarometer. This procedure indicates a depth of reaction of 0.5 to $2.0 \mathrm{~km}$ beneath the seafloor, which corresponds to maximum temperatures before adiabatic cooling of approximately $355^{\circ}-365^{\circ} \mathrm{C}$. Von Damm et al. [1985] note that ocean bottom seismic data at $21^{\circ} \mathrm{N}$ [Riedesel et al., 1982] indicate that most seismic events occur at about these same depths, and this is interpreted to be the maximum depth of large-scale hydrothermal circulation. The rapid exit velocities proposed by MacDonald et al. [1980] for vent fluids suggest that the fluids could cover the distance from depth in a few minutes, making it highly unlikely that substantial heat would be lost during the ascent. Conse-

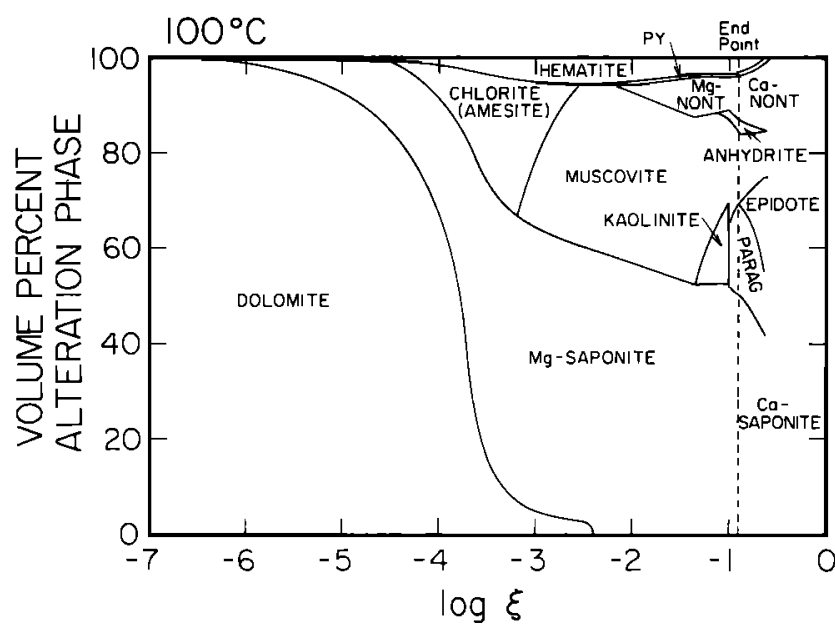

Fig. 4. Calculated volume percent of alteration phases predicted to form as the result of seawater-basalt interaction at $100^{\circ} \mathrm{C}$, plotted as a function of $\log$ reaction progress where $\log \xi=0$ corresponds to 216.0 grams of basalt dissolved in $1 \mathrm{~kg}$ of seawater. PY, pyrite; NONT, nontronite; PA, paragonite.

quently, at least at $21^{\circ} \mathrm{N}$ it appears that, even at depth, the fluids were never much hotter than $350^{\circ} \mathrm{C}$.

Further support for our assumed range of temperatures comes from the estimates of Lister [1982] and Mottl [1983]. Also, Norton [1984] has shown that the transport properties of pure $\mathrm{H}_{2} \mathrm{O}$ (buoyancy, viscosity, etc.) go through extrema near the critical point $\left(374^{\circ} \mathrm{C}\right)$; this leads to relatively rapid convection at such temperatures, explaining why this is a commonly observed upper limit in explored hydrothermal systems (e.g., EPR, Salton Sea, Larderello).

Although we are assuming in our model that the MOR fluids have been at maximum temperatures on the order of $350^{\circ}-365^{\circ} \mathrm{C}$, this does not apply to all submarine hydrothermal systems, and indeed there is evidence that much higher-temperature, sub-seafloor hydrothermal circulation must exist. For example, Gregory and Taylor [1981] estimate that hydrothermal circulation locally occurred at a depth of more than $5 \mathrm{~km}$ in the Samail Ophiolite, at temperatures greater than $500^{\circ}-600^{\circ} \mathrm{C}$, similar to values estimated by Stakes et al. [1984] for gabbros from the Indian Ocean. Gregory and Taylor [1981] and Bischoff and Rosenbauer [1984] suggest that the deeper penetration and higher temperatures occur predominantly within the layered gabbros and along the sides and beneath the axis magma chamber, and therefore are not a part of the venting axial system such as that from which the $21^{\circ} \mathrm{N}$ fluids are being collected.

\section{Results of THE COMPuter Model}

\section{General Statement}

There exist essentially an infinite number of possible temperature/water-rock ratio paths, only a few of which are considered in the present study. However, most of these possible paths can be rejected because they do not result in the simultaneous occurrence of the necessary mineralogical, chemical, and isotopic characteristics actually observed in the basalts and hydrothermal fluids. Thus, after several iterations and adjustments, we settled on a particular path and final end-point that fits most of the available observational data; the results are shown in Figures 4 to 20. The path was initiated with one kilogram of seawater heated to $100^{\circ} \mathrm{C} .26 .6$ grams 


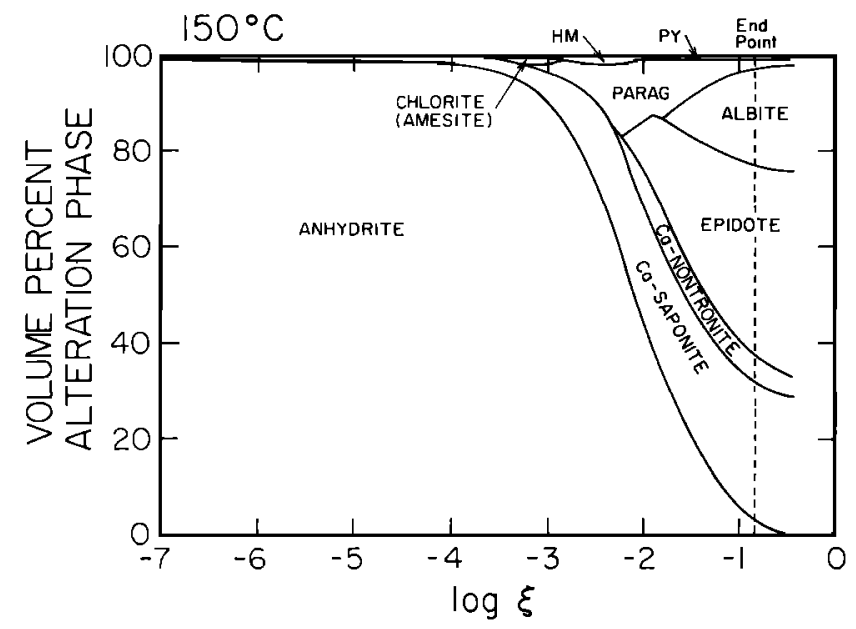

Fig. 5. Calculated volume percent of alteration phases predicted to form at $150^{\circ} \mathrm{C}$ from interaction of basalt with a fluid of composition corresponding to the results of the $100^{\circ} \mathrm{C}$ calculation shown in Figure 4, plotted as a function of log reaction progress. PY, pyrite; HM, hematite; PARAG, paragonite.

of fresh basalt were dissolved into the seawater at $100^{\circ} \mathrm{C}, 32.5$ grams at $150^{\circ} \mathrm{C}, 216.0$ grams at each of $200^{\circ}, 250^{\circ}$, and $300^{\circ} \mathrm{C}$, and finally, 1080.2 grams were added at $350^{\circ} \mathrm{C}$. A total of 1787.4 grams of basalt were thus added to the kilogram of seawater over the entire temperature range, resulting in a final (overall) water-rock ratio of approximately 0.56 (weight units).

It is important to understand that although we are concerned specifically with calculating a plausible pathline for a particular fluid packet that circulates downward close to the roof of a MOR magma chamber and which then exits at $350^{\circ} \mathrm{C}$ on the seafloor, the end-points of the calculations at each intermediate temperature step also provide insight into the overall alteration of the oceanic crust. For example, a significant proportion of the sea water that is heated to $150^{\circ} \mathrm{C}$ or $200^{\circ} \mathrm{C}$ will migrate either upward or laterally, possibly exiting at the sea floor in off-axis effluent; only a small quantity will circulate to still greater depths and ultimately exit at $350^{\circ} \mathrm{C}$ from a MOR vent. The whole-rock isotopic compositions and the mineral assemblages at the end-points described below will adequately describe each depth-segment of

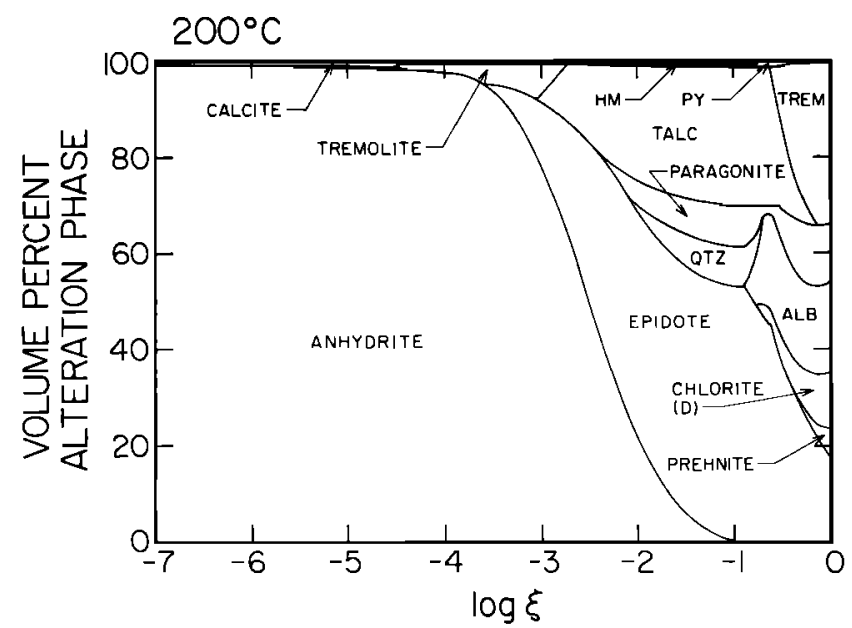

Fig. 6. Calculated volume percent of alteration phases predicted to form at $200^{\circ} \mathrm{C}$ from interaction of basalt with a fluid of composition corresponding to the results of the $150^{\circ} \mathrm{C}$ calculation shown in Figure 5, plotted as a function of log reaction progress. PY, pyrite; HM, hematite; TREM, tremolite; QTZ, quartz; AB, albite.

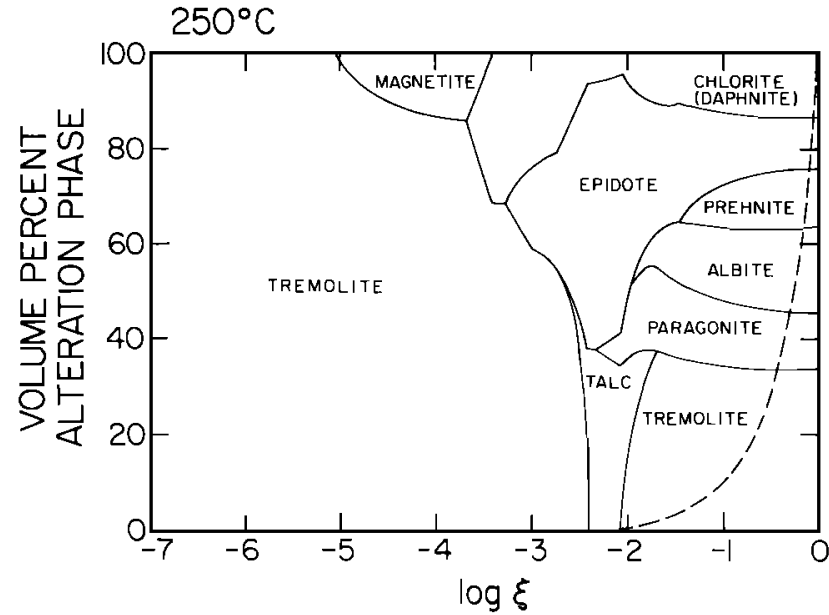

Fig. 7. Calculated volume percent of alteration phases predicted to form at $250^{\circ} \mathrm{C}$ from interaction of basalt with a fluid of composition corresponding to the results of the $200^{\circ} \mathrm{C}$ calculation shown in Figure 6, plotted as a function of log reaction progress. The dashed curve represents volume of alteration minerals at any stage as a fraction of the total volume of alteration minerals produced during the entire isothermal reaction interval.

the oceanic crust, if there is continued flushing of the bulk oceanic crust by such fluids, up to the characteristic waterrock ratio derived for each temperature-depth step.

Results of the model calculations are dependent on the endpoint of each temperature step, and selection of these endpoints therefore involves the use of several criteria. At $350^{\circ} \mathrm{C}$, the model reactions were stopped when $\delta^{18} \mathrm{O}$ of the fluid reached the observed value of +2.0 per mil, and if the predicted $\delta \mathrm{D}$ of the fluid, the solution chemistry, or the mineralogy, was not substantially in agreement with MOR systems, the entire temperature-path was considered to be inadequate. The input parameters were then modified and the calculations repeated until substantial agreement was obtained. However, no isotopic constraints exist for any of the intermediate temperature steps, so other criteria that were used included relative changes in isotopic values of the fluid, direction of change in the $p \mathrm{H}$, and reasonableness of predicted mineral assemblages.

For example, at $100^{\circ}$ and $150^{\circ} \mathrm{C} \delta^{18} \mathrm{O}_{\mathrm{H}_{2} \mathrm{O}}$ is decreasing, and

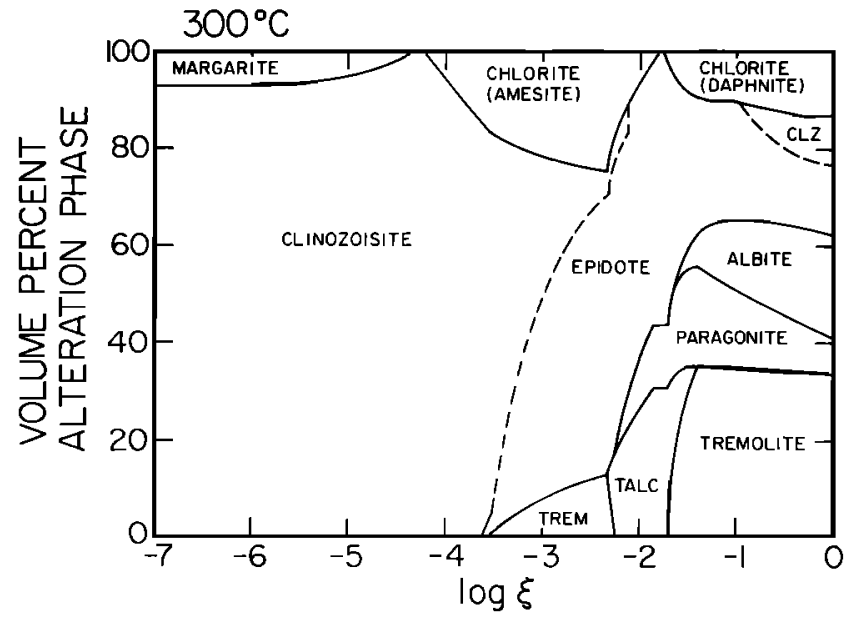

Fig. 8. Calculated volume percent of alteration phases predicted to form at $300^{\circ} \mathrm{C}$ from interaction of basalt with a fluid of composition corresponding to the results of the $250^{\circ} \mathrm{C}$ calculation shown in Figure 7, plotted as a function of log reaction progress. TREM, tremolite. 


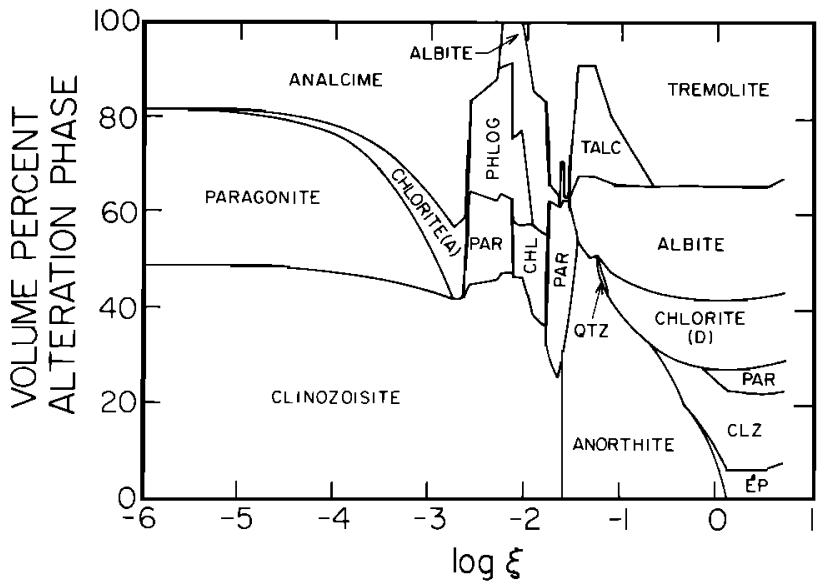

Fig. 9. Calculated volume percent of alteration phases predicted to form at $350^{\circ} \mathrm{C}$ from interaction of basalt with a fluid of composition corresponding to the results of the $300^{\circ} \mathrm{C}$ calculation shown in Figure 8 , plotted as a function of $\log$ reaction progress. PHLOG, phlogopite; CHL, chlorite; (A), amesite; (D), daphnite; PAR, paragonite; QTZ, quartz; EP, epidote.

$p \mathrm{H}$ at high values of reaction progress begins to increase rapidly; neither trend is desirable. In addition, at $100^{\circ} \mathrm{C}$ epidote is predicted at high $\log \xi$ values, and because epidote does not typically form at temperatures as low as $100^{\circ} \mathrm{C}$, the end-point can be justifiably assigned to a lower value of $\log \xi$. The endpoint at $150^{\circ} \mathrm{C}$ is set right before the onset of a very rapid increase in $p \mathrm{H}$.

Reaction at $200^{\circ}, 250^{\circ}$, and $300^{\circ} \mathrm{C}$ is uniformly stopped at $\log \xi=0$, after the development of epidote-tremolite-chloritealbite assemblages. There is little point in advancing these temperature steps to higher values of $\log \xi$ because the rate of change in $\delta^{18} \mathrm{O}_{\mathrm{H}_{2} \mathrm{O}}$ is too slight for it to reach its ultimate desired value; in addition, further reaction continues to in-
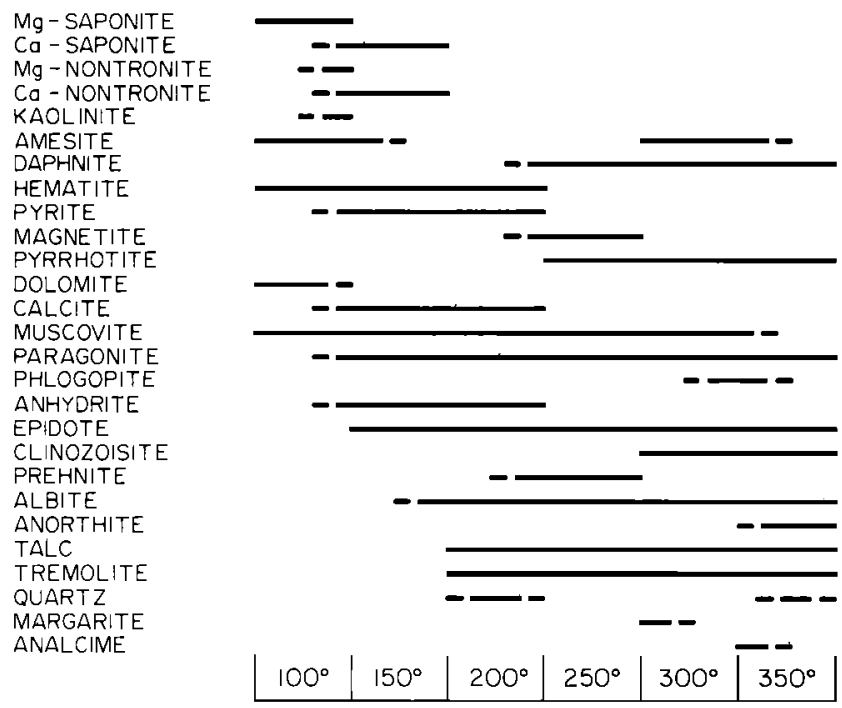

Fig. 10. Summary of predicted alteration phases as a function of temperature, corresponding to those shown in Figures 4 to 9. Minerals included here but not shown in Figures 4 to 9 comprise less than 1-2 volume percent of the alteration assemblage. $\mathrm{Mg}$-saponite, $\mathrm{Mg}_{165} \mathrm{Mg}_{3}\left(\mathrm{Al}_{33} \mathrm{Si}_{367} \mathrm{O}_{10}\right)(\mathrm{OH})_{2}$; Ca-saponite, $\mathrm{Ca}_{165} \mathrm{Mg}_{3}$ $\left(\mathrm{Al}_{33} \mathrm{Si}_{367} \mathrm{O}_{10}\right)(\mathrm{OH})_{2} ; \mathrm{Mg}$-nontronite, $\mathrm{Mg}_{165} \mathrm{Fe}_{2}\left(\mathrm{Al}_{.33} \mathrm{Si}_{3.67} \mathrm{O}_{10}\right)$ $(\mathrm{OH})_{2}$; Ca-nontronite, $\mathrm{Ca}_{165} \mathrm{Fe}_{2}\left(\mathrm{Al}_{.33} \mathrm{Si}_{3.67} \mathrm{O}_{10}\right)(\mathrm{OH})_{2}$; amesite, $\mathrm{Mg}_{4} \mathrm{Al}_{2}\left(\mathrm{Al}_{2} \mathrm{Si}_{2} \mathrm{O}_{10}\right)(\mathrm{OH})_{8}$; daphnite, $\mathrm{Fe}_{5} \mathrm{Al}\left(\mathrm{AlSi}_{3} \mathrm{O}_{10}\right)(\mathrm{OH})_{8}$; clinozoisite, $\mathrm{Ca}_{2} \mathrm{Al}_{3} \mathrm{Si}_{3} \mathrm{O}_{12}(\mathrm{OH})$; epidote, $\mathrm{Ca}_{2} \mathrm{FeAl}_{2} \mathrm{Si}_{3} \mathrm{O}_{12}(\mathrm{OH})$.

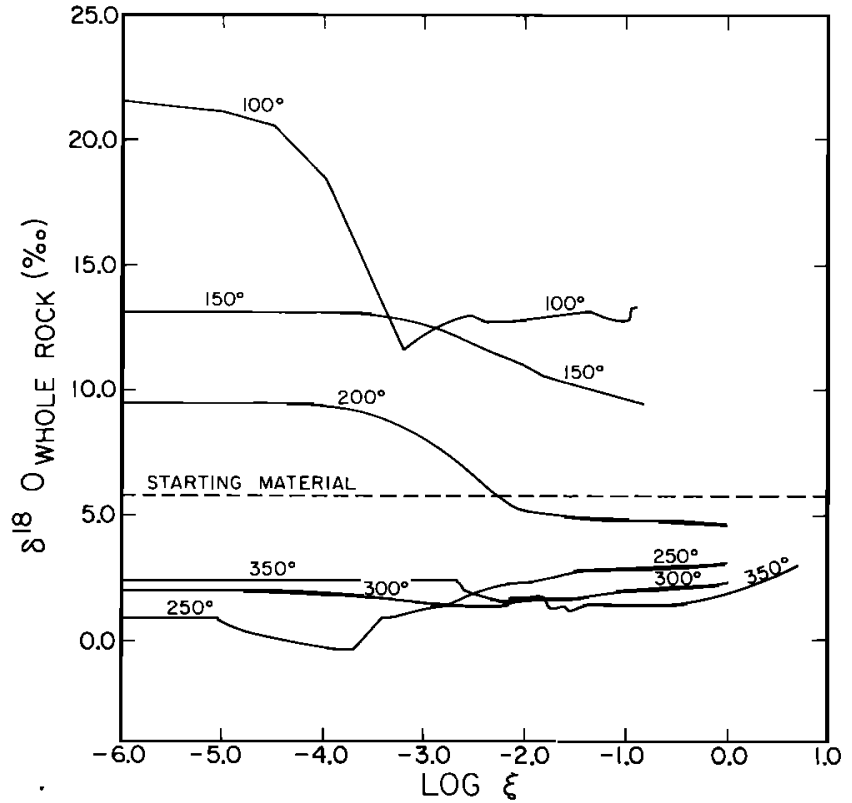

Fig. 11. Calculated $\delta^{18} \mathrm{O}$ whole-rock of the predicted mineral assemblages shown in Figures 4 to 9 as a function of log reaction progress. Contours are temperature in ${ }^{\circ} \mathrm{C}$. The horizontal dashed line at $\delta^{18} \mathrm{O}=+5.8$ is the assumed ${ }^{18} \mathrm{O} /{ }^{16} \mathrm{O}$ ratio of the initial basalt.

crease $p \mathrm{H}$. Reaction at $350^{\circ} \mathrm{C}$, as noted above, is allowed to proceed only as far as the $\log \xi$ value corresponding to $\delta^{18} \mathrm{O}_{\mathrm{H}_{2} \mathrm{O}}=+2.0$ per mil. It is important to note that in addition to the major set of calculations presented in Figures 4 to 20, many "dead-end" paths with different end-points at each temperature step were tested and rejected during the course of this work.

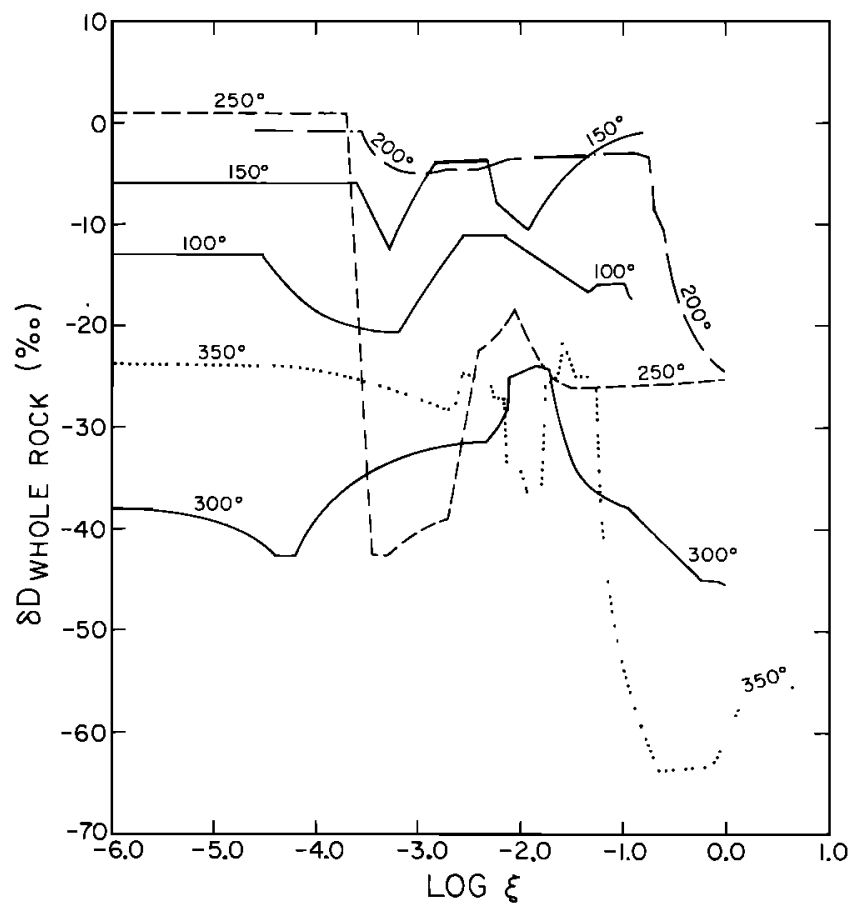

Fig. 12. Calculated whole rock $\delta \mathrm{D}$ of the predicted mineral assemblages shown in Figures 4 to 9 as a function of log reaction progress. Contours are temperature in ${ }^{\circ} \mathrm{C}$. The $200^{\circ} \mathrm{C}$ curve begins at $\log \xi \sim-4.6$ because no H-bearing alteration products are predicted to form earlier in the reaction progress. 


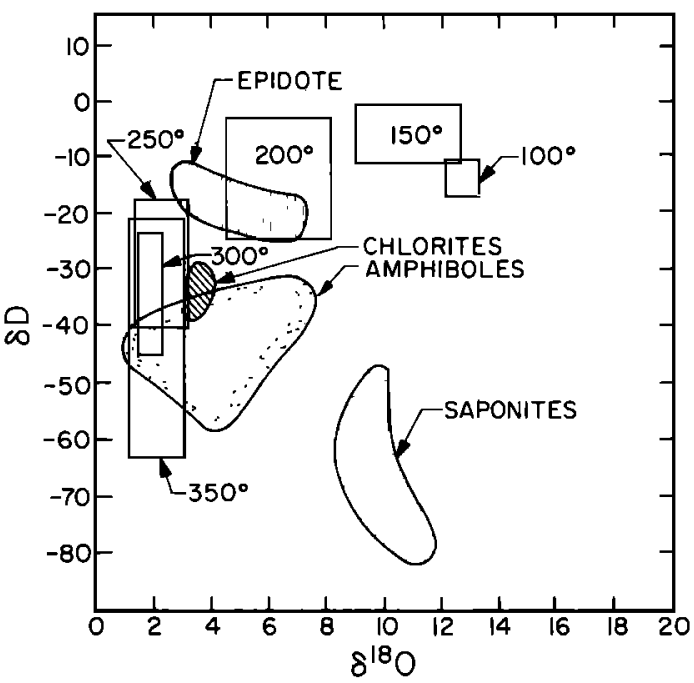

Fig. 13. $\delta \mathrm{D}$ versus $\delta^{18} \mathrm{O}$, modified after Figure 1 of Stakes and $O$ 'Neil [1982]. Saponite, amphibole, epidote, and chlorite fields from oceanic dredge hauls are from Stakes et al. [1984] and Stakes and $O^{\prime} N$ eil [1982]. Rectangular symbols represent the range of calculated $\delta \mathrm{D}$ and $\delta^{18} \mathrm{O}$ values for alteration assemblages shown in Figures 4 to 9 for a given temperature in ${ }^{\circ} \mathrm{C}$. The high calculated $\delta \mathrm{D}$ values relative to observation at $100^{\circ}$ and $150^{\circ} \mathrm{C}$ result from the lack of consideration of an $\mathrm{Fe}$-saponite end member in the thermodynamic data base and the sensitivity of $\delta \mathrm{D}$ of $\mathrm{OH}$-bearing minerals to changes in $\mathrm{Fe} / \mathrm{Mg}$ (see text).

\section{Mineralogy}

The calculated modal mineralogy of the alteration assemblages produced at the various temperature steps is shown as a function of $\log$ reaction progress $(\log \xi)$ at $100^{\circ}, 150^{\circ}, 200^{\circ}$, $250^{\circ}, 300^{\circ}$, and $350^{\circ} \mathrm{C}$ (Figures 4 to 9 ). A summary of all mineral phases calculated for the entire temperature range is given in Figure 10. Minerals shown in Figure 10 but not in the corresponding Figures 4 to 9 were predicted to appear in quantities less than 1 or 2 volume percent and thus could not be shown with clarity on these figures.

Seawater is supersaturated with respect to dolomite at $100^{\circ} \mathrm{C}$, just as it is at $2^{\circ} \mathrm{C}$, and as a result dolomite forms a large proportion of the early alteration at $100^{\circ} \mathrm{C}$. A small amount of anhydrite forms toward the end of the $100^{\circ} \mathrm{C}$ calculation, and it is a major precipitate at low values of reaction progress at both $150^{\circ}$ and $200^{\circ} \mathrm{C}$.

As reaction progress increases, the Ca-uptake in the anhydrite and dolomite is switched over to $\mathrm{Ca}$-smectites and epidote, while $\mathrm{SO}_{4}$ is reduced and pyrite forms. Abundant smectite forms at $100^{\circ}$ and $150^{\circ} \mathrm{C}$; at $200^{\circ} \mathrm{C}$ and above, precipitation of smectites is (purposely) suppressed in the computer model, and chlorites take their place. At low values of reaction progress (equivalent to high water-rock ratio) $\mathrm{Mg}$-rich saponite is the primary smectite. As the Mg concentration decreases with further reaction, $\mathrm{Mg}$-rich saponite is replaced by Ca-rich saponite, and this is joined at $150^{\circ} \mathrm{C}$ by Ca-rich nontronite. Chlorite forms over the entire temperature range; $\mathrm{Mg}$-rich chlorite (amesite) forms at $100^{\circ}$ and $150^{\circ} \mathrm{C}$, as well as at low values of reaction progress at $300^{\circ}$ and $350^{\circ} \mathrm{C}$, and Fe-rich chlorite (daphnite) forms above $200^{\circ} \mathrm{C}$, at higher values of reaction progress than for amesite.

Muscovite and paragonite (sericite) both occur over the entire temperature range, but muscovite dominates at $100^{\circ} \mathrm{C}$ and paragonite at $150^{\circ}$ to $350^{\circ} \mathrm{C}$. Quartz is predicted as a precipitate occasionally, and although it does not have a large field of stability in these diagrams, $\mathrm{Si}$ concentrations in solution arc often at values close to quartz saturation. Epidote and albite are major precipitates late in reaction progress from $150^{\circ}$ to $350^{\circ} \mathrm{C}$. Note that the computer program contains no provision for solid solution between clinozoisite and epidote, and as a result either or both phases can appear in the calculations. Talc and its replacement tremolite (serving as a proxy for actinolite) are predicted from $200^{\circ}$ to $350^{\circ} \mathrm{C}$.

The relative size of the area occupied by a phase from left to right across each of the Figures 4 to 9 does not represent the relative amounts of those phases formed (because volume percent rather than total volume is plotted on the ordinate). The total volume of alteration phases increases approximately logarithmically from left to right. The dashed logarithmic curve shown in Figure 7 displays this, where if 100 equals the total volume of alteration minerals at $\log \xi=0$, the volume of minerals formed at any value of $\log \xi<-2$ is too small to be shown on the scale. For example, the large field occupied by tremolite at $250^{\circ} \mathrm{C}$ and low values of $\log \xi$ is somewhat misleading; it is large merely because no other alteration products are forming and the small amount of tremolite therefore represents $100 \%$ of the alteration.

Our model allows dissolution of products during a given temperature step (see above). This means that a predicted

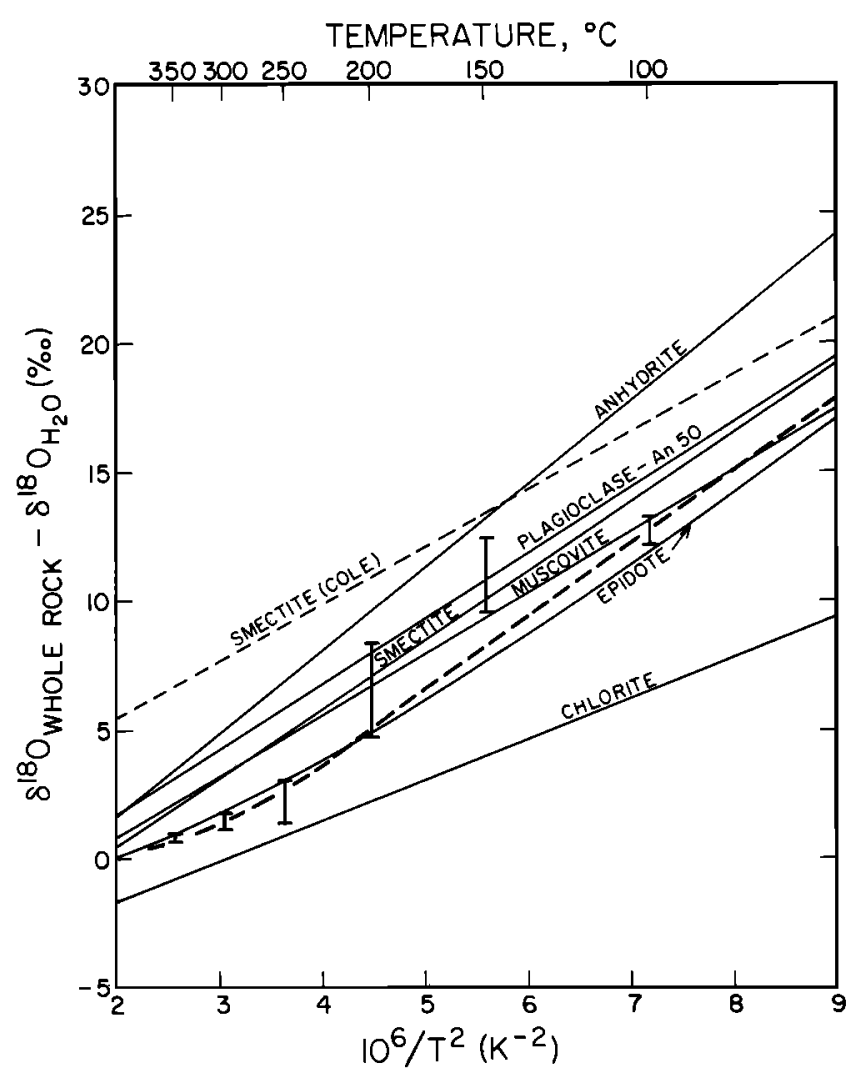

Fig. 14. Equilibrium oxygen isotope fractionations as a function of temperature for various minerals. The vertical bars represent the range of values of whole-rock $\delta^{18} \mathrm{O}$ minus $\delta^{18} \mathrm{O}_{\mathrm{H}_{2} \mathrm{O}}$ calculated for the predicted alteration assemblages shown in Figures 4 to 9 at various temperature steps. The long-dashed line is drawn through the set of vertical bars, and approximately corresponds to the equilibrium oxygen isotope fractionation between "altered basalt" and $\mathrm{H}_{2} \mathrm{O}$. Note that the vertical bars at $150^{\circ}$ and $200^{\circ} \mathrm{C}$ are above the dashed line, a result of the large amounts of anhydrite predicted to form at these temperatures. Solid curves for anhydrite, smectite, muscovite, epidote and chlorite are taken from Figure 1 . The short-dashed curve refers to a smectite- $\mathrm{H}_{2} \mathrm{O}$ curve determined by Cole [1980]. 

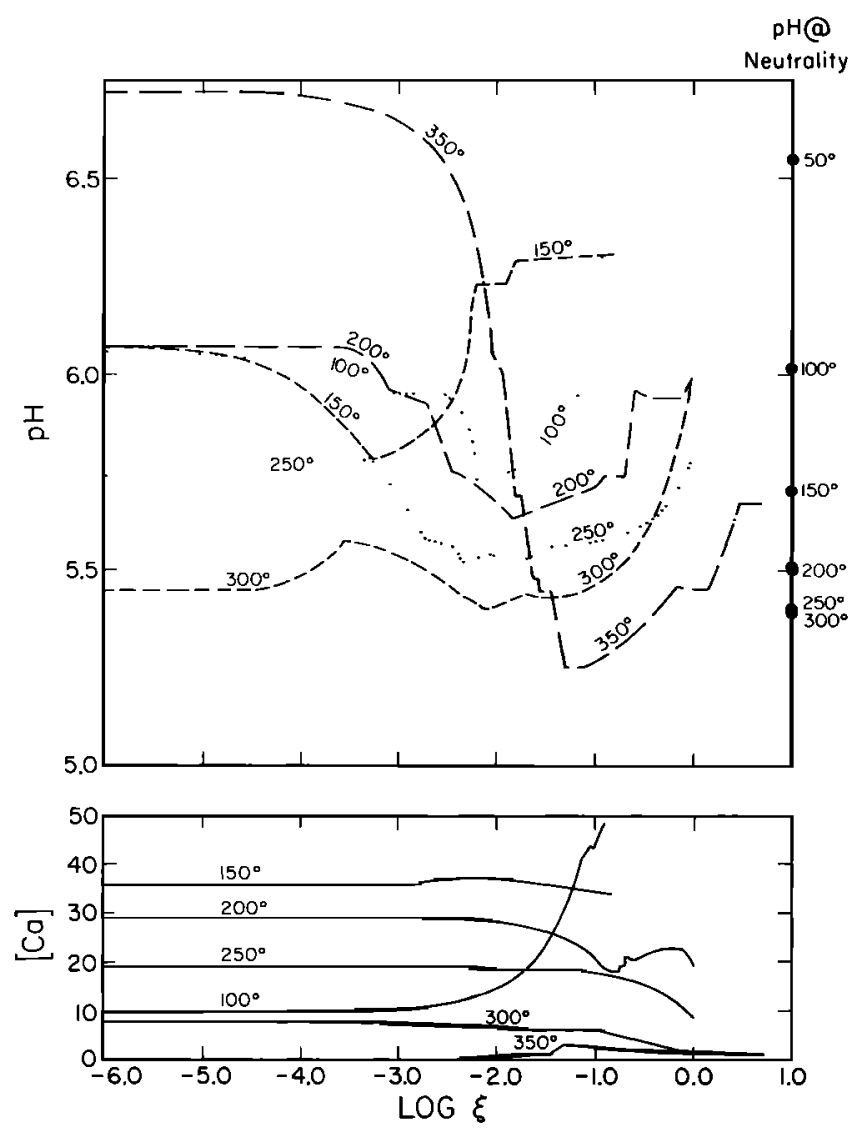

Fig. 15. Ca concentration $(\mathrm{mmol} / \mathrm{kg})$ and $\mathrm{pH}$ of the evolving solution in equilibrium with mineral assemblages shown in Figures 4 to 9 , plotted as a function of log reaction progress. Contours are temperature in ${ }^{\circ} \mathrm{C}$. The $p \mathrm{H}$ of a neutral solution at various temperatures is shown along the right-hand-side of the diagram; note that neutral $p \mathrm{H}$ steadily decreases at higher temperatures up to about $250^{\circ} \mathrm{C}$, so that at their end-points all of the calculated fluids are mildly alkaline.

alteration product can back-react and may be destroyed and replaced by another phase once it becomes unstable (e.g., anhydrite and amesite at $100^{\circ} \mathrm{C}$ and $150^{\circ} \mathrm{C}$; talc at $200^{\circ} \mathrm{C}$ to $350^{\circ} \mathrm{C}$ ). However, in reality a given phase is probably only partially replaced and any of the alteration products predicted at a particular temperature are likely to persist.

The secondary phases shown in Figures 4 to 9 agree well with observations of altered basalts sampled from the seafloor. For example, saponite-rich pillow breccias are common at low temperatures $\left(<200^{\circ} \mathrm{C}\right)$ in seawater-dominated systems (water/rock > 50; Stakes and O'Neil [1982]), and both chloriterich and epidote-rich pillow basalts were described by Humphris and Thompson [1978]. Anhydrite is frequently described in samples from active chimneys on the EPR [Styrt et al., 1981; Oudin, 1983; Haymon, 1983]; however, because of its retrograde solubility it is presumed to have been redissolved by cold seawater, and is thus not commonly observed in dredged samples. Figure 4 of Mottl [1983] shows an overview of the most common alteration phases and their relative proportions as a function of water-rock ratio. Note that the relative proportions of chlorite, epidote, actinolite and albite at low water-rock ratios shown by Mottl [1983] correspond almost exactly to the relative amounts of the same phases predicted by our computer model at $350^{\circ} \mathrm{C}$, shown in Figure 9.

Bulk chemistry in terms of the oxides can also be deter- mined for the alteration assemblages predicted by the model above to facilitate comparison with the chemical changes observed in altered basalts, as summarized by Mottl [1983] and Humphris and Thompson [1978]. Table 2 shows the oxidedistribution of a rock representing the alteration assemblage present at the conclusion of each of the isothermal calculations from $100^{\circ}$ to $350^{\circ} \mathrm{C}$. The composition of the fresh basalt starting material from Miyashiro et al. [1969] is also shown. The difference in composition between the fresh basalt and the altered rock is most dramatic at the $100^{\circ} \mathrm{C}$ step, whereas at $350^{\circ} \mathrm{C}$ the fresh and altered basalts are chemically nearly indistinguishable. The reason for this effect is that by the time that the high-temperature step is reached, the water-rock ratios are much lower and the aqueous fluid has thoroughly exchanged with the basalt; thus, most of the chemical changes in the basalts occur at $100^{\circ}-150^{\circ} \mathrm{C}$ and high water-rock ratios.

At $100^{\circ} \mathrm{C}$ the altered basalt shows a substantial gain in $\mathrm{Mg}$, considerable loss of $\mathrm{Ca}$, and a larger proportion of oxidized $\mathrm{Fe}$. In addition, the altered rock at $100^{\circ} \mathrm{C}$ shows some loss of $\mathrm{Na}$, gain of $\mathrm{K}$, and gain of $\mathrm{H}_{2} \mathrm{O}$. These computer-generated compositions agree quite well with the rocks described by Mottl [1983] as chlorite-quartz rich, which he concluded probably formed at high water-rock ratios. The altered rocks predicted at high temperature $\left(200^{\circ}-350^{\circ} \mathrm{C}\right)$ are chemically very similar to the fresh basalt, but show a slight loss of $\mathrm{Fe}$ and a gain in $\mathrm{H}_{2} \mathrm{O}$ content, in agreement with the chloritequartz poor rocks described by Mottl. Mottl [1983] reports that these rocks also typically show either small gains or
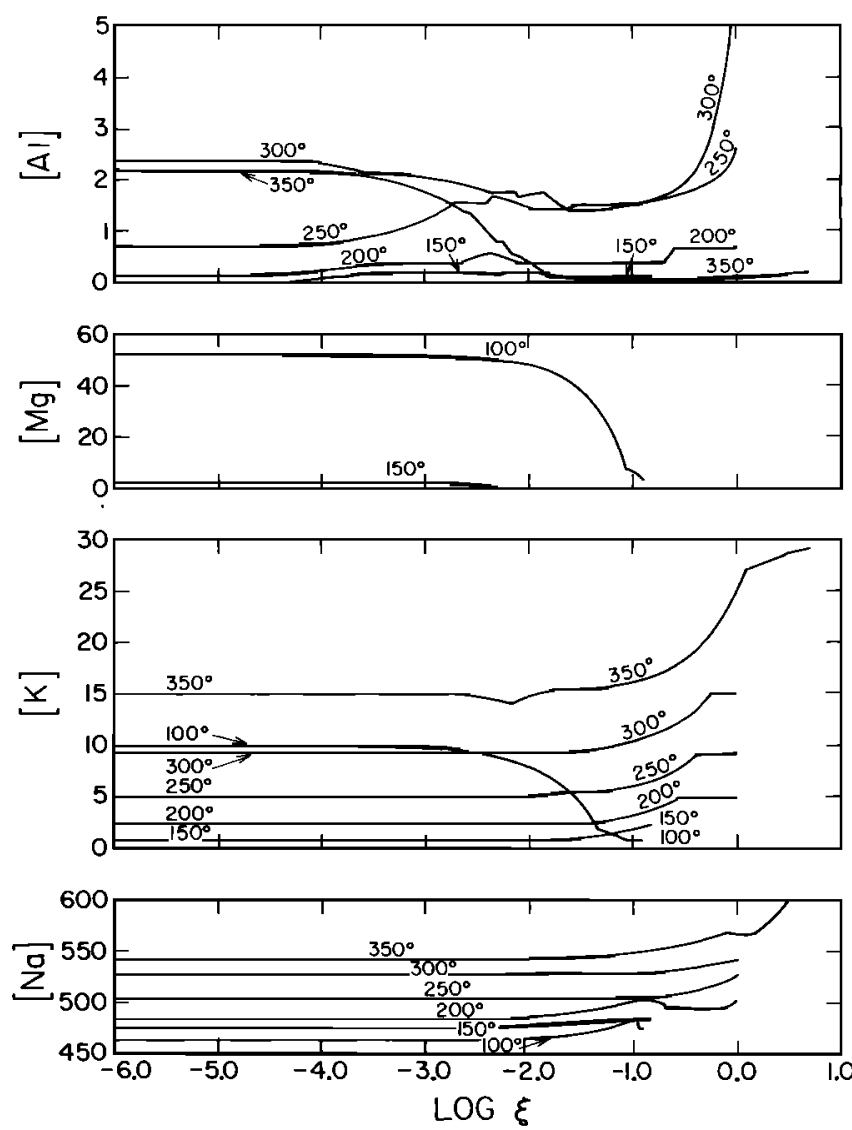

Fig. 16. $\mathrm{Na}, \mathrm{K}, \mathrm{Mg}$ and $\mathrm{Al}$ concentrations $(\mathrm{mmol} / \mathrm{kg}$ ) of the evolving solution in equilibrium with mineral assemblages shown in Figures 4 to 9 , plotted as a function of log reaction progress. Contours are temperature in ${ }^{\circ} \mathrm{C}$. 

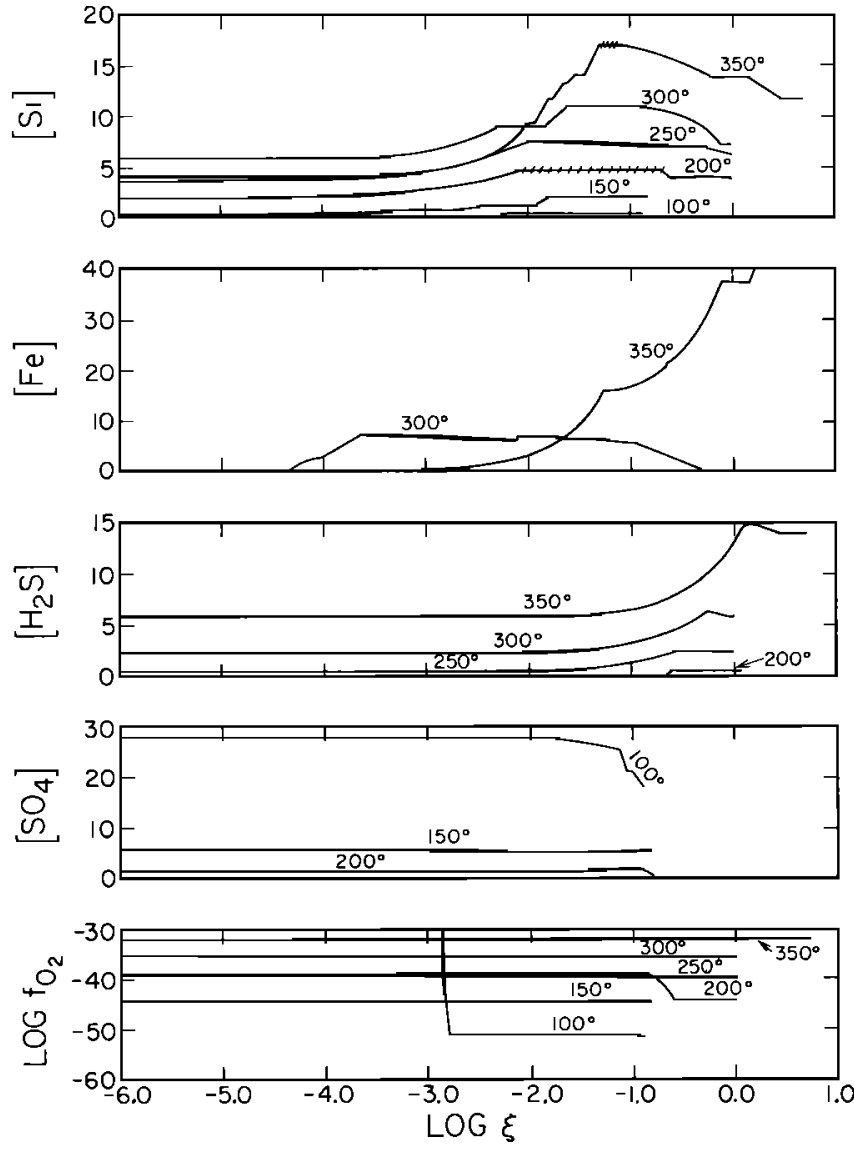

Fig. 17. Log oxygen fugactty and $\mathrm{SO}_{4}, \mathrm{H}_{2} \mathrm{~S}, \mathrm{Fe}$ and $\mathrm{Si}$ concentrations of the evolving solution in equilibrium with mineral assemblages shown in Figures 4 to 9 , plotted as a function of $\log$ reaction progress. Contours are temperature in ${ }^{\circ} \mathrm{C}$.

losses of $\mathrm{Mg}$ and small losses of $\mathrm{Ca}$. Humphris and Thompson [1978] present similar results, including evidence for takeup of $\mathrm{Mg}$ and $\mathrm{H}_{2} \mathrm{O}$ into altered basalts and loss of $\mathrm{Ca}$ and $\mathrm{Si}$, all of which are typical of the low-temperature assemblages predicted by our computer model. In general, the agreement in bulk chemistry between the predictions made in this study and the observations of midocean ridge samples is quite good.

\section{Isotopic Systematics in the Altered Rock}

Oxygen and hydrogen isotopic values are generated as a function of temperature and reaction progress for each predicted mineral product. $\delta^{18} \mathrm{O}$ and $\delta \mathrm{D}$ can be calculated from the modal abundances of the product minerals in the altered whole-rock, $R$ (assumed to include no residual fresh basalt), by the following relationship:

$$
\delta^{18} \mathrm{O}_{\mathrm{R}}=\frac{\sum_{p} n_{\mathrm{O}}{ }^{p} \delta^{18} \mathrm{O}_{p}}{\sum_{p} n_{\mathrm{O}}{ }^{p}}
$$

and a corresponding expression for $\delta \mathrm{D}$. The results of this calculation for $\delta^{18} \mathrm{O}$ and $\delta \mathrm{D}$ of the altered whole-rock are shown in Figures 11 and 12. The mineral assemblages corresponding to these curves can be determined by comparison of Figures 11 and 12 with Figures 4 to 9 at the appropriate temperature and value of reaction progress. The whole-rock isotope curves are quite sensitive to the identity of the minerals which they represent. For example, at $100^{\circ} \mathrm{C} \delta^{18} \mathrm{O}_{R}$ is high at low values of reaction progress, corresponding to the presence of dolomite as the major alteration phase (Figure 4). This is attributable to the large equilibrium value of $\Delta_{\text {dolomite- } \mathrm{H}_{2} \mathrm{O}}$ (Figure 1). When significant amounts of saponite and chlorite form, $\delta^{18} \mathrm{O}_{R}$ drops by several per mil reflecting the lower $\Delta_{\min -\mathrm{H}_{2} \mathrm{O}}$ values of chlorite and smectite. The minimum in the $100^{\circ} \mathrm{C} \delta^{18} \mathrm{O}$ curve at $\log \xi \sim-3.2$ corresponds to the point in Figure 4 where the abundance of chlorite reaches a maximum; this is caused by the fact that the equilibrium $\Delta_{\text {chlorite- } \mathrm{H}_{2} \mathrm{O}}$ value is lower than any of the other $\Delta$ values (Figure 1), except for hematite- $\mathrm{H}_{2} \mathrm{O}$ and magnetite- $\mathrm{H}_{2} \mathrm{O}$ (and these oxide minerals do not form abundant alteration products).

The value of $\delta^{18} \mathrm{O}_{R}$ generally decreases with increasing temperature, as is expected because of the accompanying decrease in $\Delta_{\min -\mathrm{H}_{2} \mathrm{O}}$. However, at low values of reaction progress between $250^{\circ}$ and $350^{\circ} \mathrm{C}, \delta^{18} \mathrm{O}_{R}$ shows the opposite trend. This is again attributable to the identity of the alteration products; tremolite- $\mathrm{H}_{2} \mathrm{O}$ at $250^{\circ} \mathrm{C}$ has a lower $\Delta$ than does epidote- $\mathrm{H}_{2} \mathrm{O}$ at $300^{\circ} \mathrm{C}$. The $\delta^{18} \mathrm{O}$ (and $\delta \mathrm{D}$ ) values calculated for higher values of reaction progress $(\log \xi>\sim-3)$ may be taken as most representative of altered basalts at the corresponding temperatures, because the alteration is more pervasive and thus better represents an average of true altered basalts than do assemblages consisting of only one product. $\delta^{18} \mathrm{O}_{R}$ curves at $250^{\circ}-350^{\circ} \mathrm{C}$ at $\log \xi>\sim-1$ show a moderately increasing trend with increasing reaction progress, and the highest value of $\delta^{18} \mathrm{O}_{R}$ at $350^{\circ} \mathrm{C}$ is higher than any value at $300^{\circ} \mathrm{C}$ and almost equivalent to the highest value at $250^{\circ} \mathrm{C}$. This trend of increasing $\delta^{18} \mathrm{O}_{R}$ with reaction progress along each isothermal temperature step is attributed to a corresponding increase in $\delta^{18} \mathrm{O}_{\mathrm{H}_{2} \mathrm{O}}$, because by material balance at $250^{\circ}-350^{\circ} \mathrm{C}$ both the $\mathrm{H}_{2} \mathrm{O}$ and the altered rock can increase in $\delta^{18} \mathrm{O}$ as a result of the continued contribution to the system of fresh rock that is 5.8 per mil higher in ${ }^{18} \mathrm{O}$ than the initial seawater.

The $\delta \mathrm{D}$ curves shown in Figure 12 are even less regular than the $\delta^{18} \mathrm{O}$ curves; again, the variations may be attributed

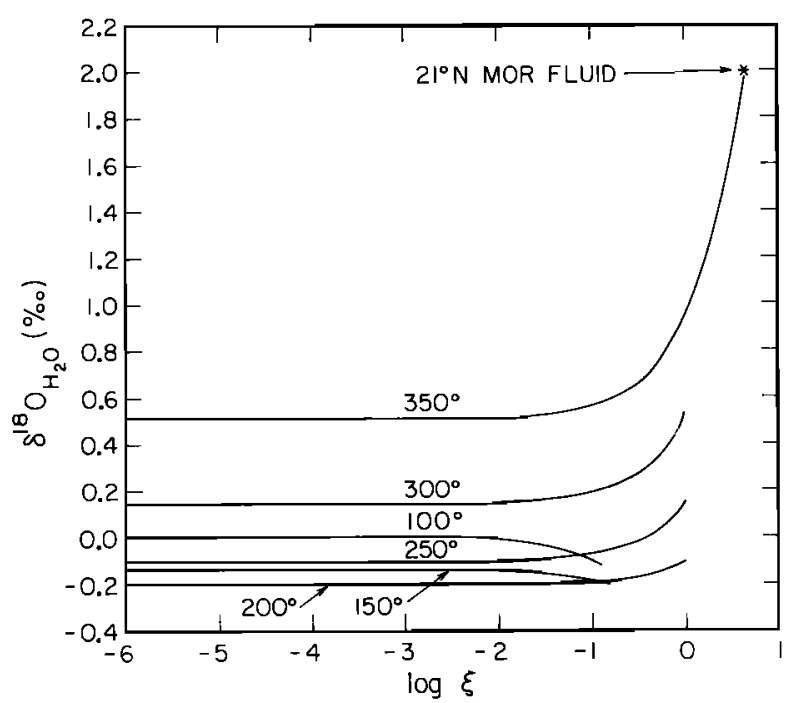

Fig. 18. $\delta^{18} \mathrm{O}$ of the evolving solution in equilibrium with mineral assemblages formed at the various temperature steps shown in Figures 4 to 9 , plotted as a function of log reaction progress; the coexisting mineral assemblages have the isotopic compositions given in Figure 11. Contours are temperature in ${ }^{\circ} \mathrm{C}$. The star corresponds to $\delta^{18} \mathrm{O}$ of the $21^{\circ} \mathrm{N}$ MOR fluid as determined by $\mathrm{H}$. Craig (personal communication, 1984). 


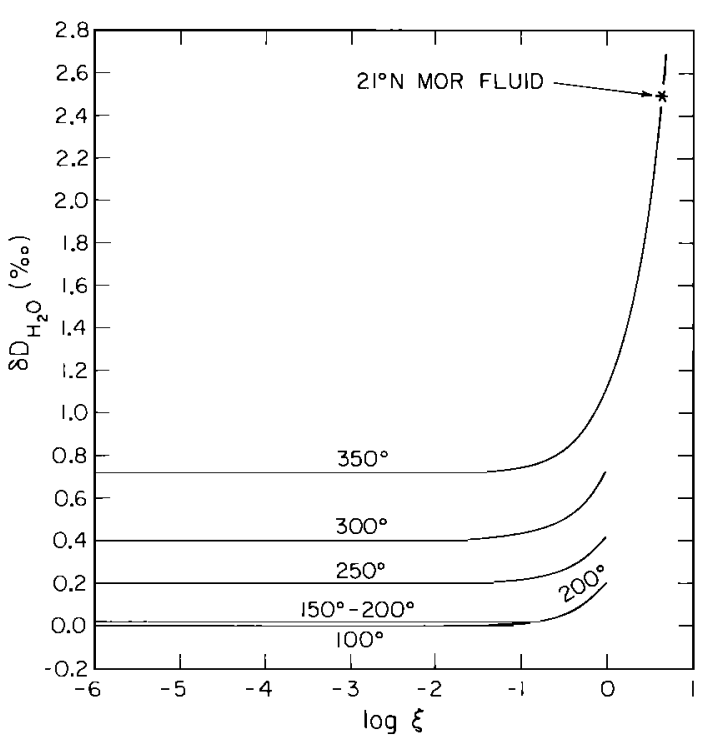

Fig. 19. $\delta \mathrm{D}$ of the evolving solution in equilibrium with mineral assemblages formed at the various temperature steps shown in Figures 4 to 9 , plotted as a function of log reaction progress; the coexisting mineral assemblages have the isotopic compositions given in Figure 12. Contours are temperature in ${ }^{\circ} \mathrm{C}$. The star corresponds to $\delta \mathrm{D}$ of the $21^{\circ} \mathrm{N}$ MOR fluid as determined by Craig et al. [1980].

primarily to the identity of the minerals making up the alteration assemblage. At high values of reaction progress there is a generally decreasing trend of $\delta \mathrm{D}$ with temperature from $150^{\circ}$ to $350^{\circ} \mathrm{C}$, corresponding roughly to the similar trend in fractionation factors shown in Figure 3.

Figure 13 shows a comparison of $\delta^{18} \mathrm{O}$ and $\delta \mathrm{D}$ values for altered basalts calculated from our computer model with analyses of altered basalts from the EPR and MAR [Stakes and O'Neil, 1982] and the Indian Ocean [Stakes et al., 1984]. This figure is after Figure 1 of Stakes and O'Neil [1982]. The high-temperature calculations agree reasonably well with observations on greenschist-facies basalts; however the $100^{\circ}$ and $150^{\circ} \mathrm{C}$ calculated fields are considerably richer in $\delta \mathrm{D}$ than the saponite-rich pillow breccias analyzed by Stakes and O'Neil.

There are two major reasons for the $\delta \mathrm{D}$ discrepancy. The $\delta \mathrm{D}$ of $\mathrm{OH}$-bearing minerals is quite sensitive to changes in $\mathrm{Fe} / \mathrm{Mg}$ and $\mathrm{Fe} / \mathrm{Al}$ (see above), and even small amounts of $\mathrm{Fe}$ substitution into the octahedral sites in the clays will significantly reduce the $\delta \mathrm{D}$ signature of the clay. The computer model correctly predicts the occurrence of saponites at low temperatures, but there is no provision for clay solid solution in the models, nor is there an Fe-saponite end member in the thermodynamic data base. As a result, the predicted saponites are $\mathrm{Mg}$ - and $\mathrm{Ca}$-rich and their calculated $\delta \mathrm{D}$ values are higher than those observed for natural oceanic saponites containing some iron substitution. Even though the low-temperature $\delta \mathrm{D}$ calculations are less than perfect, this causes negligible change in the overall results of the calculations for $\delta \mathrm{D}_{\mathrm{H}_{2} \mathrm{O}}$ (see below), because most of the modifications in $\delta^{18} \mathrm{O}_{\mathrm{H}_{2} \mathrm{O}}$ and $\delta \mathrm{D}_{\mathrm{H}_{2} \mathrm{O}}$ take place at higher temperatures at relatively low water-rock ratios.

In addition to isotopic analyses of midocean ridge altered basalts, ophiolites provide an added source of isotopic data for comparison with the calculations presented here. Oxygen and hydrogen isotopic studies of ophiolites by Javoy [1970], Magaritz and Taylor [1974, 1976], Spooner et al. [1974], Heaton and Sheppard [1977] and Gregory and Taylor [1981] have been summarized by Taylor [1983]. Ophiolite pillow lavas have typical $\delta^{18} \mathrm{O}$ values from +10 to +16 , closely corresponding to $\delta^{18} \mathrm{O}$ values calculated from our model at $100^{\circ}-150^{\circ} \mathrm{C}$. Sheeted diabases and high-level gabbros range from about +3 to +10 , corresponding to the model calculations at $>200^{\circ} \mathrm{C}$. Chlorites and amphiboles in the ophiolite complexes cover a $\delta \mathrm{D}$ range from about -65 to -35 per mil, corresponding very well with the $250^{\circ}-350^{\circ} \mathrm{C}$ range of $\delta \mathrm{D}$ values generated in our model.

An average basalt- $\mathrm{H}_{2} \mathrm{O}$ oxygen isotope fractionation curve can be approximated from our model. The range of $\Delta^{18} \mathrm{O}_{R-\mathrm{H}_{2} \mathrm{O}}$ values (excluding some from low values of reaction progress where alteration had not advanced significantly) are plotted on Figure 14 as a function of temperature. Equilibrium fractionation curves for $\mathrm{An}_{50}$ plagioclase, anhydrite, smectite, epidote, muscovite and chlorite from Figure 1 are included for reference. A dashed line is drawn approximately through the middle of the calculated $\Delta_{\text {alteredbasalt- } \mathrm{H}_{2} \mathrm{O}}$ values, and this represents the altered basalt $-\mathrm{H}_{2} \mathrm{O}{ }^{18} \mathrm{O} /{ }^{16} \mathrm{O}$ fractionation. Comparison of this curve with the curve for muscovite shows their similarity, particularly at low temperatures. The muscovite- $\mathrm{H}_{2} \mathrm{O}$ fractionation was suggested by Spooner et al. [1977] to be a plausible approximation of the basalt- $\mathrm{H}_{2} \mathrm{O}$ fractionation. Note that the dashed curve in Figure 14 lies closer to the smectite curve at low temperatures and to the chlorite curve at high temperatures, reflecting the relative contributions of smectite and chlorite to the alteration mineral assemblage at low and high temperatures, respectively. The range of calculated $\delta^{18} \mathrm{O}$ values at $150^{\circ}$ and $200^{\circ} \mathrm{C}$ are somewhat above the dashed curve. The high values are a result of the large amounts of anhydrite predicted to form at these temperatures and thus are not truly representative of altered basalts containing no anhydrite.

For comparison, the smectite- $\mathrm{H}_{2} \mathrm{O}$ fractionation curve derived by Cole [1980] from $\delta^{18} \mathrm{O}$ analyses of seawater-basalt
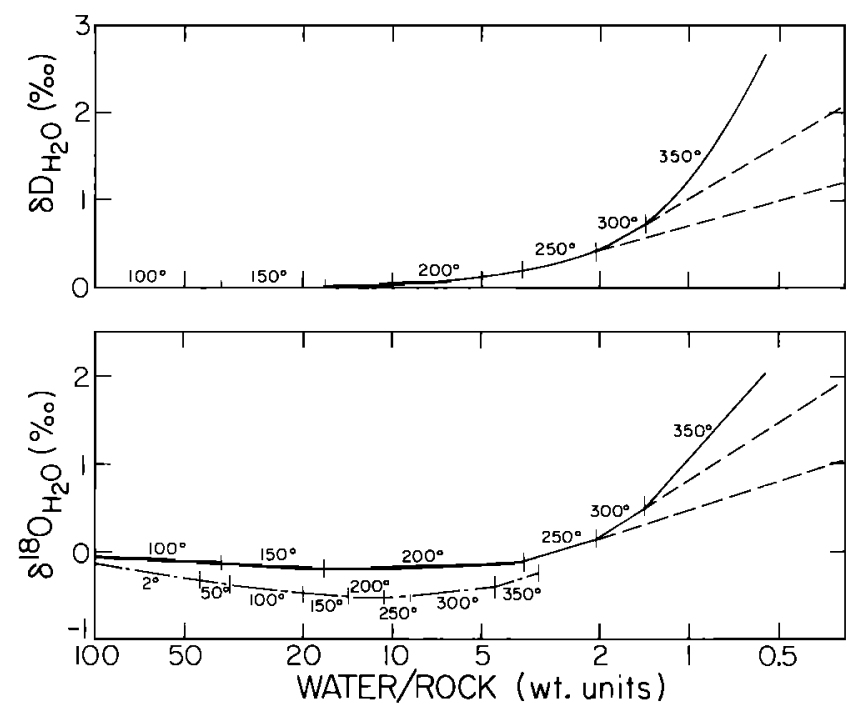

Fig. 20. As a function of water-rock ratio in weight units (solid curves), this figure shows the $\delta^{18} \mathrm{O}$ and $\delta \mathrm{D}$ of the evolving solution in equilibrium with the mineral assemblages shown in Figures 4 to 9; the latter have the isotopic compositions given in Figures 11 and 12. Dot-dash curve for $\delta^{18} \mathrm{O}_{\mathrm{H}_{2} \mathrm{O}}$ represents a second calculated temperature/water-rock path where more interaction is considered at lower temperatures (see text). The dashed curves represent approximate extrapolations of $\delta^{18} \mathrm{O}_{\mathrm{H}_{2} \mathrm{O}}$ and $\delta \mathrm{D}_{\mathrm{H}_{2} \mathrm{O}}$ if reaction is limited to maximum temperatures of $250^{\circ}$ or $300^{\circ} \mathrm{C}$. 
experiments is also shown in Figure 14. Cole's curve was used to represent the ${ }^{18} \mathrm{O} /{ }^{16} \mathrm{O}$ fractionation during basalt-seawater interaction by Cathles [1983] in his isotopic modeling of the hydrothermal systems that formed massive sulfide deposits in the Hokuroku Basin in Japan. Note that the curve of Cole [1980] is several per mil higher than the curve for basalt-water approximated from our model, and that its slope is less steep than nearly all of the experimentally determined fractionation curves for minerals. Cole [1980] gives no reason why his curve is so drastically out of step with all other experimental data, as well as with data and inferences from natural occurrences. It is well known that $\Delta^{18} \mathrm{O}_{\text {quartz- } \mathrm{H}_{2} \mathrm{O}}$ exhibits the largest fractionation observed in any silicate- $\mathrm{H}_{2} \mathrm{O}$ system [Taylor and Epstein, 1962; Matthews et al., 1983a; Friedman and O'Neil, 1977], and yet the Cole [1980] $\Delta^{18} \mathrm{O}_{\text {smectite- } \mathrm{H}_{2} \mathrm{O}}$ values are even bigger than any of the published $\Delta^{18} \mathrm{O}_{\text {quartz-H }} \mathrm{O}$ values. We thus feel justified in rejecting the Cole [1980] curve.

\section{Solution Chemistry}

Calculated dissolved concentrations of several elements, together with $\mathrm{SO}_{4}$ and $\mathrm{H}_{2} \mathrm{~S}$ concentration, $p \mathrm{H}$, and $\log$ fugacity of oxygen as a function of reaction progress and temperature are shown in Figures 15, 16, and 17. Many of the trends agree with those exhibited in laboratory experiments. A large proportion of these curves, for example potassium (Figure 16), show no change in concentration from the end of a given temperature step to the beginning of the next higher temperature step. However, the concentrations of certain species drop over the course of the heating interval, when supersaturations occur. Examples include the drop in $\mathrm{SO}_{4}$ concentration (Figure 17) from the $100^{\circ} \mathrm{C}$ temperature step to the start of the $150^{\circ} \mathrm{C}$ temperature step as a result of anhydrite precipitation, and the drop in $\mathrm{Al}$ concentration (Figure 16) from the $300^{\circ} \mathrm{C}$ step to the start of the $350^{\circ} \mathrm{C}$ step as a result of precipitation of clinozoisite and paragonite.

$\mathrm{Mg}$ concentration (Figure 16) decreases from 52.6 to 2.4 $\mathrm{mmol} / \mathrm{kg}$ at $100^{\circ} \mathrm{C}$ as a result of its uptake into $\mathrm{Mg}$-rich clay and chlorite alteration phases. This process is approximately charge-balanced by an increase in Ca concentration in solution from 10.2 to $48.3 \mathrm{mmol} / \mathrm{kg}$ (Figure 15) over the same range of reaction progress at $100^{\circ} \mathrm{C}$. Reaction at $150^{\circ} \mathrm{C}$ completes $\mathrm{Mg}$ removal, resulting in a final $\mathrm{Mg}$ concentration of $\sim 0.005 \mathrm{mmol} / \mathrm{kg}$. Charge balancing of $\mathrm{Mg}$ removal by $\mathrm{Ca}$ replacement in solution was also observed in laboratory experiments by Mottl and Holland [1978] and Seyfried and Bischoff [1981].

$\mathrm{Ca}$ concentration increases slightly with $\mathrm{Mg}$ removal at $150^{\circ} \mathrm{C}$, and subsequently decreases due to precipitation of anhydrite, a phenomenon also observed in several laboratory experiments summarized by Mottl [1983]. Ca concentration continues to drop with increasing temperature, predominantly as a result of its uptake into epidote and tremolite. The initial increase of $\mathrm{Ca}$ in solution, followed by its decrease, corresponds well to observations by Humphris and Thompson [1978]. They found that the chlorite-rich assemblages show significant depletions in Ca relative to unaltered basalt, while the epidote-rich assemblages (which presumably formed at higher temperatures and lower water-rock ratios) show little change.

Seawater sulfate is removed by anhydrite precipitation below $200^{\circ} \mathrm{C}$ (Figure 17). At $200^{\circ} \mathrm{C}$ the remaining sulfate is reduced to sulfide, which remains the dominant sulfur species in solution at higher temperatures. The reduction corresponds to a drop in oxygen fugacity of approximately $5 \mathrm{log}$ units, also shown in Figure 17. The increasing concentration of sulfide in solution from $200^{\circ}$ to $350^{\circ} \mathrm{C}$ is a result of contributions of sulfur from the fresh basalt, dampened by removal of sulfide into pyrite and pyrrhotite. Fugacity of oxygen is initially quite high because seawater is supersaturated with respect to oxygen; however, reaction with only a small amount of basalt overcomes this supersaturation and log oxygen fugacity drops markedly, from $\sim-0.8$ to $\sim-51.0$ at $100^{\circ} \mathrm{C}$.

$\mathrm{Na}$ and $\mathrm{K}$ concentrations increase in solution largely as a result of their removal from basalt; some $\mathrm{Na}$ is taken up in the development of albite as an alteration phase, and even less $K$ is consumed by the precipitation of minor amounts of K-mica. Dissolved Si (Figure 17) in the hydrothermal fluid increases at every temperature step. The fluid attains equilibrium with quartz at $200^{\circ}$ and $350^{\circ} \mathrm{C}$ during a portion of the reaction progress path (hatchured on the diagram), and it is close to quartz saturation at intermediate temperatures as well.

The $\mathrm{Fe}$ concentration (Figure 17) increases dramatically over the course of reaction, from an initial value of $\sim 1.5$ $\times 10^{-6} \mathrm{mmol} / \mathrm{kg}$ in unaltered seawater to as high as 60 $\mathrm{mmol} / \mathrm{kg}$ at the conclusion of the $350^{\circ} \mathrm{C}$ calculation. This requires substantial leaching of $\mathrm{Fe}$ from basalt, although some $\mathrm{Fe}$ is consumed in the production of products such as nontronite at low temperature and Fe-rich chlorite (daphnite) at high temperature. Al concentration (Figure 16) varies considerably over the course of reaction, showing an increasing trend at temperatures up to $300^{\circ} \mathrm{C}$, and then dropping dramatically at $350^{\circ} \mathrm{C}$.

The influence of a particular process (dissolution, precipitation, hydrolysis, electrical balancing of $\mathrm{Mg}$ uptake) on $p \mathrm{H}$ is difficult to ascertain, because these processes are occurring simultaneously with possibly opposite effects. Calculated variations in $p \mathrm{H}$ as a function of temperature and reaction progress are shown in Figure 15 . At $100^{\circ} \mathrm{C}$, the initial $p \mathrm{H}$ of $\sim 6.0$ corresponds to that calculated from a distribution-ofspecies in the solution at $100^{\circ} \mathrm{C}$, disallowing any precipitation from supersaturations at that or lower temperatures. Predictions based on laboratory experiments summarized by $\mathrm{Mottl}$ [1983] suggest a drop in $p \mathrm{H}$ during the stage at which $\mathrm{Mg}$ is being taken up by a $\mathrm{Mg}(\mathrm{OH})_{2}$ component of the alteration assemblage, followed by a rebound to near neutrality by subsequent consumption of $\mathrm{H}^{+}$in silicate hydrolysis reactions. The calculations presented here show $p \mathrm{H}$ decreasing at $100^{\circ} \mathrm{C}$ over the range of reaction progress where $\mathrm{Mg}$ concentration remains high $(\log \xi \leq-2.2)$; however the decrease in $p \mathrm{H}$ is slight compared to that observed in laboratory experiments [Mottl and Seyfried, 1980]. Nevertheless, the outcome of the calculations does agree with laboratory experimental results in that both show near-neutral $p \mathrm{H}$ solutions at the conclusion of the experiments. Except at $300^{\circ} \mathrm{C}$, the calculated curves at each temperature step show an initial decrease in $p \mathrm{H}$ at low values of reaction progress followed by a sharp increase at high values of reaction progress. The lowest $p \mathrm{H}$ reached is $\sim 5.25$ at $350^{\circ} \mathrm{C}$, corresponding to the value of reaction progress where the fluid is also saturated with respect to quartz. In all of the above discussion, it should be remembered that the $p \mathrm{H}$ of a neutral solution changes from 7.0 at $25^{\circ} \mathrm{C}$ to 6.0 at $100^{\circ} \mathrm{C}$ and 5.5 at $350^{\circ} \mathrm{C}$.

Table 1 shows the predicted values of element or species concentration in solution at the conclusion of each isothermal calculation, for comparison with the starting solution and the range of concentrations observed in analyzed samples of hydrothermal fluids from $21^{\circ} \mathrm{N}$ on the EPR [Von Damm et al., 1985]. Several of the predicted concentrations in the modeled 
$350^{\circ} \mathrm{C}$ hydrothermal endmember agree well with actual samples of the $350^{\circ} \mathrm{C}$ hydrothermal fluid. $\mathrm{Mg}$ and $\mathrm{SO}_{4}$ concentrations drop to essentially zero, in agreement with observations. Silica increases to a value in accord with observation during a portion of the $350^{\circ} \mathrm{C}$ calculation (Figure 17), although it is somewhat lower at the end-point of the $350^{\circ} \mathrm{C}$ calculation. The EPR hydrothermal fluid is apparently saturated with respect to quartz [Von Damm et al., 1985].

Prediction of $\mathrm{Cl}$ concentration is in line with observation; dissolved $\mathrm{Cl}$ increases throughout the calculations only as a result of the concentrating effect of $\mathrm{H}_{2} \mathrm{O}$ loss from solution and uptake by the altered portions of the rock. In reality, some $\mathrm{Cl}$ is also consumed by uptake into amphiboles, a process which has not been considered in these calculations and which may account for the lower end of the $\mathrm{Cl}$ range observed in the EPR fluids. Predicted $\mathrm{Na}$ concentration is slightly higher than that actually observed in the EPR fluids. Calculated $\mathrm{K}$ concentration initially decreases at low temperature and subsequently increases to a value which agrees well with EPR observations. Calculated $\mathrm{H}_{2} \mathrm{~S}$ concentration is somewhat higher than observed, and can be related to the amount of sulfur entering the solution from fresh basalt and whether or not saturation of the solution with respect to sulfide phases is reached. When no sulfur is added from the basalt, calculated $\mathrm{H}_{2} \mathrm{~S}$ concentrations are considerably lower than observed. A basalt with a lower sulfur content than the one used in these calculations should yield a closer agreement between predicted and observed $\mathrm{H}_{2} \mathrm{~S}$ concentrations.

Less agreement is seen between calculated and observed concentrations of $\mathrm{Fe}, \mathrm{Al}$ and $\mathrm{Ca}$, and $p \mathrm{H}$ (see below). $\mathrm{Al}$ though the calculated $\mathrm{Fe}$ concentrations at lower temperatures are reasonable, at the end of the $350^{\circ} \mathrm{C}$ step the predicted values are about 30 times those observed. $\mathrm{Fe}$ is also increasing very rapidly with $\log \xi$ near the end of the $350^{\circ} \mathrm{C}$ step (Figure 17). This is probably related to the inadequacies of the thermodynamic data base in not allowing for the formation of Fe-rich solid solutions in the computer model. It might also be accounted for by some precipitation of Fe-rich minerals in the hydrothermal conduit during ascent of the fluid, just prior to reaching the sea floor. We know that abundant Fe sulfides are indeed precipitated there. In any case, this is not such bad agreement considering that $\mathrm{Fe}$ concentrations must increase approximately 6 orders of magnitude from the initial cold seawater to the observed hydrothermal endmember, and our calculations show an $\mathrm{Fe}$ increase of about 7 orders of magnitude.

Al concentration in solution initially increases, then decreases, but reaches a final value which is high compared to the observed concentrations. Much of the excess $\mathrm{Al}$ in solution could be taken up by Al substitution into amphiboles. As little as 1 weight percent substitution of $\mathrm{Al}$ into the amount of tremolite predicted at $350^{\circ} \mathrm{C}$ would require more $\mathrm{Al}$ than is present in the solution. Note that at $250^{\circ}$ and $350^{\circ} \mathrm{C}$, the $\mathrm{Al}$ concentrations are enormous and are increasing very rapidly with $\log \xi$, extensive reaction at $350^{\circ} \mathrm{C}$ is required to drop the Al values anywhere close to the observed EPR value (Figure 16).

Ca concentration also presents a problem, initially increasing, then decreasing in accord with laboratory experiments as well as whole-rock bulk chemical alteration trends. However, the final $\mathrm{Ca}$ concentration predicted is an order of magnitude below that observed in the EPR fluids. $\mathrm{Na}$ substitution for $\mathrm{Ca}$ in amphibole would have the effect of simultaneously reducing the quantity of $\mathrm{Na}$ predicted and increasing the amount of $\mathrm{Ca}$ in solution. Lack of consideration of solid solution between clinozoisite and epidote, of $\mathrm{Fe}$ and $\mathrm{Al}$ substitution in amphiboles, and of chlorite and smectite solid solutions may contribute substantially to the minor problems in the predicted $\mathrm{Fe}, \mathrm{Ca}$ and $\mathrm{Al}$ concentrations of the aqueous fluids.

The final oxygen fugacity calculated is approximately $1 \mathrm{log}$ unit below the value estimated for the EPR fluids, based on assumed equilibrium between dissolved $\mathrm{CO}_{2}$ and $\mathrm{CH}_{4}$ concentrations reported by Welhan and Craig [1983]. Dissolved $\mathrm{H}_{2}$ concentrations [Welhan and Craig, 1983] yield a similar $\log$ oxygen fugacity and because of the inherent uncertainties in the measurements and the assumptions of equilibrium, we consider the calculations to represent good agreement.

\section{Isotopic Compositions of the Fluids}

Values of $\delta^{18} \mathrm{O}$ and $\delta \mathrm{D}$ of the evolving hydrothermal solution as a function of reaction progress and temperature are shown in Figures 18 and 19. At low temperature the alteration products are generally rich in ${ }^{18} \mathrm{O}$ (see above) and $\delta^{18} \mathrm{O}$ of the solution decreases, dropping most sharply at the lowest temperature considered, in this case, $100^{\circ} \mathrm{C}$ (Figure 18). $\delta^{18} \mathrm{O}_{\mathrm{H}_{2} \mathrm{O}}$ continues to decline at $150^{\circ} \mathrm{C}$, reaching a low value of about -0.2 per mil. Not until midway through the reaction at $250^{\circ} \mathrm{C}$ does $\delta^{18} \mathrm{O}_{\mathrm{H}_{2} \mathrm{O}}$ increase back to its initial value of 0 per mil. Further reaction with basalt at $300^{\circ}$ and $350^{\circ} \mathrm{C}$ results in a more rapid increase in $\delta^{18} \mathrm{O}_{\mathrm{H}_{2} \mathrm{O}}$ until the $350^{\circ} \mathrm{C}$ reaction is terminated at the point where $\delta^{18} \mathrm{O}_{\mathrm{H}_{2} \mathrm{O}} \sim+2.0$ per mil, which is the value reported by $\mathrm{H}$. Craig (personal communication, 1984) from measurements on the EPR fluids.

In contrast to $\delta^{18} \mathrm{O}$, the $\delta \mathrm{D}$ of the solution increases at all temperatures, because there is negligible, if any, input of $\mathbf{H}$ from the fresh basalt, and the $\Delta D_{\text {min- } H_{2} \mathrm{O}}$ fractionations for hydrogen are nearly all less than 0 except at very high temperatures outside the range of this study. The least rapid increase in $\delta \mathrm{D}_{\mathrm{H}_{2} \mathrm{O}}$ (Figure 19) occurs at $250^{\circ} \mathrm{C}$ because the $\Delta \mathrm{D}_{\min -\mathrm{H}_{2} \mathrm{O}}$ fractionations for some of the minerals forming the alteration assemblage are close to 0 (Figure 3 ). $\delta \mathrm{D}_{\mathrm{H}_{2} \mathrm{O}}$ increases fairly rapidly at $350^{\circ} \mathrm{C}$ to a value of $\sim+2.6$ per mil at the termination of the $350^{\circ} \mathrm{C}$ reaction. This is in excellent agreement with the value of +2.5 measured by Craig et al. [1980] for EPR hydrothermal fluids.

Although $\delta^{18} \mathrm{O}_{\mathrm{H}_{2} \mathrm{O}}$ is controlled primarily by temperature of interaction, $\delta \mathrm{D}_{\mathrm{H}_{2} \mathrm{O}}$ is chiefly affected by the identity of the alteration products. For example, over $50 \%$ of the hydrogen is taken up by clays during low-temperature alteration and by Fe-rich chlorite during high-temperature alteration. This accounts for the sharp increase in $\delta \mathrm{D}_{\mathrm{H}_{2} \mathrm{O}}$ at the higher temperatures because of the large negative $\Delta \mathrm{D}$ fractionations employed for $\mathrm{Fe}$-rich chlorites.

Variations in $\delta^{18} \mathrm{O}$ and $\delta \mathrm{D}$ of solution as a function of water-rock ratio over the temperature range employed are shown in Figure 20. High water-rock ratios correspond to low temperature, where only a small amount of rock has interacted with a given packet of fluid. At high temperatures this same packet of fluid has traveled through and interacted with considerably more rock, corresponding to low water-rock ratios. The lower diagram in Figure 20 shows the decrease and subsequent increase in $\delta^{18} \mathrm{O}$ of the solution as a function of temperature to a final value of +2 per mil at water/ rock $\sim 0.56$. Below this curve a second curve is shown for a similar series of seawater-basalt interactions from $2^{\circ} \mathrm{C}$ up to $350^{\circ} \mathrm{C}$. Note that the final $\delta^{18} \mathrm{O}$ of this latter solution at water/rock $\sim 3.2$ is still $<0$ per mil. This gives some indication of the proportion of low- and high-temperature interaction that 

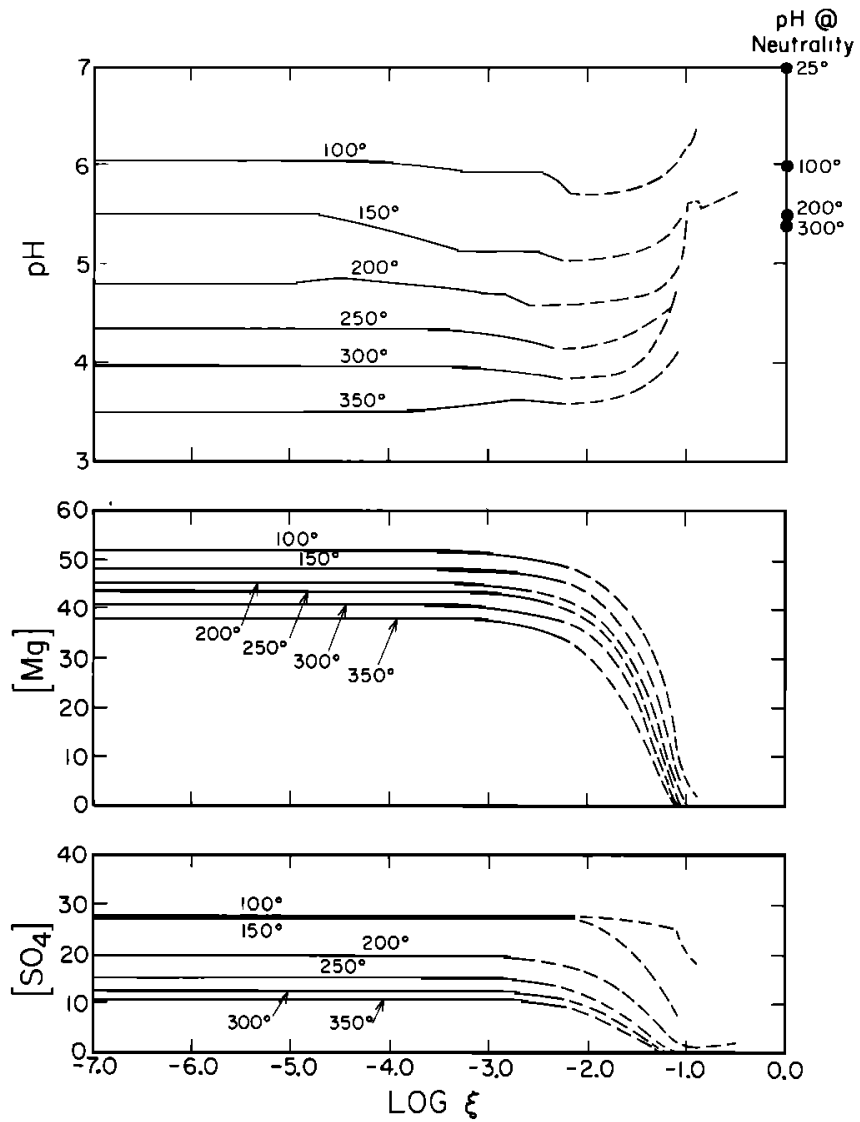

Fig. 21. $\mathrm{Mg}$ and $\mathrm{SO}_{4}$ concentration $(\mathrm{mmol} / \mathrm{kg}$ ) and $\mathrm{pH}$ of an evolving solution corresponding to a high water-rock ratio, low-pH path, plotted as a function of log reaction progress. Contours are temperature in ${ }^{\circ} \mathrm{C}$. Reaction at each temperature except $100^{\circ} \mathrm{C}$ begins with a solution composition corresponding to that at the termination of the solid portion of the curve at the next lower temperature. The dashed portion of the curves exhibits the changes in concentrations, had we considered continued reaction at each temperature.

a given packet of fluid must undergo to exhibit a +2 per mil $\delta^{18} \mathrm{O}$ signature, as measured for exiting hydrothermal fluids at $21^{\circ} \mathrm{N}$ on the EPR.

\section{Calculations at High Water-Rock Ratios}

Observations summarized by Mottl [1983] that the $p \mathrm{H}$ of hydrothermal solutions produced in laboratory experiments initially becomes quite acidic and remains so while $\mathbf{M g}$ concentration is high and water-rock ratio is greater than 50 are further supported here by a set of computer calculations at high water-rock ratio. This series of calculated reaction paths from $100^{\circ}-350^{\circ} \mathrm{C}$ is the outgrowth of an attempt to find a possible path resulting in an acidic fluid similar to those actually sampled at $21^{\circ} \mathrm{N}$.

The solution composition generated by this series of calculations at a water/rock of about 150 does indeed exhibit an acidic $p \mathrm{H}$ of around 3.5 at $350^{\circ} \mathrm{C}$. However, low $p \mathrm{H}$ and saturation of the fluid with respect to quartz are the only similarities between the calculated fluid composition and the $21^{\circ} \mathrm{N}$ analyzed fluid compositions. $\mathrm{Mg}$ and $\mathrm{SO}_{4}$ concentrations remain high, and $\delta \mathrm{D}$ and $\delta^{18} \mathrm{O}$ of the fluid remain close to 0 . Although this series of calculations in no way represents the hydrothermal endmember that is currently exiting from vents on the EPR, it may correspond to the low-temperature, high water-rock ratio fluids at shallow levels in the pillow basalts or in off-axis circulation systems.

Dissolved $\mathrm{Mg}$ and $\mathrm{SO}_{4}$ and $p \mathrm{H}$ are shown in Figure 21 as a function of reaction progress and temperature from $100^{\circ}-$ $350^{\circ} \mathrm{C}$. The results of the calculations at $100^{\circ} \mathrm{C}$ are identical to those shown in Figures 4 and 15, 16, and 17. However, the solution composition used to initiate the $150^{\circ} \mathrm{C}$ reaction in Figure 21 is taken from $\log \xi \sim-2.2$ at $100^{\circ} \mathrm{C}$ rather than $\log \xi \sim-0.9$ as in the former set of calculations. The termination of each isothermal calculation shown in Figure 21 is represented by the end of the solid curve. The dotted portion of the curve at higher values of reaction progress shows the results if the calculation had been carried further. At each temperature, reaction is terminated at the point where the lowest value of $p \mathrm{H}$ is reached. Therefore, the $p \mathrm{H}$ of $\sim 3.5$ for the $350^{\circ} \mathrm{C}$ solution is as low a $p \mathrm{H}$ as could be calculated with this procedure. However, note that the low $p \mathrm{H}$ at each temperature corresponds to high $\mathrm{Mg}$ and $\mathrm{SO}_{4}$ concentrations in the solution. When $\mathrm{Mg}$ begins to drop (dotted portion of curves in Figure 21), $\mathrm{SO}_{4}$ also drops and $\mathrm{pH}$ rises dramatically. This is in accord with observations by Seyfried and Bischoff [1977], summarized by Mottl [1983], who showed in laboratory experiments that $\mathrm{pH}$ rises from acidic levels to near-neutrality once $\mathrm{Mg}$ concentration drops.

Alteration products precipitated along this reaction path are summarized as a function of temperature in Figure 22. Predominant products are $\mathrm{Mg}$-saponite, chlorite, and muscovite plus small amounts of hematite and pyrite at $100^{\circ}$ and $150^{\circ} \mathrm{C}$, and chlorite, talc, anhydrite, quartz and hematite above $200^{\circ} \mathrm{C}$. These results correspond well to the chloritequartz-rich rocks described by Mottl [1983] as typical alteration products at high $(>50)$ water-rock ratios.

\section{SUMMARY AND CONCLUSIONS}

We have attempted to model the chemical, mineralogical, and isotopic effects of hydrothermal circulation of seawater at a midocean ridge, where seawater presumably encounters fresh basalt, diabase, and gabbro at decreasing water-rock ratios with depth and increasing temperature up to a maximum temperature of approximately $350^{\circ} \mathrm{C}$. Our results are summarized in schematic fashion in Figure 23, which shows a hypothetical path taken by a packet of fluid that will eventually exit at a MOR vent. Also shown are schematic flow lines for lower-temperature, off-axis fluids. The model is realistic because it provides for sharply increasing temperatures and decreasing water-rock ratios as the fluid approaches the top of the magma chamber. The effective water-rock ratio, defined by the amount of rock that chemically interacts with a given amount of initial fluid, decreases downward because: (1) much fluid that circulates at shallow depths in the low-temperature
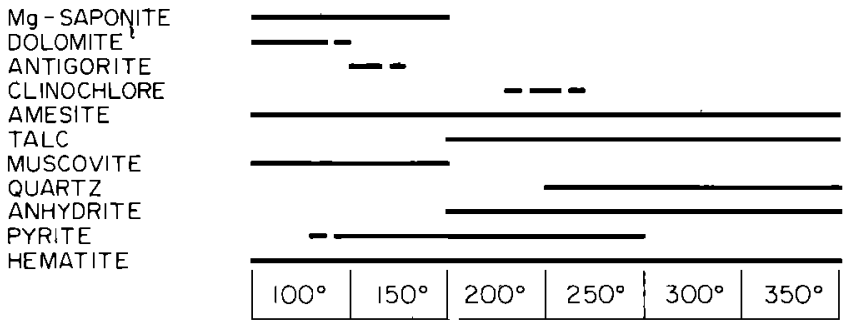

Fig. 22. Summary of predicted alteration phases as a function of temperature, corresponding to a calculated high water-rock ratio, low-pH path, part of which is shown in Figure 21. 


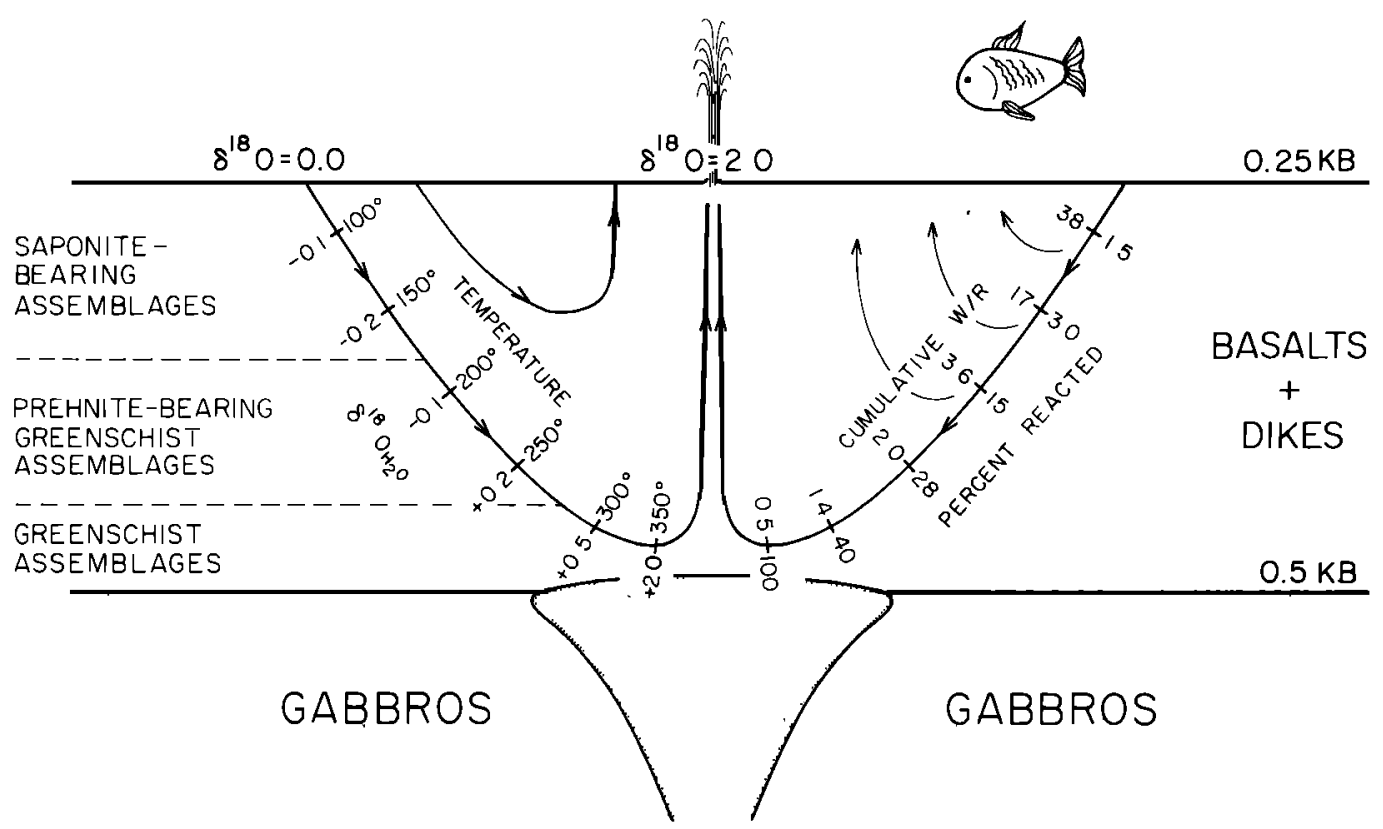

Fig. 23. Schematic illustration of the model described in this paper, showing a hypothetical path taken by the fluid from its initial penetration of seafloor basalts at low temperature, its circulation downward to the magma-chamber contact, and finally to its eventual exit at $350^{\circ} \mathrm{C}$ from MOR vents. Cumulative water-rock ratio, percent reaction progress, and $\delta^{18} \mathrm{O}_{\mathrm{H}_{2} \mathrm{O}}$ are shown along the two symmetrical path-lines at each $50^{\circ} \mathrm{C}$ temperature step at which the calculations were carried out. The temperatures increase and the effective water-rock ratios decrease very rapidly with depth. The calculations lead to a sharply increasing grade of hydrothermal metamorphism downward and they provide a good match with the assemblages actually observed in nature. In the near-surface environment, saponite-bearing assemblages form at high water-rock ratios as a result of low-temperature interaction of the fluids with submarine basalts. With increasing depth, these assemblages are replaced by prehnite-bearing transitional greenschist assemblages, and eventually by true greenschist assemblages formed at $300^{\circ}-350^{\circ} \mathrm{C}$. Pressure ranges from approximately 250 bars at the seafloor to approximately 500 bars at the top of the magma chamber [Von Damm et al., 1985]. All of the model calculations were performed at a constant pressure of 500 bars, but this is a reasonable assumption because variations over this limited pressure range have little or no effect on the calculations. It is also assumed that no significant alteration of the fluid occurs during its trip from depth to the seabed interface. Details concerning the calculated mineral assemblages and calculated chemical and isotopic compositions of the fluids at each temperature step are shown in Figures 4 to 20.

regions does not reach the high-temperature regions at depth, and (2) reaction rates are more rapid at high temperature, implying that more rock will interact with a given packet of water per unit time in the high-temperature regions of the hydrothermal system. Note that the effective water-rock ratio is a material-balance parameter that is meaningful only for a system of sufficient size (e.g., a significant portion of the entire MOR hydrothermal circulation system). This parameter is not related in any simple way to the actual amount of $\mathrm{H}_{2} \mathrm{O}$ that may interact with a cubic meter of rock; for example, in the active upflow region beneath a MOR hydrothermal vent, the integrated mass flux of $\mathrm{H}_{2} \mathrm{O}$ can easily be as high as $6 \times 10^{6}$ $\mathrm{kg} / \mathrm{m}^{2}$, which in weight units translates into an integrated water-rock ratio of 2000 for the cubic meter of basalt [Norton and Taylor, 1979; Cathles, 1983].

Although appreciable water clearly must penetrate into regions with temperatures above $350^{\circ} \mathrm{C}$, we are assuming that that component of the fluid does not contribute significantly to the upflow zone at the ridge crest, at least in the active venting situation presently observed on the East Pacific Rise. Water-rock ratios of about 0.5 are necessary to obtain the ${ }^{18} \mathrm{O}$ and D enrichments observed in the EPR hot-spring fluids (Figure 23). Our calculations indicate that the major proportion of the water/rock interaction had to take place at at least $300^{\circ}-350^{\circ} \mathrm{C}$ in order to produce the appropriate isotopic signatures in the fluids.

Calculated alteration assemblages in this work are in good agreement with observations on dredged samples from the oceans and in ophiolite complexes; these include saponites at low temperatures, Mg-rich and chloritic assemblages at high water-rock ratios, and epidote-chlorite-actinolite (tremolite)albite assemblages at high temperatures and low water-rock ratios. The calculated concentrations of the major elements in the evolved fluid also agree substantially with analyses made on actual samples of the $350^{\circ} \mathrm{C}$ hydrothermal endmember.

There are two important discrepancies between the calculations (or the laboratory experiments) and the sampled hydrothermal solutions: $p \mathrm{H}$ and saturation state of the solution with respect to certain minerals.

The lowest $p \mathrm{H}$ reached in the main set of reaction-path calculations is 5.25 , and most laboratory experiments conducted to date also exhibit similar, near-neutral $p H$ values except (1) in the initial stages of the experiments where $\mathrm{Mg}$ concentration is still high [Mottl, 1983], or (2) at $400^{\circ}$ to $500^{\circ} \mathrm{C}$ [Mottl et al., 1979]. The sampled $21^{\circ} \mathrm{N}-\mathrm{EPR}$ solutions have a $p \mathrm{H}$ in the range 3.3 to $3.8\left(25^{\circ} \mathrm{C}\right.$ measurements $)$ and are saturated only with respect to quartz [Von Damm et al., 1985]. Solutions sampled from $13^{\circ} \mathrm{N}$ on the EPR also have low $p \mathrm{H}$ values: approximately 3.8 to 3.9 for the samples with the smallest component of seawater mixing [Michard et al., 1984].

The $p \mathrm{H}$ and mineral saturation problems are related. Increasing the $p \mathrm{H}$ from 3.5 to 5.5 will result in many silicates being closer to saturation, even with no other change to the solution but an adjusted $\mathrm{Na}$ value to maintain charge balance. 
For example, if the $21^{\circ} \mathrm{N}$ EPR fluid composition given in Table 1 is considered to have a $p \mathrm{H}$ of 5 , calculated affinities of the minerals show that the resulting solution would be close to saturation with respect to albite, epidote, prehnite and anorthite, among others. Slightly higher Al contents would result in saturation of the fluid with respect to many of these phases, and this problem is most likely attributable to poor thermodynamic data on aqueous Al-complexes, or to a lack of consideration of solid solutions. Note that the state of saturation of the fluid with respect to quartz is not substantially affected by changes in $\mathrm{pH}$ alone.

A contrast to midocean ridge solutions is found in geothermal solutions from Iceland, which also formed from seawater flowing through basalt. Solutions from Svartsengi [Ragnarsdottir et al., 1984] more closely resemble the results of calculations presented here in that they exhibit high $p \mathrm{H}$ values $(\sim 5.4)$ and are saturated with respect to several minerals observed in drill cuttings from the hydrothermally altered zone in the tholeiitic basalt, including quartz, calcite, albite, chlorite and epidote. Our calculations predict greenschist-facies alteration of basalt, including formation of chlorite, epidote, actinolite, and quartz at $350^{\circ} \mathrm{C}$. The solution is, therefore, obviously saturated with respect to the alteration products that have precipitated from it. It appears on the basis of laboratory experiments and analyses of geothermal water, such as those at Svartsengi, that this process occurs at neutral $p \mathrm{H}$, between 5 and 6 , much the same as the $p \mathrm{H}$ calculated here.

Several possibilities remain which could account for this discrepancy in $\mathrm{pH}$. These include pressure effects occasioned by the fluid's ascent up the conduit, inaccuracies in the measurements at $21^{\circ} \mathrm{N}$ (and at $13^{\circ} \mathrm{N}$ ), possible selective precipitation of some minerals from the fluid or degassing of the fluid before the measurements are made, inaccuracies or omissions in the thermodynamic data base used to calculate the in situ $p \mathrm{H}$ values from the $25^{\circ} \mathrm{C}$ values, or the possibility that we have overlooked a major, $p \mathrm{H}$-affecting process which occurs before the fluids vent. Also, there may have been some addition of high-temperature magmatic $\mathrm{H}_{2} \mathrm{O}$ at depth, or possibly water/rock interaction occurred at higher temperatures than considered here $\left(400^{\circ}-450^{\circ} \mathrm{C}\right)$, and then during ascent there was more extensive cooling than we have envisioned (mixing with cooler fluids?). We are left with a puzzle that will require further work to sort out.

The results of the calculations presented here seem to validate the selected hydrogen isotope fractionation curves used in this work, at least over the temperature range for which they have been employed (Figure 3). Calculations of $\delta D_{\mathrm{H}_{2} \mathrm{O}}$ for the same temperature/water-rock interaction paths shown in Figures 4 to 9 , but utilizing different $\mathrm{D} / \mathrm{H}$ fractionation curves, give values that are markedly different from the observed deuterium enrichments of +2.5 per mil in midocean ridge hot springs. For example, assuming a constant $\mathrm{D} / \mathrm{H}$ fractionation curve of $\Delta_{\min -\mathrm{H}_{2} \mathrm{O}}=-20$ for all minerals results in a final $\delta \mathrm{D}_{\mathrm{H}_{2} \mathrm{O}}=+1.2$ per mil, a value too low by half. If $\Delta_{\mathrm{m} 1 \mathrm{n}-\mathrm{H}_{2} \mathrm{O}}=$ -60 , the calculated $\delta \mathrm{D}_{\mathrm{H}_{2} \mathrm{O}}=+3.5$, which is too high. Clearly, the average value of $\Delta_{\text {min- } \mathrm{H}_{2} \mathrm{O}}$ over the reaction path considered in this work must be about -40 , which is in fact very close to the average measured difference between seawater and hydrothermal OH-bearing minerals obtained from marine dredge hauls and ophiolite complexes.

At high water-rock ratios, $\delta^{18} \mathrm{O}_{\mathrm{H}_{2} \mathrm{O}}$ and $\delta \mathrm{D}_{\mathrm{H}_{2} \mathrm{O}}$ are affected primarily by temperature of interaction (and composition of the mineral phases in the case of $\delta \mathrm{D}$ ). However, when the water-rock ratio is less than $10, \delta^{18} \mathrm{O}_{\mathrm{H}_{2} \mathrm{O}}$ and $\delta \mathrm{D}_{\mathrm{H}_{2} \mathrm{O}}$ also become sensitive to the value of the water-rock ratio. This is best illustrated by the curves shown in Figure 20, which represent the dependency of $\delta^{18} \mathrm{O}_{\mathrm{H}_{2} \mathrm{O}}$ and $\delta \mathrm{D}_{\mathrm{H}_{2} \mathrm{O}}$ on temperature and water-rock ratio for the particular "path of interaction" utilized in the present study, and described in detail above. The fact that calculated $\delta^{18} \mathrm{O}_{\mathrm{H}_{2} \mathrm{O}}$ and $\delta \mathrm{D}_{\mathrm{H}_{2} \mathrm{O}}$ simultaneously attain values substantially in agreement with those reported for midocean ridge hot springs at a cumulative water-rock ratio of 0.56 argues strongly that the particular combination of amount of interaction at the chosen temperatures is an adequate description of how these hydrothermal fluids could have evolved. The proportion of high-temperature to lowtemperature interaction must be large in order to produce the positive $\delta^{18} \mathrm{O}$ anomalies actually observed in the hot-spring fluids. Substantial amounts of interaction at low temperatures will result in negative $\delta^{18} \mathrm{O}_{\mathrm{H}_{2} \mathrm{O}}$ values and indeed, any interaction at all between seawater and basalt below approximately $200^{\circ}-250^{\circ} \mathrm{C}$ will decrease $\delta^{18} \mathrm{O}_{\mathrm{H}_{2} \mathrm{O}}$, as demonstrated in this study and that by Stakes and $O^{\prime} N e i l$ [1982]. Although it is quite likely that off-axis hydrothermal alteration at low temperatures is occurring and does result in negative $\delta^{18} \mathrm{O}_{\mathrm{H}_{2} \mathrm{O}}$ values, it is clear that the fluid sampled at the MOR vents cannot have undergone any substantial stage of lowtemperature, low-water/rock interaction with newly-formed oceanic crust. If it had, it would be virtually impossible to produce the observed $\delta^{18} \mathrm{O}_{\mathrm{H}_{2} \mathrm{O}}$ value of +2 per mil.

The lightly dashed lines in Figure 20 illustrate approximate water-rock ratios for both oxygen and hydrogen that must be attained if the observed isotopic ratios are to result from a maximum temperature of interaction of $300^{\circ}$ or $250^{\circ}$ rather than $350^{\circ} \mathrm{C}$ as assumed in this study. At $300^{\circ} \mathrm{C}$, the water-rock ratio required to attain $\delta^{18} \mathrm{O}_{\mathrm{H}_{2} \mathrm{O}}=+2$ per mil is $\sim 0.3$, and to attain a $\delta \mathrm{D}_{\mathrm{H}_{2} \mathrm{O}}=+2.5$ per mil, it is $\sim 0.2$. At $250^{\circ} \mathrm{C}$ these water-rock ratios are 0.04 and 0.015 , respectively. A maximum temperature of alteration above $350^{\circ} \mathrm{C}$ would result in attainment of the appropriate $\delta^{18} \mathrm{O}$ and $\delta \mathrm{D}$ values of the vent fluids at somewhat higher water-rock ratios. Note, however, that only at $350^{\circ} \mathrm{C}$ are the appropriate $\delta^{18} \mathrm{O}$ and $\delta \mathrm{D}$ values for the fluid of +2.0 and +2.5 , respectively, achieved simultaneously at approximately the same value of water-rock ratio.

Muehlenbachs and Clayton [1976] proposed that hydrothermal circulation within the oceanic crust "buffers" the $\delta^{18} \mathrm{O}$ of ocean water as a result of a near-perfect cancellation of the ${ }^{18} \mathrm{O}$ enrichment of seawater due to high-temperature alteration by a corresponding ${ }^{18} \mathrm{O}$ depletion resulting from low-temperature alteration. Support for their hypothesis was obtained by a material-balance integration of a $\delta^{18} \mathrm{O}$ profile through a section of the Samail ophiolite in Oman [Gregory and Taylor, 1981]. In the present study, we have emphasized the need for a higher proportion of high-temperature $\left(300^{\circ}-\right.$ $350^{\circ} \mathrm{C}$ ) alteration products to produce the +2 per mil $\delta^{18} \mathrm{O}$ value observed in the EPR exiting hot springs by $\mathrm{H}$. Craig (personal communication, 1984). Obviously, if this were the only process affecting the isotopic composition of seawater, the effect would be to produce an increasing $\delta^{18} \mathrm{O}$ of ocean water with time as a result of hydrothermal alteration of the oceanic crust. However, the process producing ridge-crest hot springs, which is responsible for the positive $\delta^{18} \mathrm{O}_{\mathrm{H}_{2} \mathrm{O}}$ anomaly, is apparently only a relatively shallow, axial process, affecting perhaps the upper 2 to $3 \mathrm{~km}$ of the oceanic crust; it clearly cannot represent the whole story.

Active hot springs have not, to date, been observed off-axis. Off-axis circulation cells probably involve larger quantities of 
water, and they certainly involve lower temperatures than do those in the immediate neighborhood of the ridge-crest (Figure 23). Seawater-basalt interaction at temperatures less than approximately $200^{\circ} \mathrm{C}$ results in negative $\delta^{18} \mathrm{O}_{\mathrm{H}_{2} \mathrm{O}}$ values; thus, extensive off-axis circulation at low temperatures could serve to cancel the effects of the positive $\delta^{18} \mathrm{O}$ fluids venting from the ridge crests. The $\delta^{18} \mathrm{O}_{\mathrm{H}_{2} \mathrm{O}}$ results of two calculated paths shown in Figure 20 indicate that low-temperature alteration possibly lowers $\delta^{18} \mathrm{O}$ of seawater to -0.2 to -0.5 . These values would require that approximately 4 to 10 times the volume of water circulate through the off-axis circulation systems with a concomitant reduction in $\delta^{18} \mathrm{O}$ in order to cancel the ridge-crest enrichment of ${ }^{18} \mathrm{O}$. If the lowtemperature effects on $\delta^{18} \mathrm{O}_{\mathrm{H}_{2} \mathrm{O}}$ are not as negative as suggested here, an even larger volume of water would be required to circulate through the off-axis systems in order to achieve the "buffering" effect on seawater of $\delta^{18} \mathrm{O}$ proposed by Muehlenbachs and Clayton [1976] and Gregory and Taylor [1981]. The problem is compounded by the fact that in this work we have also ignored the truly high-temperature, very deep ( $>3$ $\mathrm{km}$ ) circulation of exchanged sea water down along the flanks (and underneath?) the MOR axial magma chamber. Although Gregory and Taylor [1981] showed that this circulation involves a very low water/rock ratio $(\sim 0.2)$, in the Oman ophiolite its isotopic effects are significant, because they are observed throughout a large part of the lower oceanic crust, at least down to the MOHO. To even a greater degree than the shallow, axial system considered extensively in this study, the deep system also produces marked ${ }^{18} \mathrm{O}$ depletions in the rocks; thus, its effects must also be counter-balanced by an appropriate amount of low-temperature, off-axis hydrothermal activity and submarine weathering. In order to obtain a complete picture of the isotopic, chemical, and mineralogical alteration of the entire oceanic crust, future computermodeling studies should include provision for the effects of the deep hydrothermal circulation, as well as the off-axis hydrothermal alteration. Unfortunately, at the present time, appropriate high-temperature thermodynamic data $\left(>400^{\circ} \mathrm{C}\right)$ are almost nonexistent, and most of the constraining parameters for the low-temperature circulation are also very poorly known.

In contrast to the $\delta^{18} \mathrm{O}$ effects described above, the hydrothermal alteration of oceanic crust has a much different effect on the $\delta \mathrm{D}$ of seawater. The $\delta \mathrm{D}$ of seawater should steadily increase at all temperatures of hydrothermal interaction up to approximately $700^{\circ} \mathrm{C}$. This is attributable to the fact that fresh basalt contributes essentially no $\mathrm{H}$ to the system, and all hydroxyl-bearing minerals formed as a result of hydrothermal alteration exhibit negative $\delta \mathrm{D}$ values compared to $\mathrm{H}_{2} \mathrm{O}$ (Figure 3). Because ocean water is a substantially larger reservoir of hydrogen relative to the whole earth than it is for oxygen, the steady increase in $\delta \mathrm{D}$ of ocean water would take place very slowly. It is also probably counterbalanced by recycled $\mathrm{H}_{2} \mathrm{O}$ from subducted hydrous minerals in the form of emanations of low-D magmatic $\mathrm{H}_{2} \mathrm{O}$ elsewhere in the world [Taylor, 1974]. Even though there are still many gaps in the required data-base, it would be useful to carry out a complete material-balance computer modeling study of both the $\mathrm{D} / \mathrm{H}$ and the ${ }^{18} \mathrm{O} /{ }^{16} \mathrm{O}$ in the oceans, taking into account these other factors, as well as the predictions of the present work.

Integrated chemical and stable-isotope models such as the one presented here can also be used to place important constraints on other types of (on-land) hydrothermal systems, in addition to seawater-basalt hydrothermal circulation. Al- though less information is typically available for the hightemperature parts of active systems on continents, the possibility of imposing constraints on temperatures, temperature gradients, pressures, and water-rock ratios suggest that similar computer models that combine a chemical and stable isotope approach may prove to be very useful.

Acknowledgments. Financial support for this research was provided by the National Science Foundation, grants OCE-8019021 and OCE-8315280, and by The Resource Geology Research Fund of the Division of Geological and Planetary Sciences, California Institute of Technology. We are indebted to John Edmond, Sam Epstein, Hal Helgeson, Dave Janecky, Peter Larson, Denis Norton, Debra Stakes, and Karen Von Damm for their helpful suggestions, assistance, and encouragement during the course of this research, and we wish to thank Harmon Craig for allowing us to quote his unpublished isotopic analyses of MOR hydrothermal fluids. We would also like to express our appreciation to J. K. Böhlke, Dave Janecky, Mike Mottl, K. Valla Ragnarsdöttir, and Karen Von Damm for their constructive reviews of the manuscript and helpful suggestions for improvement. Contribution 4146 of the Division of Geological and Planetary Sciences, California Institute of Technology.

\section{REFERENCES}

Becker, R. H., Carbon and oxygen isotope ratios in iron-formation and associated rocks from the Hamersley Range of western Australia and their implications, Ph.D. thesis, Univ. of Chicago, Chicago, Ill., 1971.

Bird, D. K., and H. C. Helgeson, Chemical interaction of aqueous solutions with epidote-feldspar mineral assemblages in geologic systems, I, Thermodynamic analysis of phase relations in the system $\mathrm{CaO}-\mathrm{FeO}-\mathrm{Fe}_{2} \mathrm{O}_{3}-\mathrm{SiO}_{2}-\mathrm{H}_{2} \mathrm{O}-\mathrm{CO}_{2}, \mathrm{Am} . \mathrm{J} . \mathrm{Sci}$., 280, 907-941, 1980.

Bischoff, J. L., and F. W. Dickson, Seawater-basalt interaction at $200^{\circ} \mathrm{C}$ and 500 bars: Implications for origin of seafloor heavy-metal deposits and regulation of seawater chemistry, Earth Planet. Sci. Lett., 25, 385-397, 1975.

Bischoff, J. L., and R. J. Rosenbauer, A note on the chemistry of seawater in the range $350^{\circ}-500^{\circ} \mathrm{C}$, Geochim. Cosmochim. Acta, 47, 139-144, 1983.

Bischoff, J. L., and R. J. Rosenbauer, The critical point and two-phase boundary of seawater, $200-500^{\circ} \mathrm{C}$, Earth Planet. Sci. Lett., 68,172 $180,1984$.

Bischoff, J. L., and W. E. Seyfried, Jr., Seawater as a geothermal fluid: Chemical behavior from $25^{\circ}$ to $350^{\circ} \mathrm{C}$, in Proceedings of the 2nd International Symposium on Water-Rock Interaction, pp. IV165IV172, International Association for Geochemistry and Cosmochemistry, Strasbourg, France, 1977.

Bischoff, J. L., and W. E. Seyfried, Jr., Hydrothermal chemistry of seawater from $25^{\circ}-350^{\circ} \mathrm{C}, A m$. J. Sci., $278,838-860,1978$.

Böhlke, J. K., J. C. Alt, and K. Muehlenbachs, Oxygen isotope-water relations in altered deep-sea basalts: Low-temperature mineralogical controls, Can. J. Earth Sci., 21, 67-77, 1984.

Bowers, T. S., K. L. Von Damm, and J. M. Edmond, Chemical evolution of mid-ocean ridge hot springs, Geochim. Cosmochim. Acta, in press, 1985.

Brimhall, G. H., Lithologic determination of mass transfer mechanisms of multiple-stage porphyry copper mineralization at Butte, Montana: Vein formation by hypogene leaching and enrichment of potassium-silicate protore, Econ. Geol., 74, 556-589, 1979.

Brimhall, G. H., Deep hypogene oxidation of porphyry copper potassium-silicate protore at Butte, Montana: A theoretical evaluation of the copper remobilization hypothesis, Econ. Geol., 75, 384$409,1980$.

Brimhall, G. H., and M. S. Ghiorso, Origin and ore-forming consequences of the advanced argillic alteration process in hypogene environments by magmatic gas contamination of meteoric fluids, Econ. Geol., 78, 73-90, 1983.

Cathles, L. M., An analysis of the hydrothermal system responsible for massive sulfide deposition in the Hokuroku Basin of Japan, Econ. Geol. Monogr., 5, 439-487, 1983.

Chiba, H., M. Kusakabe, S. Hirano, S. Matsuo, and S. Somiya, Oxygen isotope fractionation factors between anhydrite and water from 100 to $550^{\circ} \mathrm{C}$, Earth Planet. Sci. Lett., 53, 55-62, 1981.

Clayton, R. N., J. R. O'Neil, and T. K. Mayeda, Oxygen isotope exchange between quartz and water, J. Geophys. Res., 77, 30573067,1972 . 
Cole, D. R., Mechanism and rates of stable isotope exchange in hydrothermal rock-water systems, Ph.D. thesis, Pa. State Univ., University Park, 1980.

Cole, D. R., H. Ohmoto, and A. C. Lasaga, Isotopic exchange in mineral-fluid systems, I, Theoretical evaluation of oxygen isotopic exchange accompanying surface reactions and diffusion, Geochim. Cosmochim. Acta, 47, 1681-1693, 1983.

Craig, $H$., Hydrothermal plumes and tracer circulation along the East Pacific Rise: $20^{\circ} \mathrm{N}$ to $20^{\circ} \mathrm{S}$ (abstract), Eos Trans. AGU, 62, 893, 1981.

Craig, H., J. A. Welhan, K. Kim, R. Poreda, and J. E. Lupton, Geochemical studies of the $21^{\circ} \mathrm{N}$ EPR hydrothermal fluids (abstract), Eos Trans. $A G U, 61,992,1980$.

Delaney, J. R., R. E. McDuff, and J. E. Lupton, Hydrothermal fluid temperatures of $400^{\circ} \mathrm{C}$ on the Endeavor segment, northern Juan de Fuca (abstract), Eos Trans. AGU, 65, 973, 1984.

East Pacific Rise Study Group, Crustal processes of the mid-ocean ridge, Science, 213, 31-40, 1981.

Edmond, J. M., The chemistry of the $350^{\circ} \mathrm{C}$ hot springs at $21^{\circ} \mathrm{N}$ on the East Pacific Rise (abstract), Eos Trans. AGU, 61, 992, 1980.

Edmond, J. M., C. Measures, R. E. McDuff, L. H. Chan, R. Collier, B. Grant, L. I. Gordon, and J. B. Corliss, Ridge crest hydrothermal activity and the balances of the major and minor elements in the ocean: The Galapagos data, Earth Planet. Sci. Lett., 46, 1-18, 1979.

Eslinger, E. V., and S. M. Savin, Mineralogy and oxygen isotope geochemistry of the hydrothermally altered rocks of the OhakiBroadlands, New Zealand geothermal area, Am. J. Sci., 273, 240 $267,1973$.

Friedman, I., and J. R. O'Neil, Compilation of stable isotope fractionation factors of geochemical interest, U.S. Geol. Surv. Prof. Pap., 440-KK, 1977.

Graham, C. M., S. M. F. Sheppard, and T. H. E. Heaton, Experimental hydrogen isotope studies, I, Systematics of hydrogen isotope fractionation in the systems epidote- $\mathrm{H}_{2} \mathrm{O}$, zoisite- $\mathrm{H}_{2} \mathrm{O}$ and $\mathrm{AlO}(\mathrm{OH})-\mathrm{H}_{2} \mathrm{O}$, Geochim. Cosmochim. Acta, 44, 353-364, 1980.

Gregory, R. T., and H. P. Taylor, Jr., An oxygen isotope profile in a section of Cretaceous oceanic crust, Samail ophiolite, Oman: Evidence for $\delta^{18} \mathrm{O}$ buffering of the oceans by deep $(>5 \mathrm{~km})$ seawaterhydrothermal circulation at midocean ridges, J. Geophys. Res., 86, $2737-2755,1981$.

Hajash, A., Hydrothermal processes along mid-ocean ridges: An experimental investigation, Contrib. Mineral. Petrol., 53, 205-226, 1975.

Haymon, R. M., Growth history of hydrothermal black smoker chimneys, Nature, 301, 695-698, 1983.

Heaton, T. H. E., and S. M. F. Sheppard, Hydrogen and oxygen isotope evidence for sea-water hydrothermal alteration and ore deposition, Troodos complex, Cyprus, in Volcanic Processes in Ore Genesis, Spec. Pap. 7, pp. 42-57, Geological Society of London, London, 1977.

Helgeson, H. C., Evaluation of irreversible reactions in geochemical processes involving minerals and aqueous solutions, I, Thermodynamic relations, Geochim. Cosmochim. Acta, 32, 853-877, 1968.

Helgeson, H. C., Thermodynamics of hydrothermal systems at elevated temperatures and pressures, $A m$. $J$. Sci., 267, 729-804, 1969.

Helgeson, H. C., and D. H. Kirkham, Theoretical prediction of the thermodynamic behavior of aqueous electrolytes at high pressures and temperatures, I, Summary of the thermodynamic/electrostatic properties of the solvent, Am. J. Sci., 274, 1089-1198, 1974a.

Helgeson, H. C., and D. H. Kirkham, Theoretical prediction of the thermodynamic behavior of aqueous electrolytes at high pressures and temperatures, II, Debye-Huckel parameters for activity coefficients and relative partial molal properties, Am. J. Sci., 274, 1199 $1261,1974 b$.

Helgeson, H. C., T. H. Brown, A. Nigrini, and T. A. Jones, Calculation of mass transfer in geochemical processes involving aqueous solutions, Geochim. Cosmochim. Acta, 34, 569-592, 1970.

Helgeson, H. C., J. M. Delaney, H. W. Nesbitt, and D. K. Bird, Summary and critique of the thermodynamic properties of the rock-forming minerals, Am. J. Sci., 278 A, 1-228, 1978.

Helgeson, H. C., D. H. Kirkham, and G. C. Flowers, Theoretical prediction of the thermodynamic behavior of aqueous electrolytes at high pressures and temperatures, IV, Calculation of activity coefficients, osmotic coefficients, and apparent molal and standard and relative partial molal properties to $600^{\circ} \mathrm{C}$ and $5 \mathrm{~kb}, \mathrm{Am}$. J.Sci., 281, 1249-1516, 1981.

Humphris, S. E., and G. Thompson, Hydrothermal alteration of oceanic basalts by seawater, Geochim. Cosmochim. Acta, 42, 107$125,1978$.

Ito, E., and A. T. Anderson, Jr., Submarine metamorphism of gabbros from the Mid-Cayman Rise: Petrographic and mineralogic constraints on hydrothermal processes at slow-spreading ridges, Contrib. Mineral. Petrol., 82, 371-388, 1983.

Ito, E., and R. N. Clayton, Submarine metamorphism of gabbros from the Mid-Cayman Rise: An oxygen isotopic study, Geochim. Cosmochim. Acta, 47, 535-546, 1983.

Janecky, D. R., Serpentinization of peridotite within the oceanic crust: Experimental and theoretical investigations of seawaterperidotite interaction at $200^{\circ} \mathrm{C}$ and $300^{\circ} \mathrm{C}, 500$ bars, Ph.D. thesis, Univ. of Minn., Minneapolis, 1982.

Javoy, M., Ultisation des isotopes de l'oxygene en magmatologie, thèse de doctorat d'état des sci. phys., Faculté des Sci. de Paris, Paris, 1970

Kendall, C., I.-M. Chou, and T. B. Coplen, Salt effect on oxygen isotope equilibria (abstract), Eos Trans. AGU, 64, 334-335, 1983.

Kim, K.-R., J. A. Welhan, and H. Craig, The hydrothermal vent fields at $13^{\circ} \mathrm{N}$ and $11^{\circ} \mathrm{N}$ on the East Pacific Rise: ALVIN 1984 results (abstract), Eos Trans. AGU, 65, 973, 1984.

Kulla, J. B., and T. F. Anderson, Experimental oxygen isotope fractionation between kaolinite and water, U.S. Geol. Surv. Open File Rep., 78-701, 234-235, 1978.

Lambert, S. J., and S. Epstein, Stable isotope investigations of an active geothermal system in Valles Caldera, Jemez Mountains, New Mexico, J. Volcanol. Geotherm. Res., 8, 111-129, 1980.

Lawrence, J. R., and H. P. Taylor, Jr., Deuterium and oxygen-18 correlation: Clay minerals and hydroxides in Quaternary soils compared to meteoric waters, Geochim. Cosmochim. Acta, 35, 9931003,1971

Lawrence, J. R., and H. P. Taylor, Jr., Hydrogen and oxygen isotope systematics in weathering profiles, Geochim. Cosmochim. Acta, 36, $1377-1393,1972$

Lister, C. R. B., "Active" and "passive" hydrothermal systems in the oceanic crust: Predicted physical conditions, in The Dynamic Environment of the Ocean Floor, edited by K. A. Fanning and F. T. Manheim, pp. 441-470, D. C. Heath, Lexington, Mass., 1982.

Liu, K.-K., and S. Epstein, The hydrogen isotope fractionation between kaolinite and water, Isot. Geosci., 2, 335-350, 1984.

MacDonald, K. C., K. Becker, F. N. Speiss, and R. D. Ballard, Hydrothermal heat flux of the "black smoker" vents on the East Pacific Rise, Earth Planet. Sci. Lett., 48, 1-7, 1980.

Magaritz, M., and H. P. Taylor, Jr., Oxygen and hydrogen isotope studies of serpentinization in the Troodos ophiolite complex, Cyprus, Earth Planet. Sci. Lett., 23, 8-14, 1974.

Magaritz, M., and H. P. Taylor, Jr., Oxygen, hydrogen, and carbon isotope studies of the Franciscan formation, Coast Ranges, California, Geochim. Cosmochim. Acta, 40, 215-234, 1976.

Mathez, E. A., Sulfur solubility and magmatic sulfides in submarine basalt glass, J. Geophys. Res., 81, 4269-4276, 1976.

Matthews, A., J. R. Goldsmith, and R. N. Clayton, On the mechanisms and kinetics of oxygen isotope exchange in quartz and feldspars at elevated temperatures and pressures, Geol. Soc. Am. Bull., 94, 396-412, 1983a.

Matthews, A., J. R. Goldsmith, and R. N. Clayton, Oxygen isotope fractionations involving pyroxenes: The calibration of mineral-pair geothermometers, Geochim. Cosmochim. Acta, 47, 631-644, 1983b.

Matthews, A., J. R. Goldsmith, and R. N. Clayton, Oxygen isotope fractionation between zoisite and water, Geochim. Cosmochim. Acta, $47,645-654,1983 c$.

Michard, G., F. Albarede, A. Michard, J.-F. Minster, J.-L. Charlou, and N. Tan, Chemistry of solutions from the $13^{\circ} \mathrm{N}$ East Pacific Rise hydrothermal site, Earth Planet. Sci. Lett., 67, 297-307, 1984.

Miyashiro, A., S. Fumiko, and M. Ewing, Diversity and origin of abyssal tholeiite from the Mid-Atlantic Ridge near $24^{\circ} \mathrm{N}$ and $30^{\circ} \mathrm{N}$ latitude, Contrib. Mineral. Petrol., 23, 38-52, 1969.

Moore, J. G., and B. P. Fabbi, An estimate of the juvenile sulfur content of basalt, Contrib. Mineral. Petrol., 33, 118-127, 1971.

Mottl, M. J., Chemical exchange between seawater and basalt during hydrothermal alteration of the oceanic crust, Ph.D. thesis, Harvard Univ., Cambridge, Mass., 1976.

Mottl, M. J., Metabasalts, axial hot springs, and the structure of hydrothermal systems at mid-ocean ridges, Geol. Soc. Am. Bull., 94, $161-180,1983$.

Mottl, M. J., and H. D. Holland, Chemical exchange during hydrothermal alteration of basalt by seawater, I, Experimental results for major and minor components of seawater, Geochim. Cosmochim. Acta, 42, 1103-1115, 1978 .

Mottl, M. J., and W. E. Seyfried, Jr., Experimental basalt-seawater interaction: Rock- vs. seawater-dominated systems with the origin of submarine hydrothermal deposits (abstract), Geol. Soc. Am. Abstr. Programs, 9, 1104-1105, 1977. 
Mottl, M. J., and W. E. Seyfried, Jr., Sub-seafloor hydrothermal systems: Rock- vs. seawater-domunated, in Seafloor Spreading Centers. Hydrothermal Systems, edited by P. A. Rona and R. P. Lowell, pp. 66-82, Dowden, Hutchinson, and Ross, Straudsburg, Pa., 1980.

Mottl, M. J., H. D. Holland, and R. F. Carr, Chemical exchange during hydrothermal alteration of basalt by seawater, II, Experimental results for $\mathrm{Fe}, \mathrm{Mn}$, and sulfur species, Geochim. Cosmochim. Acta, 43, 869-884, 1979.

Muehlenbachs, K., and R. N. Clayton, Oxygen isotope composition of the oceanic crust and its bearing on seawater, J. Geophys. Res., $81,4365-4369,1976$.

Norton, D., Theory of hydrothermal systems, Annu. Rev. Earth Planet. Sci., 12, 155-177, 1984.

Norton, D., and R. Knapp, Transport phenomena in hydrothermal systems: The nature of porosity, Am. J.Sci., 277, 913-936, 1977.

Norton, D., and J. Knight, Transport phenomena in hydrothermal systems: Cooling plutons, Am. J. Sci., 277, 937-981, 1977.

Norton, D., and H. P. Taylor, Jr., Quantitative simulation of the hydrothermal systems of crystallizing magmas on the basis of transport theory and oxygen isotope data: An analysis of the Skaergaard Intrusion, J. Petrol., 20, 421-486, 1979.

O'Neil, J. R., and J. K. Kharaka, Hydrogen and oxygen isotope exchange reactions between clay minerals and water, Geochim. Cosmochim. Acta, 40, 241-246, 1976.

O'Neil, J. R., and H. P. Taylor, Jr., The oxygen isotope and cation exchange chemistry of feldspars, Am. Mineral., 52, 1414-1437, 1967.

O'Neil, J. R., and H. P. Taylor, Jr., Oxygen isotope equilibrium between muscovite and water, J. Geophys. Res., 74, 6012-6022, 1969.

O'Neil, J. R., R. N. Clayton, and T. K. Mayeda, Oxygen isotope fractionation in divalent metal carbonates, J. Chem. Phys., 51, 5547-5558, 1969.

Oudin, E., Hydrothermal sulfide deposits of the East Pacific Rise $\left(21^{\circ} \mathrm{N}\right)$, I, Descriptive mineralogy, Mar. Min., 4, 39-72, 1983.

Parmentier, E. M., Numerical experiments on ${ }^{18} \mathrm{O}$ depletion in igneous intrusions cooling by groundwater convection, $J$. Geophys. Res., 86, 7131-7144, 1981.

Perry, E. C., and F. C. Tan, Significance of oxygen and carbon isotope variations in early Precambrian cherts and carbonate rocks of southern Africa, Geol. Soc. Am. Bull., 83, 647-664, 1972.

Ragnarsdóttir, K. V., J. V. Walther, and S. Arnórsson, Description and interpretation of the composition of fluid and alteration mineralogy in the geothermal system, at Svartsengi, Iceland, Geochim. Cosmochim. Acta, 48, 1535-1553, 1984.

Reed, M. H., Seawater-basalt reaction and the origin of greenstones and related ore deposits, Econ. Geol., 78, 446-485, 1983.

Riedesel, M., J. A. Orcutt, K. C. MacDonald, and J. S. McClain, Microearthquakes in the black smoker hydrothermal field, East Pacific Rise at $21^{\circ}$ N, J. Geophys. Res., 87, 10,613-10,623, 1982.

Robie, R. A., B. S. Hemingway, and J. R. Fisher, Thermodynamic properties of minerals and related substances at $298.15^{\circ} \mathrm{K}$ and 1 bar ( $10^{5}$ pascals) pressure and at higher temperatures, U.S. Geol. Surv. Bull., 1452, 456 pp., 1978.

Rona, P. A., Pattern of hydrothermal mineral deposition: MidAtlantic Ridge crest at latitude $26^{\circ} \mathrm{N}$, Mar. Geol., 21, M59-M66, 1976.

Rona, P. A., Criteria for recognition of hydrothermal mineral deposits in oceanic crust, Econ. Geol., 73, 135-160, 1978.

Sakai, H., and M. Tsutsumi, Experimental determination of D/H fractionation factors between serpentine and water at $100^{\circ}$ to $500^{\circ} \mathrm{C}$ under 2000 bars water pressure: Some implication to the $\mathbf{D} / \mathbf{H}$ ratios of natural serpentinites, U.S. Geol. Surv. Open File Rep., 78701, 370-372, 1978.

Savin, S. M., and S. Epstein, The oxygen and hydrogen isotope geochemistry of clay minerals, Geochim. Cosmochim. Acta, 34, 25-42, $1970 a$.

Savin, S. M., and S. Epstein, The oxygen and hydrogen isotope geochemistry of ocean sediments and shales, Geochim. Cosmochim. Acta, 34, 43-63, $1970 b$.

Seyfried, W. E., Jr., Seawater-basalt interaction from $25^{\circ}-300^{\circ}$ and 1-500 bars: Implications for the origin of submarine metal bearing hydrothermal solutions and regulation of ocean chemistry, Ph.D. thesis, Univ. of S. Calif., Los Angeles, 1976.

Seyfried, W. E., Jr., and J. L. Bischoff, Hydrothermal transport of heavy metals by seawater: The role of seawater/basalt ratio, Earth Planet. Sci. Lett., 34, 71-77, 1977.

Seyfried, W. E., Jr., and J. L. Bischoff, Low temperature basalt alteration by seawater: An experimental study at $70^{\circ} \mathrm{C}$ and $150^{\circ} \mathrm{C}, \mathrm{Ge}$ ochim. Cosmochim. Acta, 43, 1937-1947, 1979.

Seyfried, W. E., Jr., and J. L. Bischoff, Experimental seawater-basalt interaction at $300^{\circ} \mathrm{C}$ and 500 bars: Chemical exchange, secondary mineral formation and implications for the transport of heavy metals, Geochim. Cosmochim. Acta, 45, 135-147, 1981.

Seylried, W. E., Jr., and W. E. Dibble, Jr., Seawater-peridotite interaction at $300^{\circ} \mathrm{C}$ and 500 bars: Implications for the origin of oceanic serpentinites, Geochim. Cosmochim. Acta, 44, 309-321, 1980.

Seyfried, W. E., Jr., and M. J. Mottl, Origin of submarine metal-rich hydrothermal solutions: Experimental basalt-seawater interaction in a seawater-dominated system at $300^{\circ} \mathrm{C}, 500$ bars, in Proceedings of the 2nd International Symposium on Water-Rock Interaction, pp. IV173-IV180, International Association for Geochemistry and Cosmochemistry, Strasbourg, France, 1977.

Seyfried, W. E., Jr., and M. J. Mottl, Hydrothermal alteration of basalt by seawater under seawater-dominated conditions, Geochim. Cosmochim. Acta, 46, 985-1002, 1982.

Sheppard, S. M. F., R. L. Nielson, and H. P. Taylor, Jr., Oxygen and hydrogen isotope ratios of clay minerals from porphyry copper deposits, Econ. Geol., 64, 755-777, 1969.

Spooner, E. T. C., R. D. Beckinsale, W. S. Fyfe, and J. D. Smewing, ${ }^{18} \mathrm{O}$ enriched ophiolitic metabasic rocks from E. Liquria (Italy), Pindos (Greece), and Troodos (Cyprus), Contrib. Mineral. Petrol., 47, 41-62, 1974.

Spooner, E. T. C., R. D. Beckinsale, P. C. England, and A. Senior, Hydration, ${ }^{18} \mathrm{O}$ enrichment and oxidation during ocean floor hydrothermal metamorphism of ophiolitic metabasic rocks from E. Liguria, Italy, Geochim. Cosmochim. Acta, 41, 857-872, 1977.

Stakes, D. S., and J. R. O'Neil, Mineralogy and stable isotope geochemistry of hydrothermally altered oceanic rocks, Earth Planet. Sci. Lett., 57, 285-304, 1982.

Stakes, D. S., H. P. Taylor, Jr., and R. L. Fisher, Oxygen isotope and geochemical characterization of hydrothermal alteration in ophiolite complexes and modern oceanic crust, in Ophiolites and Oceanic Lithosphere, edited by I. G. Gass, S. J. Lippard, and A. W. Shelton, pp. 199-214, Blackwell Scientific Publications, Oxford, England, 1984.

Stoessell, R. K., Regular solution site-mixing model for chlorites, Clays Clay Miner., 32, 205-212, 1984.

Styrt, M. M., A. J. Brackmann, H. D. Holland, B. C. Clark, V. Pisutha-Arnond, C. S. Eldridge, and H. Ohmoto, The mineralogy and the isotopic composition of sulfur in hydrothermal sulfide/sulfate deposits on the East Pacific Rise, $21^{\circ} \mathrm{N}$ latitude, Earth Planet. Sci. Lett., 53, 382-390, 1981.

Suzuoki, T., and S. Epstein, Hydrogen isotope fractionation between OH-bearing minerals and water, Geochim. Cosmochim. Acta, 40, $1229-1240,1976$.

Taube, H., Use of oxygen isotope effects in the study of hydration of ions, J. Phys. Chem., 58, 523-528, 1954.

Taylor, H. P., Jr., The application of oxygen and hydrogen isotope studies to problems of hydrothermal alteration and ore deposition, Econ. Geol., 69, 843-883, 1974.

Taylor, H. P., Jr., Water/rock interactions and the origin of $\mathrm{H}_{2} \mathrm{O}$ in granitic batholiths, J. Geol. Soc. London, 133, 509-558, 1977.

Taylor, H. P., Jr., Oxygen and hydrogen isotope studies of hydrothermal interactions at submarine and subaerial spreading centers, in NATO Symposium Volume on Hydrothermal Processes at Seafloor Spreading Centers, edited by P. A. Rona, K. Bostróm, L. Laubier, and K. Smith, Jr., pp. 83-139, Plenum, New York, 1983.

Taylor, H. P., Jr., and S. Epstein, Relationship between $\mathrm{O}^{18} / \mathrm{O}^{16}$ ratios in coexisting minerals of igneous and metamorphic rocks, I, Principles and experimental results, Geol. Soc. Am. Bull., 73, 461480, 1962.

Taylor, H. P., Jr., and R. W. Forester, An oxygen and hydrogen isotope study of the Skaergaard intrusion and its country rocks: A description of a 55-m.y. old fossil hydrothermal system, J. Petrol., 20, 355-419, 1979.

Truesdell, A. H., Oxygen isotope activities and concentrations in aqueous salt solutions at elevated temperatures-Consequences for isotope geochemistry, Earth Planet. Sci. Lett., 23, 387-396, 1974.

Von Damm, K. L., J. M. Edmond, B. Grant, C. I. Measures, B. Walden, and R. F. Weiss, Chemistry of submarine hydrothermal solutions at $21^{\circ} \mathrm{N}$ East Pacific Rise, Geochim. Cosmochim. Acta, in press, 1985.

Walther, J. V., and D. M. Rye, Possible stable isotopic systematics of progressive metamorphism (abstract), Geol. Soc. Am. Abstr. Programs, 14, 641, 1982.

Welhan, J. A., and H. Craig, Methane and hydrogen in East Pacific Rise hydrothermal fluids, Geophys. Res. Lett., 6, 829-831, 1979.

Welhan, J. A., and H. Craig, Methane, hydrogen and helium in hydrothermal fluids at $21^{\circ} \mathrm{N}$, East Pacific Rise, in NATO Symposium Volume on Hydrothermal Processes at Seafloor Spreading Centers, 
edited by P. A. Rona, K. Boström, L. Laubier, and K. L. Smith, Jr., pp. 391-409, Plenum, New York, 1983.

Wenner, D. B., and H. P. Taylor, Jr., Temperatures of serpentinization of ultramafic rocks based on ${ }^{18} \mathrm{O} /{ }^{16} \mathrm{O}$ fractionation between coexisting serpentine and magnetite, Contrib. Mineral. Petrol., 32, 165-185, 1971.

Wenner, D. B., and H. P. Taylor, Jr., Oxygen and hydrogen isotope studies of serpentinization of ultramafic rocks in oceanic environments and continental ophiolite complexes, Am. J. Sci., 273, 207$239,1973$.

Wolery, T. J., Some chemical aspects of hydrothermal processes at mid-oceanic ridges-A theoretical study, I, Basalt-seawater reaction and chemical cycling between the oceanic crust and the oceans, II, Calculation of chemical equilibrium between aqueous solutions and minerals, Ph.D. thesis, Northwestern Univ., Evanston, Ill., 1978.

Wolery, T. J., Calculation of chemical equilibrium between aqueous solutions and minerals: The EQ3/6 software package, Rep. UCRL 52658, Lawrence Livermore Natl. Lab., Livermore, Calif., 1979.

Wolery, T. J., EQ3NR, a computer program for geochemical aqueous speciation-solubility calculations, Rep. UCRL S, Distrib. Category UC-70, Lawrence Livermore Natl. Lab., Livermore, Calif., 1983.
Yeh, $H_{\text {., }}$ and S. M. Savin, The extent of oxygen isotope exchange between clay minerals and sea water, Geochim. Cosmochim. Acta, 40, 743-748, 1976.

Yeh, H., and S. M. Savin, Mechanism of burial metamorphism of argillaceous sediments, 3, O-isotope evidence, Geol. Soc. Am. Bull., $88,1321-1330,1977$.

Yund, R. A., and T. F. Anderson, Oxygen isotope exchange between potassium feldspar and $\mathrm{KCl}$ solution, in Geochemical Transport and Kinetics, edited by A. Hoffman, B. J. Giletti, H. S. Yoder, and R. A. Yund, pp. 99-105, Carnegie Institution of Washington, Washington, D. C., 1974.

T. S. Bowers, Department of Earth, Atmospheric and Planetary Sciences, Massachusetts Institute of Technology, Cambridge, MA 02139 .

H. P. Taylor, Jr., Division of Geological and Planetary Sciences, California Institute of Technology, Pasadena, CA 91125.

(Received December 14, 1984; revised July 26, 1985 ; accepted July 30,1985 . 